\title{
2 Daniele del Giudice: Atlante occidentale
}

\section{1 „La scomparsa delle cose“ - De- bzw. An-Ästhetisierung und Fiktionalisierung bzw. Poietisierung der Wirklichkeit}

Daniele Del Giudices 1985 erschienener Roman Atlante occidentale ${ }^{18}$ erzählt von der Freundschaft zwischen Pietro Brahe, einem jungen italienischen Atomphysiker, der im europäischen Zentrum für Nuklearforschung (CERN) in Genf arbeitet, und Ira Epstein, einem erfolgreichen deutschen Schriftsteller fortgeschrittenen Alters mit vorübergehendem Wohnsitz in Genf. Ihre gemeinsame Leidenschaft für das Fliegen bringt sie zusammen: Eine von Epstein im Flug provozierte BeinaheKollision mit Brahes Maschine - der Zwei-Kulturen-Konflikt ist hier ebenso ins Plastische übersetzt wie die am CERN durchgeführten Kollider-Experimentebildet den Ausgangspunkt dieser rasch sich entwickelnden und vertiefenden Männerfreundschaft. ${ }^{19}$

Die Romanhandlung ist in der Gegenwart angesiedelt, gleichwohl wird die synchrone Ereignisachse über Namen, Motivik, chronotopische Strukturen und vor allem die literarische Entwicklung Epsteins von einer diachronen gekreuzt und auf diese Weise die postmoderne Romanwelt an eine primär als Aufklärung verstandene Moderne rückgebunden. Der Roman markiere, so Del Giudices eigene Formu-

18 Daniele Del Giudice: Atlante occidentale, Turin 1985 (im Folgenden zitiert unter der Sigle AO. In eckigen Klammern Seitenangaben der dt. Übersetzung: Daniele Del Giudice: Der Atlas des Westens, aus dem Italienischen v. Karin Fleischanderl, München 1987). Sofern in den Anmerkungen nur auf die Übersetzung rekurriert wird, erfolgt dies unter der Sigle AW.

19 Zur „poetologischen Funktion“ dieser Beinah-Kollision vgl. Thomas Klinkert: Daniele Del Giudice: Literatur und Erfahrung im Zeitalter virtueller Realität, in: Italienische Erzählliteratur der Achtziger und Neunziger Jahre. Zeitgenössische Autorinnen und Autoren in Einzelmonographien, hrsg. v. Felice Balletta u. Angela Barwig, Frankfurt/M. 2003, S. 299-308, hier S. 306, ferner Julia Fendt: Intersecting Lines: An Ecocritical Reading of Daniele Del Giudice's Lines of Light, in: Literature, Ecology, and Ethics. Recent Trends in Ecocriticism, hrsg. v. Timo Müller u. Michael Sauter, Heidelberg 2012, S. 163-169, bes. S. 162 f., sowie dies.: Wissenschaft und Imagination in der Literatur. Kulturökologische Analysen zeitgenössischer Romane, Würzburg 2015, S. 67 u. 70. Fendt zufolge initiert die Beinah-Kollision einen „reintegrativen Interdiskurs [...], welcher zu einer Annäherung der beiden gegenübergestellten Wissenskulturen führt“ (ebd., S. 67) und diese im Lauf der sich entwickelnden Freundschaft zwischen Epstein und Brahe in eine „kulturökologischen Balance“ (S. 88) bringt. Zur Flug, Absturz- und Schiffbruchmetphorik bei Del Giudice allgemein vgl. Philippe Daros: Le temps qui vient: Science et literature dans l'œvre de Daniele Del Giudice, in: Literature and Science/Literatur und Wissenschaft, hrsg. v. Monika Schmitz-Emans Würzburg 2008, S. 239-250. 
lierung, ein „mutamento di epoca sostanziale“, ${ }^{20}$ einen Epochenwandel, für den symptomatisch ist, dass die „cose ormai cominciano ad essere non-cose“ (AO 66). Entsprechend ist auch der Dialog zwischen Brahe und Epstein, zwischen Naturwissenschaft und Literatur, im Wesentlichen um die Frage nach den Möglichkeiten von Wahrnehmung, Darstellung und Erkenntnis einer im Schwinden begriffenen Wirklichkeit zentriert. ${ }^{21}$

Seinen dezidiert epistemologischen Charakter erhält der Roman auf der Ebene des narrativen Diskurses ebenso wie auf der Ebene des - seinerseits primär diskursiv-dialogisch vermittelten - Geschehens. Um die vielfältigen epistemologischen Funktionen aufzuzeigen, sollen zunächst die von beiden Protagonisten jeweils durchgeführten Experimente - Brahes physikalisches und Epsteins ästhetischpoetologisches Experiment - getrennt dargestellt und sodann in ihren vielfältigen Bezügen analysiert werden.

\subsubsection{Poiesis der ,Natur - Zur technologischen Konstruktion von Sichtbarkeiten}

Die Perspektive, aus der Brahes Experiment beschrieben wird, fokussiert weniger die augenscheinlich relevanten Fragen nach den wissenschaftlichen Inhalten (so sind die Informationen über theoretische Voraussetzungen und Annahmen, über Gegenstand und Zielsetzung des Experiments eher dürftig) als vielmehr den Prozess der Wissensgenerierung in seinen spezifischen Produktionskontexten, wobei dieser Prozess von der Frage nach den epistemischen Inhalten nicht zu trennen ist, sondern im Gegenteil diese Frage erst problematisierend ins Licht rückt. Zwei dieser im Roman thematisierten Produktionskontexte sollen im folgenden genauer betrachtet werden: die technischen Apparaturen, mit deren Hilfe die experimentelle Hochenergiephysik die zu untersuchenden ,Naturobjekte، konfiguriert, und die semiotisch-rekonstruktiven Verfahren, deren sie sich zur Darstellung und Interpretation dieser technisch erzeugten Realität bedient. Vorab soll jedoch das realistische setting, in dem Brahes Experiment verortet ist, kurz beschrieben werden.

20 Daniele Del Giudice: Il tempo dell'invisibile nell'Atlante di Daniele del Giudice (Gespräch Del Giudices mit S. Bertolucci, T. Gaddi, A. Pastorino u. G. L. Saraceni), in: Palomar. Quaderni di Porto Venere 1 (1986), S. 93.

21 Ausführlich - und mit einschlägigen Belegen - rückt Dilmac ähnliche Aspekte des Romans in den Kontext von Del Giudices schriftstellerischem Selbstverständnis (vgl. Betül Dilmac: Literatur und moderne Physik. Literarisierungen der Physik im französischen, italienischen und lateinamerikanischen Gegenwartsroman, Freiburg i. Br. u.a. 2012, S. 288-291). 


\section{Exkurs}

Die experimentelle Hochenergiephysik zielt ganz allgemein darauf ab, „die Grundbausteine des Universums zu verstehen “. ${ }^{22}$ Dazu werden, wie etwa am CERN, dem europäischen Zentrum für Nuklearforschung in Genf, sogenannte Collider-Experimente durchgeführt: unterschiedliche Elementarteilchen werden in einem Teilchenbeschleuniger zur Kollision gebracht, wodurch es (in Abhängigkeit der zur Verfügung stehenden Energie) zur Freisetzung neuer Teilchen kommen kann. So handelte es sich bei den am CERN durchgeführten Experimenten UA1 und UA ${ }^{23}$ um Elektronen-Positronen-Experimente, die 1983 zum erstmaligen Nachweis sogenannter W- und Z-Bosonen durch die Forschergruppe um den italienischen Physiker Carlo Rubbia führten, der dafür ein Jahr später mit dem Nobelpreis ausgezeichnet wurde. ${ }^{24}$ Einer Vermutung Gerhard Regns zufolge, könnte Del Giudice Rubbias Nachweis der Z- und W-Bosonen aufgegriffen und auf den 1989 fertiggestellten, also zur Entstehungszeit des Romans noch im Bau befindlichen LEP ${ }^{25}$ überspielt haben. ${ }^{26}$ In der Tat arbeitet Brahe an einem Collider-Experiment (AO 140), das auf die Entdeckung neuer Teilchen ausgerichtet ist. ${ }^{27}$ Denkbar wäre aber auch - und dies wird vor allem durch den Titel Atlante occidentale nahegelegt -, dass Del Giudice bereits von dem geplanten ATLAS-Experiment wusste, das sich aus UA2 von zirka 1989 an entwickelte und den experimentellen Nachweis des Higgs-Mechanismus zum Ziel hatte. ${ }^{28}$ Der Higgs-Mechanismus bezeichnet den Vorgang, bei dem Elementarteilchen durch eine spontane Symmetriebrechung Masse erhalten. ${ }^{29}$ Da die neuen Teilchen, die Brahe und seine Kollegen am Ende des Romans

22 Hier und im Folgenden Karin Knorr-Cetina: Wissenskulturen. Ein Vergleich naturwissenschaftlicher Wissensformen, Frankfurt/M. 2002, S. 14.

23 UA steht dabei für Underground Area (vgl. Knorr-Cetina: Wissenskulturen, S. 27).

24 Vgl. hierzu die vertiefenden Ausführungen zur „Weinberg-Glashow-Salam-Theorie“ in Dilmac: Literatur und moderne Physik, S. $310 \mathrm{f}$.

25 Beim LEP (= Large Electron Positron Ring) handelt es um einen Collider, dessen Maximalenergie für den Nachweis des Higgs-Mechanismus sich als zu gering erwies und deshalb den Bau des LHCs (= Large Hadron Collider) notwendig machte (vgl. Knorr-Cetina: Wissenskulturen, S. 26 f.).

26 Vgl. Gerhard Regn: Nach der Moderne. Literatur und Naturwissenschaft in Daniele Del Giudices ,Atlante Occidentale‘, in: Konflikt der Diskurse. Zum Verhältnis von Literatur und Wissenschaft im modernen Italien, hrsg. v. Helene Harth, Susanne Kleiner u. Birgit Wagner, Tübingen 1991, S. 327-352, hier S. 339.

27 Vgl. AO 145 [195], wo die Rede ist von den „particelle che loro vedevano per la prima volta quella notte“.

28 Vgl. Knorr-Cetina: Wissenskulturen, S. 27 u. 30.

29 Knorr-Cetina erläutert den Higgs-Mechanismus im Zusammenhang mit ihrer These, dass experimentelle Hochenergiephysik „theoretisch motiviert“ und aktiv in die Suche nach fehlenden Theoriestücken eingebunden ist: „Nach dem physikalischen Prinzip der Symmetrie werden die elektromagnetische Kraft (die für die elektrische Ladung von Teilchen und die magnetischen Vorgänge verantwortlich ist) und die schwache Kraft (die für den radioaktiven Zerfall verantwortlich ist) ineinander umgewandelt; dies ist das Grundprinzip, auf dem die elektroschwache Theorie des Standardmodells beruht. Die beiden Kräfte werden von definierten Teilchen getragen; die elektromagnetische Kraft von masselosen Photonen und die schwache Kraft von den massiven W- und Z-Bosonen. Die Symmetrie, nach der Photonen, W-Bosonen 
entdecken, jedoch die Vorstellung von einer einzigartigen Symmetrie evozieren (vgl. AO 193), ist es eher unwahrscheinlich, dass es sich bei dieser Entdeckung um den literarisch antizipierten experimentellen Nachweis des Higgs-Mechanismus ${ }^{30}$ und damit um eine reale Bezugnahme auf das ATLAS-Experiment handelt. Wahrscheinlicher ist es, dass Del Giudice die Inhalte des zeitgenössischen UA2-Experiments mit der Bezeichnung für das später eingerichtete ATLAS-Experiment verbunden hat. - Die Experimente im CERN sind unterirdisch angelegt, ein Umstand, auf den auch der Roman mehrfach hinweist. Von Brahes Sicht auf das Gelände, auf dem sich der dreißig Kilometer lange unterirdische Ring befindet (vgl. AO 30) heißt es:

Come tutti, Brahe aveva una doppia immagine del luogo: il grande anello sotterraneo arrivava fino al Giura inclinandosi di qualche grado, passava sotto una decina di paesi con campanile e monumento che davano nome alle vicine hall in profondità, e dunque Brahe pensava la topografia della pianura in forma circolare, ma le strade in superficie collegavano i paesini come in qualsiasi altro posto, con diagonali nette che tenevano conto soltanto degli espropri, delle fattorie, delle piccole colline naturali, del reticolo rurale di campi di colza e girasole. Cosí la rotazione, la grande rotazione e circolarità del sotto non corrispondeva alla geometria del sopra e, per andare dove voleva andare, Brahe doveva passare da un ordine mentale all'altro, secondo un orientamento di immaginazione [...]. $(\mathrm{AO} 36)^{31}$

Die durchaus realistische Topographie des Geländes - und dies gilt auch für weitere Landschafts- und Gebäudebeschreibungen ${ }^{32}$ - ist vielfältig semantisiert: die Lebenswelt kontrastiert mit der Wissenschaftswelt, die sinnlich erfahrbare Welt der Phänomene mit der unterirdischen Welt der Nicht-Dinge; spatialisiert wird auch die Wissenschaftsgeschichte, insofern ,überirdisch“ die Gesetze der klassischen Physik gelten, ,unterirdisch' die Gesetze der neuen usw. Bezeichnend ist ferner, und auch diese Beobachtung lässt sich für den Roman verallge-

und Z-Bosonen ineinander transformiert werden, wird allerdings bei abkühlenden Temperaturen des Universums spontan gebrochen, was Photonen ohne Masse und die W- und Z-Teilchen mit Masse zurücklässt“ (Knorr-Cetina: Wissenskulturen, S. 26).

30 Erste Anzeichen für den Nachweis des Higgs-Mechanismus wurden nach Knorr-Cetina im April 1994 vom Fermilab bekannt gegeben, der vollständige Nachweis blieb jedoch weiterhin eine Herausforderung (Knorr-Cetina: Wissenskulturen, S. 27).

31 „Wie alle anderen sah auch Brahe das Gelände auf zweifache Weise: Der große unterirdische Ring reichte, mit einem Gefälle von ein paar Graden, bis zum Jura, verlief unter einem Dutzend kleiner Dörfer mit Kirchturm und Denkmal, die den Hallen direkt unter ihnen den Namen gaben; und deshalb stellte sich Brahe die Topographie der Ebene kreisförmig vor, aber die Straßen oberhalb der Erde verbanden die Dörfer wie an jedem anderen Ort auch, mit gerade Diagonalen, die nur auf die enteigneten Felder, die Bauernhäuser, die kleinen, natürlichen Hügel Rücksicht nahmen, auf das ländliche Netz aus Raps- und Sonnenblumenfeldern. So entsprach die Rotation, die große Rotation und Kreisförmigkeit unter der Erde nicht der Geometrie auf der Oberfläche, und um an sein Ziel zu gelangen, musste Brahe von einer geistigen Ordnung zur anderen übergehen, entsprechend einer imaginären Orientierung [...]“ (AW 52).

32 Vgl. die Beschreibung des Gästehauses des CERN (AO 37 [52-53]), die Ausführungen zum Schloss Voltaire (AO 109-114 [146-153]) oder zum alten und neuen Genf (AO 82-92 [112-114]). 
meinern und ist Kennzeichen seiner postmodernen Grundierung, dass die topographischsemantischen Räume zwar einer binären, auf oppositionelle Strukturen gerichteten Logik folgen, diese jedoch nicht auf den Wertediskurs übergreift. Weder ist die Romanatmosphäre geprägt von der „Melancholie der Moderne“ noch von dem „zynischen Eklektizismus des ,Alles ist erlaubt“'“;3 vielmehr ist sie bestimmt durch eine wesentliche Reflexivität, ${ }^{34}$ was im Zitat unter dem Hinweis auf die unterschiedlichen ,geistigen Ordnungen' angedeutet ist und in den folgenden Analysen vertieft aufgezeigt werden soll.

\title{
Der Anfang des zweiten Kapitels führt den Leser mitten hinein in den für den Roman zentralen Problemzusammenhang von Wahrnehmung, Darstellung, Deutung und Erkenntnis wissenschaftlicher Objekte und Phänomene, denen kein dinghaft-phänomenaler Charakter mehr zugesprochen werden kann. ${ }^{35}$
}

\begin{abstract}
All'alba l'ultima immagine era perfettamente identica alle prime che Brahe aveva osservato all'inizio della notte: dal buio si formava sul monitor prima una cornice col numero della serie, il tempo, la sigla dell'esperimento; poi da destra e da sinistra entravano linee rapidissime, alcune collidenti al centro dove l'impatto generava altre linee continue o tratteggiate, curve e parabole e ellissi e piccoli vortici attorcigliati su se stessi. Tutto restava cosí per qualche istante, bloccato, accaduto; poi tutto spariva di nuovo. Ogni dieci secondi le note di diapason si fermavano su un tono calante, i numeri delle quantità toccavano il limite massimo, e sullo schermo c'era questa specie di paf visivo. Di ogni linea Brahe conosceva il destino e la natura, e anzi l'ideale sarebbe stata una linea nuova, inspiegabile e dunque probabile, lí dove avrebbe potuto esserci e non c'era; però la visualizzazione nel complesso poteva sembrare tutto: una metropoli illuminata vista dall'alto, la
\end{abstract}

33 Lyotard: Immaterialität, S. 38. Im Anschluss an Lyotard grenzt auch Welsch die „PseudoPostmoderne“ von der „veritablen Postmoderne“ ab (vgl. Wolfgang Welsch: Die Postmoderne in Kunst und Philosophie und ihr Verhältnis zum technologischen Zeitalter, in: Technologisches Zeitalter oder Postmoderne?, hrsg. v. Walther Ch. Zimmerli, München 1988, S. 36-72, bes. S. 59-61).

34 Im Gespräch mit Daghini charakterisiert Lyotard die postmoderne Malerei, zu der er auch die avantgardistische Malerei der Moderne zählt, als „wesentlich reflexiv“ im Unterschied zu jenem „Postmodernismus der Abschlaffung“ in Werken, „die eher das Gefühl als die Reflexion ansprechen“ (Lyotard: Immaterialität, S. 38). Die Analyse von Epsteins poetologischem Experiment wird allerdings zeigen, dass das Gefühl nicht im Gegensatz zur Reflexion stehen muss, sondern die Reflexion den Weg zum Gefühl - zu einer ,neuen Sensibilität‘ - bahnen kann.

35 Entsprechend heißt es auch von Brahe, er arbeite „nell’ assoluta scomparsa delle cose“ (AO 68 [94]). Brahes historischer Namensgeber ist der dänische Astronom Tycho Brahe (1546-1601); mit ihm sind nicht nur relevante wissenschaftliche Einsichten über planetarische Bewegungen mittels neuer Techniken zu verbinden, sondern auch wissenschaftsorganisatorische und institutionelle Innovationen: Seine 1576 eingerichtete Beobachtungsstation kann als Vorläufer dessen gelten, was heute „Zentrumslaboratorium“ (wie z. B. das CERN) genannt wird (vgl. Karin Knorr-Cetina: Die Fabrikation von Erkenntnis. Zur Anthropologie der Naturwissenschaft, zweite, erweiterte Auflage, Frankfurt/M. 2002, S. XIX). 
fotografia notturna di una via con striature rosse e bianche di fari d'auto in movimento, il pannello degli scambi di una stazione, perline colorate sul velluto nero di un inanellatore. Erano immagini molto preliminari, selezionate, artificiali, non tutto l'evento ma soltanto quella parte che avrebbe potuto rivelare novità; gli eventi completi, migliaia di eventi di una notte, andavano in memoria. (AO 19) $)^{36}$

Die Bilder, die Brahe auf dem Monitor sieht, eröffnen sich zwar durchaus der Vorstellbarkeit für den Rezipienten, mehr aber noch erregen sie dessen Neugier, indem sie vor allem die Frage evozieren, wovon diese Bilder eigentlich Bilder sind, welchen originalen Naturgegenstand sie abbilden, auf welchen Referenzbereich sie bezogen sind. Der Roman gibt auf diese Fragen auch im weiteren Verlauf keine Antwort; im Gegenteil: In dem Maße, in dem der genannte Problemzusammenhang in nahezu endlosen Variationen wiederholt wird - er dominiert die wissenschaftliche ebenso wie die literarische und allägliche Welt des Romans -, expandiert gleichsam auch die vom Leser wahrgenommene Leerstelle. Diese ,bezeichnet' und umfasst das gesamte naturwissenschaftliche Wissen, das mit dem Projekt am CERN verbunden ist und markiert damit jene Schnittstelle, die den Laien vom Experten trennt. ${ }^{37}$ Umgekehrt jedoch lenkt die gezielte Aussparung

36 „Im Morgengrauen waren die letzten Bilder noch immer völlig identisch mit den ersten, die Brahe am Anfang der Nacht gesehen hatte: Zuerst tauchte auf dem dunklen Monitor ein Rahmen mit der Seriennummer, der Uhrzeit und der Experimentbenennung auf, dann schossen von links und rechts Linien über den Bildschirm, von denen einige in der Mitte aufeinanderprallten, und jede Kollision erzeugte wiederum durchgehende oder gestrichelte Linien, Kurven und Parabeln und Ellipsen und kleine Wirbel, die sich um die eigene Achse drehten. Einen Augenblick lang blieb alles so, der Vorgang war fixiert, dann war der Bildschirm wieder schwarz. Alle zehn Sekunden fiel die Tonfolge auf den Ausgangston zurück, die Zahlengrößen erreichten die Höchstgrenze, und auf dem Bildschirm gab es diese Art von sichtbarem Paff. Brahe kannte die Bestimmung und die Art jeder einzelnen Linie, das Ideal wäre jedoch eine neue, unerklärliche und deshalb auch mögliche Linie gewesen, dort, wo sie hätte sein können, jedoch nicht war; die Bildschirmdarstellungen hätten im Ganzen jedoch auch etwas anderes sein können: eine hell erleuchtete Stadt aus der Vogelperspektive, die Nachtaufnahme einer Straße mit Autos, deren Scheinwerfer rot-weiße Schlieren zogen, das Stellwerk eines Bahnhofes, bunte Perlenschnüre vor dem schwarzen Samt eines Teilchenbeschleunigers. Es waren vorläufige, ausgewählte, künstliche Bilder: Nicht der ganze Vorgang, sondern nur jener Teil, der etwas Neues offenbaren konnte, die vollständigen Vorgänge, die tausend Vorgänge einer Nacht wurden gespeichert“ (AW 29).

37 Auf der naturwissenschaftlichen Sachebene verhindert die Leerstelle sowohl eine identifikatorische Lektüre durch den Leser als auch ein auf Identifikation und hermeneutische Horizontverschmelzung gerichtetes Gespräch der Protagonisten: Epstein und der Leser sind gleichsam vom epistemischen Subjekt Brahe getrennt. Die Kluft zwischen Laien und Experten thematisiert der Roman mehrmals auch ganz explizit: So etwa wundert sich Brahe während eines Aufenthalts in einer Buchhandlung, „daß es alle Bücher gab, nur keine über sein Fach, 
des ,positiven“ Wissens die Aufmerksamkeit auf den genannten Problemzusammenhang und damit auf wissenschafts- und erkenntnistheoretische Fragen, von deren Antwort die ,Natur' des ,positiven“ Wissens nicht unberührt bleibt. ${ }^{38}$ In nahezu allen Werken der poetica scientiae ist dieses narrative Verfahren der Fokussierung des ,negativen“, ,schwachen‘, ,impliziten“ Wissens durch Dezentrierung oder Ausblendung des ,positiven“ Wissens anzutreffen. Im Unterschied je-

und wenn es sie doch gab, waren es Bücher für die breite Masse, und die Dinge, mit denen er sich beschäftigte, wurden darin zu Orangenschnitzen, zu Sandwiches mit verschiedenen Schichten, zu Tennisbällen [...], und am häufigsten kam der Satz vor: ,Stellen Sie sich vor, wie...', und meistens musste er sich andere Dinge vorstellen als die, mit denen er zu tun hatte; [...]. Sicher, Erklärungen waren notwendig, aber hätte er je erklären können, daß es für das, was er sah und zu sehen versuchte, buchstäblich kein Bild gab außer jenen konventionellen und von einer rigorosen Phantasie formalisierten Bilder, die sich im Hinblick auf die Dinge so willkürlich und allmächtig verhielten wie das Alphabet“ (AW 79). Sehr deutlich wird hier die kapitalistische Vermarktung des ,Abenteuers Wissenschaft', vor allem aber die bildhafte Vergegenständlichung wissenschaftlicher Sachgehalte zum Zwecke ihrer Popularisierung als ein gewaltsamer Eingriff in die wahre Natur wissenschaftlicher Erkenntnisse kritisiert und ein jeglicher auf Wahrheit gegründete Zusammenhang zwischen ,eigentlicher‘ und populär vermittelter Wissenschaft dementiert. Brahes problematisierende Einschätzung populärwissenschaftlicher Bücher erhellt sich, wie im Folgenden zu zeigen ist, vor allem aus der relevanten Bedeutung von Bildern für den wissenschaftlichen Diskurs selbst: Während darin Bilder in Ordnungen des Wissens eingebunden sind, fehlt es dem Laien in der Regel an solchen sachlich fundierten Zuordnungs- und Einordnungsmöglichkeiten. Die Folge davon ist, dass die populären Bilder nicht mehr als didaktische - und entsprechend personalisierte, dramatisierte und veralltäglichte Objekte der Wissensvermittlung rezipiert, sondern für Wissen und Wirklichkeit selbst gehalten werden. Brahes Kritik zielt letztlich auf die Gefahr einer Entfesselung und Verselbständigung des ästhetischen Potentials populistischer Bilddarstellungen, auf die Gefahr also, dass sich die metaphorischen und imaginären Bedeutungsüberschüsse der Bildmedien von ihrer szientifischen message emanzipieren und damit der Erzeugung eines fiktiven Bildes von der Wissenschaft als ganzer Vorschub geleistet wird. - Zur Kluft zwischen Laien und Experten vgl. auch AO 21 [32], 29 f. [43] sowie 104 f. [141 f.].

38 Vgl. hierzu auch den Beitrag von Wirth zur „Konjektur als blinder Fleck“, in dem er im Rekurs u.a. auf Michel Serres’ „para-epistemisches ,in-between““, Charles S. Peirces Kategorie der „Abduktion“ und Poppers „Hypothesen“-Begriff (Uwe Wirth: Die Konjektur als blinder Fleck einer Geschichte bedingten Wissens, in: Caroline Welsh/Stefan Willer: „Interesse für bedingtes Wissen“. Wechselbeziehungen zwischen den Wissenskulturen, München 2008, S. 269-294, hier S. 269 ff.) die „epistemologische Relevanz“ des intuitiven „Problems des Anfangs von Denkprozessen“ sowie der Bewusstwerdung „unbewussten, intuitiven Wissens“ (ebd., S. 273) hervorhebt. Zu dem von Parnes eindrucksvoll unternommenen Versuch, am Beispiel von „Theodor Schwanns Entdeckung der Zellen“ die „Vorgeschichte [einer] Intuition“ wissenschaftsgeschichtlich zu rekonstruieren, vgl. den im selben Band enthaltenen Beitrag von Ohad Parnes: Von der Schwierigkeiten der Wissenschaftsgeschichte, mit der Intuition umzugehen, und vom Versuch, diese Schwierigkeiten zu überwinden, S. 343-359, hier S. 348 u. 349). 
doch zu den bisher untersuchten Romanen berührt hier das negative Wissen primär nicht historische Kontexte, nicht kulturell verankertes Wissen, welches das szientifische mitprägen würde, sondern die technologisch-ästhetische Innenwelt des szientifischen Wissens, das auf intermediale und interdisziplinäre Strategien und Methoden der Wissenserzeugung und Wissensdeutung angewiesen ist.

Für Brahe sind die Bildschirmdarstellungen Teil der experimentellen Praxis und des wissenschaftlichen Diskurses. Er liest sie als diskursive Bilder, ${ }^{39}$ deren epistemische Funktion und argumentativer Wert streng determiniert und auf einen spezifischen Gebrauchskontext beschränkt ist. ${ }^{40}$ Ihrer ,Lektüre' und Deutung innerhalb dieses Kontextes - der Kontext des wissenschaftlichen Experiments geht eine ,Ordnung des Wissens‘ voraus, ein festgelegtes System, auf das die Bilder bezogen, dem sie zugeordnet, in das sie übersetzt werden und das ihren Status als Wissenschaftsbilder begründet. ${ }^{41}$ Dass die Zielsprache, in die Brahe die Bilder übersetzt, lediglich eine Möglichkeit unter vielen darstellt, verdeutlichen die von ihm durchgespielten Alternativen ihrer Anders-Wahrnehmbarkeit, An-

39 Zur Unterscheidung diskursiver und aisthetischer Medien bzw. Kunstbildern und wissenschaftlichen Bildern vgl. Dieter Mersch: Einleitung: Wort, Bild, Ton, Zahl - Modalitäten medialen Darstellens, in: Die Medien der Künste. Beiträge zur Theorie des Darstellens, hrsg. v. ders., München 2003, S. 9-49; Dieter Mersch: Das Bild als Argument. Visualisierungsstrategien in den Naturwissenschaften, in: Ikonologie des Performativen, hrsg. v. Christoph Wulf u. Jörg Zirfas, München 2005, S. 322-344; Gottfried Boehm: Die Wiederkehr der Bilder, in: Was ist ein Bild?, hrsg. v. ders., München 1994, S. 11-38; Gottfried Boehm: Zwischen Auge und Hand: Bilder als Instrumente der Erkenntnis, in: Mit dem Auge denken. Strategien der Sichtbarmachung in wissenschaftlichen und virtuellen Welten, hrsg. v. Bettina Heintz u. Jörg Huber, Wien, New York 2001, S. 53-54; Gottfried Boehm: Jenseits der Sprache? Anmerkungen zur Logik der Bilder, in: Iconic Turn. Die neue Macht der Bilder, hrsg. v. Christa Maar u. Hubert Burda, Köln 2004, S. 28-43. Eine knappe Übersicht über diese u.a. Positionen bei Martina Heßler: Einleitung, in: Konstruierte Sichtbarkeiten. Wissenschafts- und Technikbilder seit der Frühen Neuzeit, hrsg. v. dies., München 2006, S. 11-37, hier S. 22-23.

40 Der seinerseits definierte Kontext definiert ihren Geltungsbereich. Werden sie mit neuen Kontexten in Verbindung gebracht, ändert sich ihr gesamter Bildstatus, d.h. ihre Logik, ihre Funktion. - Ihren „rhetorischen Beweischarakter“ haben Wissenschaftsbilder, so Knorr-Cetina, nur dadurch, „daß es sich um ,Inskriptionen“ (von Maschinen aus der ,Natur' produzierte Signale) handelt und nicht um bloße Deskriptionen“ (Karin Knorr-Cetina: „Viskurse“ der Physik: Konsensbildung und visuelle Darstellung, in: Mit dem Auge denken, S. 305-320, hier S. 309).

41 Diese ,Ordnung des Wissens“ verzweigt sich wiederum in eine Vielfalt von Ordnungen (etwa eine mathematische und eine technologische), die fließend ineinander übergehen. 
ders-Lesbarkeit und Anders-Deutbarkeit. ${ }^{42}$ Die szientifische Sprache - sei diese nun begrifflicher oder mathematischer Natur - wird damit von Beginn an in das ,parataktische، Gefüge einer Pluralität von Sprachen und kulturellen Codes gestellt und in ihrem Gültigkeitsanspruch in die präzise definierten Schranken des Experiments verwiesen. ${ }^{43}$ Zugleich wird eine Differenz zwischen dem Offenen und Phantasmatischen des Visuellen und dem ,Definitorischen“ und Eindeutigen der szientifischen Sprache etabliert, eine Differenz, die im szientifisch motivierten Übersetzungs- und Interpretationsvorgang zugunsten fixierter, identifikatorischer

42 Dass die Wissenschaftsbilder auch als ästhetische Objekte gesehen werden können, ist Teil ihrer ,medialen Natur` und ein Aspekt ihres problematischen erkenntnistheoretischen Stellenwerts: „Die Transformation von Bildern in einen anderen Kontext verändert ihren epistemischen Status und führt zu einer Bedeutungsverschiebung und manchmal dazu, daß Wissenschaftsbilder keine mehr sind, sondern beispielsweise zu Kunst oder auch zu Elementen der Popkultur werden“, so Martina Heßler in ihrer Einleitung, S. 36. Die Anderswahrnehmbarkeit von Gegenständen ist bereits für Hegel konstitutives Merkmal von Wahrnehmung: „[D]as Ding ist das Auch oder das allgemeine Medium“, d.h. in der pointierten Deutung von Wiesing: „Die Wahrnehmung kann das Bewußtsein nur auf ein Objekt richten, das auch anders sinnlich wahrnehmbar ist, weil Wahrnehmung immer eine durch das Wahrnehmungsbewußtsein vollzogene Identifizierung von sinnlichen Differenzen ist. Das Objekt einer Wahrnehmung gibt sich dem Wahrnehmenden immer als ein Objekt für mehrere Sinne, weshalb mit jeder Wahrnehmung eine Identifizierungsleistung verbunden sein muß“ (Lambert Wiesing: Einleitung: Philosophie der Wahrnehmung, in: Philosophie der Wahrnehmung. Modelle und Reflexionen, hrsg. v. ders., Frankfurt/M. 2002, S. 9-64, hier S. 53; die entsprechenden Abschnitte aus Hegels Phänomenologie des Geistes finden sich auf S. 139-145, das Hegel-Zitat auf S. 144). - Indem der Roman die genannten Alternativen explizit durchspielt, thematisiert er implizit auch die erkenntnistheoretische Relevanz dessen, was Wirth so treffend als „synekdochisches Sensorium“ im Sinne eines „kultivierten Ratevermögens“ bezeichnet hat, eines „Erschließens [...], das vor dem Hintergrund vorbegrifflicher Prägungen und kulturellen Vorwissens [erfolgt]“ (Wirth: Die Konjektur als blinder Fleck, S. 277).

$43 \mathrm{Zu}$ diesem Kontext vgl. auch Lyotard, der in Anlehnung an Wittgensteins Theorie der Sprachspiele von heterogenen, nicht ineinander übersetzbaren und auf keine allgemeine Logik oder Metasprache rückführbaren „Diskursgenres“ spricht und diese definiert als „Modi der Satzverknüpfungen, die durch je verschiedenartige Zwecke bestimmt werden“ (Lyotard: Immaterialität, S. 41) und die je verschiedene Bezugnahmen auf Wirklichkeit zulassen (Wirklichkeit aufgefasst als eine zwischen Partnern verabredete Form des Konsens über Erkenntnisse und Verpflichtungen, vgl. Lyotard: Beantwortung der Frage: Was ist postmodern?, S. 41). Der aus dieser Pluralität von Diskursgenres, Satzordnungen und Zwecken entstehende Widerstreit bildet nach Lyotard „die Basis des Widerstands gegen eine ,kommunikative“ Verflachung und Vereinheitlichung“ (Lyotard: Immaterialität, S. 49). Mit diesen Ausführungen relativiert Lyotard seine frühe Position, wonach die wissenschaftliche Erkenntnis mit der Erzählung zu identifizieren sei (vgl. Lyotard: Das postmoderne Wissen, S. 83 ff. u. 96 ff.; zu dieser Selbstkorrektur ausdrücklich: Jean-François Lyotard: Randbemerkungen zu den Erzählungen, in: Postmoderne und Dekonstruktion, S. 49-53, v. a. S. 51 f.). 
Bedeutungen geschlossen und aufgehoben wird: Das Bild wird dem wissenschaftlichen Diskurs und den diesen bestimmenden Regeln gleichsam einverleibt, ein Vorgang, der notwendig mit dem Verlust des Bild-,Anderen', insbesondere seiner ästhetischen Merkmale wie Metaphorizität, Polyvalenz und Autonomie einhergeht. ${ }^{44}$ Schließlich erscheint auch die Wahrnehmung selbst durch mentale Einstellungen und Erwartungshaltungen gesteuert, strukturiert und in die pluralen Formen einer technologisch-szientifischen, (quasi-)naturalistischen und ästhetischen Perzeption gespaltet. Wie sehr das Bewusstsein den spezifischen Erscheinungs- und in der Folge auch Deutungsmodus eines Gegenstandes reguliert, zeigt sich besonders in jenen Passagen, in denen die ,wirklichkeitsgetreuen' Wahrnehmungen des Erzählers mit den wissenschaftlich modellierten Wahrnehmungen seiner Figuren überblendet werden: „Al fondo di una curva Brahe ha guardato il lago, e le montagne; ma le ha guardate come un puro movimento altimetrico, montagne lago montagne, linee inclinate di discesa, linee orizzontali a pelo dell'aqua, linee impennate in risalita“ (AO 89). ${ }^{45}$ Durch das narrative ,blending“ relativieren sich Erzähler- und Figuren-Blick und das in ihm sich Zeigende wechselseitig. Analog der Wahrnehmung der Visualisierungen auf dem Bildschirm wird auch hier Wahrnehmung als eine intentional gerichtete, gleichwohl intuitiv und instantan sich vollziehende Lektüre und Interpretation von Welt - und damit Welt als lediglich zeichen- und bildhaft zugängliche - ausgewiesen. Zugleich sind es wiederum Bewusstseinsgehalte im wahrnehmenden Subjekt, die die wahrgenommenen Zeichen- und Bildobjekte in ihrer spezifischen Erscheinungsweise gestalten. Im Ergebnis, und dies wird die Analyse technologischer Bildherstellungsverfahren erhärten, ist Wahrnehmung beschreibbar als ein zugleich rezeptiver (zeichenempfangender und -lesender) und poietischer (zeichenprozessieren-

44 Wissenschaftsbilder werden instrumentell, argumentativ und damit auch rhetorisch eingesetzt - sie sind „vollzugsorientiert“ und haben ,ihren Zweck notwendigerweise außer sich selbst“; entsprechend wird die Ikonizität des Bildes weitgehend ignoriert. Pointiert spricht Boehm in diesem Zusammenhang von „schwachen“ Bildern im Gegensatz zu den „starken“ Bildern der Kunst (Boehm: Zwischen Auge und Hand, S. 52 f.). Die Ambivalenz zwischen dem Ästhetischen von Wissenschaftsbildern und dem ihnen beigemessenen Anspruch auf Objektivität vgl. v. a. die Arbeiten von Lorraine Daston und Peter Galison (z.B. Das Bild der Objektivität, in: Ordnungen der Sichtbarkeit. Fotografie in Wissenschaft, Kunst und Technologie, hrsg. v. Peter Geimer, Frankfurt/M. 2003, S. 29-99).

45 „Am Ende einer Kurve hat Brahe den See betrachtet und die Berge; aber er hat sie wie eine rein altimetrische Bewegung betrachtet: Berge See Berge, abfallende Linien, horizontale Linien über dem Wasser, ansteigende Linien“ (AW 121). Vgl. jene Passage, in der die Luftveränderungen beim Fliegen beschrieben werden und die Luft sich unter Brahes Auge schließlich in Ziffern verwandelt, die eine immer höhere Geschwindigkeit anzeigen (,trasformandosi in numeri di velocità crescenti sotto gli occhi di Brahe“, AO 100 [136]). 
der) Vorgang, wobei die unterschiedliche Wahrnehmung desselben Gegenstandes zum einen auf die intentionale (d.h. auf etwas gerichtete) Struktur der Wahrnehmung, zum anderen auf den je individuellen psychischen, physischen und kognitiven Zustand des wahrnehmenden Subjekts zurückgeführt werden kann. ${ }^{46}$

Als Medium weist das Bild jedoch nicht nur ,voraus' in Richtung epistemische Zielsprache, sondern vor allem ,zurück‘ auf den natürlichen Referenten, als dessen Abbild es fungiert. Als Bilder visualisieren sie ,etwas', von dem es buchstäblich kein Bild gibt, „cose di cui non c'era immagine, se non quelle convenzionali e formalizzate di rigorosa fantasia, arbitrarie e potenti, rispetto alle cose, come un alfabeto“ (AO 79). ${ }^{47}$ Das Verhältnis zwischen Signifikant und Signifikat kann hier nicht länger in einer Rhetorik der Repräsentation beschrieben werden: Die traditionelle Vorstellung einer konventionalistischen oder

46 In diesem Zusammenhang sei vor allem auf die phänomenologisch ausgerichtete Wahrnehmungstheorie von Thomas Reid (1764) und in dessen Gefolge von Konrad Fiedler (1887) und Charles Sanders Peirce (1903) verwiesen. Reid, der erstmals zwischen Empfindung (d.h. in einem bestimmten Zustand sein) und Wahrnehmung (d.h. auf etwas gerichtet sein) unterscheidet, erklärt Wahrnehmung als einen unbewussten „Leseakt“, innerhalb dessen die durch das wahrgenommene Objekt im Subjekt ausgelösten Empfindungen, Reize bzw. Zeichen „durch eine lesende Interpretation zu Wahrnehmungen von dieser Sache werden“ (Lambert Wiesing: Einleitung: Philosophie der Wahrnehmung, S. 39). Im Rekurs auf Reids „Modell von den unbewußten Tätigkeiten“ (ebd., S. 36) beschreibt Fiedler die Wahrnehmungen sowohl als intentionale Wahrnehmungen von etwas als auch als „Gestaltungen eines psychophysischen Subjekts [...]. Das Subjekt faßt durch die Wahrnehmung nicht ein vorgegebenes Ding auf, sondern macht durch die Wahrnehmung das Wahrgenommene zu dem, was es ist“ (ebd., S. 43). Die Erzeugung dieser Gestalten kann als eine ,Semiose in Permanenz' beschrieben werden, als ein „rastloses Werden und Vergehen, eine Unendlichkeit von Vorgängen, in denen die Elemente alles Seins in den mannigfaltigsten Arten auf den mannigfachsten Stufen ihrer Verarbeitung erscheinen, ohne daß das flüchtige, sich immer erneuernde Material jemals zu festen, unveränderlichen Formen erstarrte“ (ebd.). Das Wahrnehmungssubjekt ,liest“ nicht mehr, wie bei Reid, „eine vorgegebene Bedeutung aus seinen Empfindungen, sondern ist ein schaffender Künstler, der sich immer in einem bestimmten Zustand befindet“" (ebd., S. 44). Während es Fiedler auf die poietische Gestaltung von Empfindungen und Vorstellungen ankommt, rekonstruiert Peirce die „innere Entstehungslogik der Wahrnehmungsurteile“: „Wahrnehmungsurteile entstehen durch unbewußte Abduktionen aus wahrgenommenen Zeichen“ (ebd., S. 45), wobei Abduktion, so Peirce’ eigene Formulierung den „Vorgang des Aufstellens einer erklärenden Hypothese“ meint (Peirce, zit. n. ebd., S. 45). Wahrnehmen kann damit als „,unbewusstes, kontinuierliches und abduktives Schlussfolgern in Zeichen““ definiert werden (Alexander Roesler, zit. n. ebd., S. 45; zu Peirce vgl. auch Wirth: Die Konjektur als blinder Fleck, v.a. S. 275-285).

47 Dinge, „von denen es keine Bilder gab außer den konventionellen und von einer rigorosen Phantasie formalisierten Bilder, die sich im Hinblick auf die Dinge so willkürlich und allmächtig verhielten wie das Alphabet“ (AW 109). 
ontologischen Korrespondenz zwischen Bild und einer von ihm unabhängig existierenden Wirklichkeit ist aufgekündigt. ${ }^{48}$ An die Stelle von Repräsentationen treten Konstruktions-, Inszenierungs- und Interaktionsprozesse, welche sowohl die Bilder als auch die wissenschaftlichen ,Objekte‘ allererst generieren. ${ }^{49}$ Wissenschaftsbilder sind folglich nicht Repräsentationen, sondern ,kons-

48 Mersch unterscheidet drei grundlegende historische Phasen der Bildkultur: 1. die repräsentationale Funktion des Wissenschaftsbildes zwischen dem 17. und frühen 19. Jahrhundert; 2. die ,mechanische“ oder ,nichtinterventorische‘ Aufzeichnung seit der 2. Hälfte des 19. und der 1. Hälfte des 20. Jahrhunderts und 3. die Bildkultur der allein auf mathematischen Algorithmen beruhenden Digitalisierung (Dieter Mersch: Naturwissenschaftliches Wissen und bildliche Logik, in: Konstruierte Sichtbarkeiten, S. 405-429, hier S. 407-410).

49 Vgl. dazu die Beiträge von Sabine Flach („It’s not easy being green!“ Schnittpunkte von Kunst, Medientechnik und Naturwissenschaften am Beispiel der Transgenic Art), Michael Hagner (Bilder der Kybernetik: Diagramm und Anthropologie, Schaltung und Nervensystem) und Dieter Mersch (Naturwissenschaftliches Wissen und bildliche Logik), in: Konstruierte Sichtbarkeiten, S. 281-302, 383-404 u. 405-429; ferner: Michael Lynch u. Samuel Edgerton: Aesthetics and digital image processing: Representational craft in contemporary astronomy, in: Picturing Power. Visual Depiction and Social Relations, hrsg. v. Gordon Fye u. John Law, London 1988, S. 184-220. Der prekäre Status wissenschaftlicher Bilder hängt mit dem prekären Status ihrer Referenten eng zusammen. „In Hochenergiephysik-Experimenten“, so Knorr-Cetina, „werden natürliche Ordnungen als Zeichenordnungen rekonfiguriert“ (Knorr-Cetina: Wissenskulturen, S. 61). Mehr als alle anderen Experimentalwissenschaften werde die Hochenergiephysik von Zeichenprozessen dominiert. Ihre Experimente nehmen in Zeichenprozessen ihren Ausgang: „Die Konstruktion von Objekten als Spuren oder ,Unterschriften“ von Ereignissen und nicht die Ereignisse selbst bestimmen und beeinflussen alle experimentellen Strategien“ (ebd., S. 62). „Die Objekte selbst sind [...] ,unwirklich'; sie sind in den Termini eines Physikers irreale Gegenstände. Sie sind zu klein, um je - außer indirekt durch Detektoren - gesehen werden zu können, zu schnell, um eingefangen und im Labor gesammelt werden zu können, zu gefährlich als Teilchenstrahlen, um direkt manipuliert werden zu können. Die interessierenden Teilchen treten in der Regel in Kombinationen mit anderen Komponenten auf, die ihre Gegenwart maskieren. Die meisten subatomaren Teilchen sind überdies kurzlebige, in ständiger Veränderung begriffene Entitäten, die nur für den billionsten Teil einer Sekunde existieren. Aufgrund ihrer häufigen Metamorphosen und ihres Zerfalls treten sie daher als immer schon vergangene, immer schon historische Objekte auf“ (ebd., S. 76 f.). Ursache dafür ist eine Arbeitsteilung zwischen Labor und Experiment: „Die materiellen Prozesse der Teilchenbeschleunigung, die zur Zeichenproduktion führen, werden aus dem Aufgabenbereich der Experimente ausgeschlossen“ (ebd., S. 63). Dabei arbeitet bereits das Labor nicht mit „naturbelassenen Objekten“, sondern mit „Objektzeichen, mit ihren physiologischen, chemischen, elektrischen u. a. Komponenten, mit ihren Extrakten und ,gereinigten“ Versionen“ (ebd., 45-46), kurz mit hochkultivierten, inszenierten Naturobjekten (vgl. ebd., S. 47, 65). In Laboratorien werden „im Prinzip alle Objektaspekte neu verhandelt und neu definiert“ und „manche Objekte auch neu erzeugt, z.B. Teilchenzerfälle in der Hochenergiephysik“ (ebd., 65). In Anlehnung an Lacan spricht Knorr-Cetina in diesem Zusammenhang auch von der „Rekonfiguration von Selbst- 
truierte Sichtbarkeiten“: Sie „geben nicht das Sichtbare wieder, sondern machen [das Unsichtbare] sichtbar". ${ }^{50}$ Sie bilden nicht Wirklichkeit ab, sondern erzeugen vielmehr einen „effet de réell“, ${ }^{51}$ eine Illusion von Wirklichkeit, in der die zeichenhaft konstituierte Realität mit der natürlichen, materiellen Realität nur scheinbar zur Deckung gelangt. ${ }^{52}$ Insofern sich die wissenschaftlichen Gegenstände und Bilder nicht mehr auf einen externen Referenten beziehen

anderen Dingen“ (vgl. ebd., S. 65). - Auch nach Lyotard sind die meisten ,Immaterialien“ „auf der Grundlage der Technowissenschaften Informatik und Elektronik erzeugt“ (Lyotard: Immaterialität, S. 80), und er verweist ausdrücklich auf die digitalen Bilder, die „nur produziert und nicht reproduziert werden“ (ebd., S. 59). Ins Kommunikationstheoretische übersetzt: Der Gegenstand bzw. das Phänomen wird als Nachricht (= eine Kombination von Zeichen) betrachtet, die Zeichen wiederum „sind aus diskreten Elementen gebildet, welche distinktive Merkmale des Trägers oder Materials (des Materiellen) sind [...]. Die distinktiven Unterschiede, nach denen diese Merkmale verteilt sind, bilden den Code der Nachricht. Diese geht von einem Sender-Pol zu einem Empfänger-Pol, wobei je nachdem am oberen Ende Inkodierung und am unteren Ende Dekodierung stattfindet. Die Nachricht liefert eine Information über wenigstens einen Referenten (das, um was es sich handelt)“. Interaktion meint hier allgemein, 1. dass „jeder der Pole der Struktur allein in seinen Beziehungen zu den anderen Polen relevant ist“ und 2. dass „eine Änderung in der Funktion einer der Pole eine Destrukturierung und Restrukturierung des Ganzen nach sich zieht: es handelt sich dann um eine andere Nachricht“. Fazit: „Die Nachricht ist von ihrem Träger (dem Materiellen) nicht zu lösen; der Code selbst ist in den Träger eingeschrieben als die geregelte Anordnung der diskreten Elemente (Körner), die das Materielle (elektronische Wellen, Schallwellen, Lichtwellen, Elementarteilchen und ihre distinktiven Merkmale usw.) konstituieren. Das Materielle verschwindet als unabhängige Einheit. Das Prinzip, auf dem die Operationsstruktur aufgebaut ist, ist nicht das einer stabilen ,Substanz', sondern einer unstabilen Menge von Interaktionen. Das Modell der Sprache ersetzt das Modell der Materie“ (ebd., S. 80-81). - Zur Analyse digitaler Bilder, insbesondere zu ihrer „Doppelexistenz“ als „Bildschirmerscheinung“ und „Zeichensatz“, vgl. auch Gernot Grube: Digitale Abbildungen - ihr prekärer Zeichenstatus, in: Konstruierte Sichtbarkeiten, S. 179-196, bes. S. 186-189.

50 Heßler: Einleitung, S. 13. Heßler bezieht sich dabei auf den von Hans-Jörg Rheinberger geprägten Begriff der „Sichtbarmachung“.

51 Vgl. Roland Barthes: L'effet de réell, in : Communications 11 (1986), S. 84-89.

52 Diese ,Deckungsgleichheit‘ geht notwendig mit einem Vergessen des Bildcharakters des Bildes - mit dem ,Tod der Metapher - einher. Vgl. dazu auch Grube, der drei Aspekte eines wissenschaftlichen Bildes identifiziert: 1. das Bild ist eine Abbildung, deren Referenzgegenstand unabhängig von der Abbildung existiert; 2. die Abbildungsrelation wird durch ein maschinengesteuertes Aufnahme- bzw. Aufzeichnungsverfahren realisiert und begründet und 3. das Bild entbirgt Wirklichkeit, es überrascht und erlaubt Schlüsse auf ein sonst unzugängliches Phänomen (Grube: Digitale Abbildungen, S. 179-196, hier S. 183 u. 195). Bedauerlicherweise bleibt Grube gerade mit Blick auf den 3. Aspekt eine plausible Antwort auf die Frage, wie ein virtuelles Bildobjekt Aufschlüsse über ein real-natürliches Objekt erlauben, wie es also auf der Grundlage von Abbildungen überhaupt zu gesicherten Erkenntnissen kommen kann, schuldig. 
lassen - es sind „stellvertretende Instanzen“, „Supplemente“, welche die Anwesenheit eines natürlichen Referenten nurmehr fingieren ${ }^{53}$-, erscheint die Wissenschaft selbst als eine entreferentialisierte: Die Natur ist nicht länger die objektive Bezugsgröße des naturwissenschaftlichen Denkens. Die epistemisch allererst konfigurierte und konstruierte Referentialität ist damit ein intrinsisches Moment des wissenschaftlichen Systems, Referentialität letztlich ein Aspekt seiner Selbstreferentialität. Die Dekonstruktion des Repräsentationsmodus führt zwangsläufig in ein erkenntnistheoretisches Dilemma, verbindet sich mit den intern erzeugten Referenten und den aus ihnen gewonnenen Erkenntnissen doch immer noch der Anspruch, etwas ,Wahres‘ über die ,wirkliche Wirklichkeit‘ auszusagen. Wissenschaftsbilder zählen damit nicht nur zu den wichtigsten Faktoren in der Ästhetisierung des Anästhetischen, sondern auch zu den maßgeblichen Akteuren in der Erzeugung wissenschaftlicher Erkenntnisse.

Dabei liegen der Erzeugung von Sichtbarkeiten institutionelle Organisationseinheiten, hochtechnologisierte Maschinerien und komplexe Prozesse und Verweisungsketten zugrunde, die von der instrumentellen, personalen und ökonomischen Infrastruktur des Laboratoriums über diffizil konstruierte Apparaturen und experimentelle Einrichtungen wie Teilchenbeschleuniger und Detektoren bis hin zu den mit Programmen, Daten- und Zeichensätzen gespeisten Computeranlagen und den vielfältigen Möglichkeiten medialer Aufzeichnungs-, Simulations- und Transformationspraktiken reichen und in ihrer spezifischen Konfiguration das konstituieren, was im Bild jeweils zu sehen ist. Stefan Ditzen spricht in diesem Zusammenhang von „Bildmycel“, das die „Gesamtheit der Voraussetzungen an der Produktion eines artifiziellen Bildes“" ${ }^{\text {“5 }}$ verkörpert. Während das Bild selbst die Prämissen und Prozeduren seiner Genese - seinen „demiurgischen Charakter“55

53 Vgl. Jacques Derrida: Grammatologie [1974], übers. v. Hans-Jörg Rheinberger u. Hanns Zischler, Frankfurt/M. ${ }^{3} 1990$, S. 250 f. u. 521.

54 Stefan Ditzen: Der Satyr auf dem Larvenrücken. Zum Verhältnis von instrumentellem Sehen und Bildtraditionen, in: Konstruierte Sichtbarkeiten, S. 41-56, hier S. 56. „Der Begriff ist an die biologische Organisationsform des Mycels bei Pilzen angelehnt, das in einem unterirdischen Wachstum den eigentlichen Pilz ausbildet. Dieser ist zunächst nicht sichtbar und von den Fruchtkörpern, die gemeinhin unter dem Begriff ,Pilz‘ verhandelt werden, zu unterscheiden. Die biologische Terminologie charakterisiert mit dem Wort ,Pilz‘ die Gesamtheit, die im eigentlichen Sinn anteilig mehr dem Pilzmycel zukommt, als dem oberirdisch auswachsenden Fruchtkörper“ (ebd., S. 55).

55 Mit dieser Formulierung beschreibt Grube Wissenschaftsbilder als Sinnbilder, die zeitgenössische Auffassungen, nicht aber naturgetreue Formen wiedergeben (Grube: Digitale Abbildungen, S. 184). Das eigentlich Demiurgische besteht darin, dass das wissenschaftliche Bild durch den wissenschaftlich trainierten und konditionierten Blick einerseits, durch Verfahren der Bildverbesserung andererseits seinen Bildcharakter zu verlieren droht: „Die Raffinesse des 
verbirgt und diese auch in der real erfolgenden wissenschaftlichen Forschung kaum thematisiert, methodisch veranschlagt und in ihren faktischen Auswirkungen auf die Erkenntnis reflektiert werden, legt der Roman diese ,mycelische“ Bildstruktur und deren vielschichtigen Verweisungs- und Wirkungshorizont offen.

Eine im siebten Kapitel geschilderte Episode stellt den Konnex zwischen instrumentellen bzw. experimentellen Prädispositionen und naturwissenschaftlicher Visualisierung und Perzeption explizit her. Auf der Suche nach einem Ersatzteil schreiten Brahe und sein Kollege Rüdiger die Abteilungen und Regale eines Maschinenlagers ab. Die Anordnung der Materialien korrespondiert dabei der Relevanz, die den einzelnen Teilen für das Sehen zukommt. An den ersten Regalen, die unter anderem gefüllt sind mit Teilen für den Vakuumaufbau, mit Isolierrohren, Gelenken aus Metallegierungen, Drehgelenken, Labyrinthdichtungen und Leitungsröhren, gehen sie rasch vorüber, ohne sich noch einmal umzublicken, denn „tutto questo non riguardava i rivelatori e non era ancora il vedere, ma soltanto la base per produrre quello che forse si sarebbe visto“ (AO 69 f.). ${ }^{56}$ Sie verlangsamen ihren Schritt vor den Regalen, „dove cominciavano i ricambi del vedere“ (AO 70) und in denen Szintillationsplättchen, Optikfasern und nach Typ und Leistung geordnete Photovervielfacher gelagert sind. Schließlich bleiben sie zwischen Racks und diversen Karten für Rechnergehäuse, Prozess-Trigger, SpeechProcessoren, kurz: bei den Teilen für die Datenerfassung - „il culmine del vedere“ (AO 70) - stehen. Wie schon angedeutet korreliert die horizontale, parataktisch

Bildes liegt darin, sich als Bild zum Verschwinden zu bringen, um dadurch gerade als Bild in die Welt einzugreifen, wirksam und unmerklich. [...] Das wissenschaftliche Bild wird gefährlicher, weil es als digitales Bild seinen Status als Zeichen teilweise verliert. Die Bedrohung [...] in den scheinbar unbegrenzten Fälschungsmöglichkeiten [...] liegt in der unaufgedeckten Selbstverleugnung“ (ebd., S. 185, Hervorhebung im Original). Nach Mersch ist es die „fehlende Negation bzw. die „genuine ,Affirmität“ des Bildlichen“, die ihm sein „Unheimliches“, seine besondere Macht und Suggestibilität verleiht (Mersch: Naturwissenschaftliches Wissen und bildliche Logik, S. 413 u. 415). Das Opake, das den Bildern als „konstruierten Sichtbarkeiten“ anhaftet, beruht auf einer „doppelten Unsichtbarkeit [...], insofern sowohl ein Nichtsichtbares den Ausgangspunkt für die Sichtbarmachung bildet, als sich auch andererseits die Unsichtbarkeit der technischen Erzeugungsbedingungen im Bild zurückhält“ (ebd., S. 420). Da dem Bild die „indexikalische Anbindung“ an einen natürlichen Referenten fehlt - „die Daten und die Software bilden den Referenten“ - ist es mit Blick auf eben diesen natürlichen Referenten „spurenlos“ und „grundlos in seiner Funktion als Zeugenschaft“ (Bettina Heintz, Jörg Huber: „Der verführerische Blick“ - Formen und Folgen wissenschaftlicher Visualisierungsstrategien, in: Mit dem Auge denken, S. 9-40, hier S. 30).

56 ,[...], denn alles das betraf nicht die Detektoren und das Sehen, sondern war nur die Grundlage zur Erzeugung dessen, was man vielleicht sehen würde“ (AW 96-97). 
gefügte Ordnung der Materialien ${ }^{57}$ mit einer vertikal-hypotaktischen, an der Relevanz für das Sehen ausgerichteten Werteskala; durch diese sinnlichphysiologisch determinierte Wertzuschreibung werden die technischen Bausteine an das Humane gebunden, das seinerseits in einem Dependenzverhältnis zu den technologischen ,Prothesen des Auges` steht. Dabei ist die vertikale Achse, die Mensch und Technik in ein Verhältnis setzt, durch eine gegenläufige Bewegung charakterisiert: Je wertvoller die Materialien für das Sehen werden, desto langsamer schreiten Brahe und Rüdiger die Regale ab. Dem Weg von den grundlegenden, aber gleichsam ,blinden“ Materialien bis zum Gipfel des Sehens entspricht eine kontinuierliche Verlangsamung des Schritttempos bis hin zum Stillstand. Der Klimax des Sehens korrespondiert die Antiklimax des Gehens - ein Hinweis darauf, dass am Gipfel des Sehens die anatomischen Strukturen und physiologischen Prozesse des menschlichen Auges ${ }^{58}$ vollkommen von den technologischen

57 Diese parataktische Ordnung wird am Ende der Passage unterstrichen: „Jedes Ding war gleichberechtigt mit den anderen ausgestellt [in pari diginità, AO 71]. Die Maschine, die Maschinen, die Teile und ihre Intelligenz waren alle da, mit ihrer Katalognummer: geordnet und verfügbar, wie ein Wörterbuch [ordinate e disponibili, come un vocabolario, AO 71]“ (AW 98).

58 Das Gehen ist neben dem Fliegen die zentrale Bewegungsmetapher des Romans und nimmt in ihren vielfältigen Verweisungsbezügen nahezu dingsymbolischen Charakter an. Auf einige Facetten sei im Folgenden hingewiesen: Das Gehen fungiert als eine Art Barometer, das den Stand der Freundschaft zwischen Brahe und Epstein, insbesondere auch den Grad des Gelingens ihres kommunikativen ,Eingehens' aufeinander anzeigt (vgl. AW 16, 74). Bedeutsam ist das Gehen vor allem für Epstein. Es ist Thema seines literarischen Erstlingswerks Atlas der Gangarten und von besonderer poetologischer Relevanz: Schreiben wie Gehen sind für ihn Bewegungsabläufe, die einem inneren Rhythmus und - im Gegensatz zum Fliegen und den Vorgängen im Teilchenbeschleuniger - einem humanen Tempo folgen (AW 75, vgl. auch 48, 65). Sofern sich Schreiben und Gehen quasi-automatisch vollziehen, kommt ihnen lediglich der Status von Ablenkungsmanövern, Digressionen und Umwegen zu, die wegführen von den ihnen impliziten, nicht zuletzt auch human aufzufassenden Schwierigkeiten; vollziehen sie sich hingegen reflektiert und konzentriert, dann zeigen sie sich in ihrer Komplexität und Problematik und erweisen sich als eine Abfolge von „Aufgeben und Wiederfinden des Gleichgewichts zu sich“, als „Ungleichheit und Wechsel“, dem nur durch eine „Absicht“ oder eine „Richtung“ der Anschein von Kontinuität zuwächst (AW 75 f.). - Auf der diskursiven Ebene wird das Gehen mit einer ganzen Reihe von Gegebenheiten parallelisiert: Die Spuren, die Epstein beim Gehen durch den Garten hinterlässt, werden von seinem kuriosen Diener mit Pflastersteinen ausgelegt, so dass der Garten allmählich das Aussehen einer Landkarte annimmt, durchzogen von „Abzweigungen und Verästelungen, als gewährte man mir eine Erweiterung des Straßennetzes“; parallel heißt es auch von den Gefühlen, die Epstein mit dem neuen Sehen verbindet, dass sie immer „intimer und verästelter“ waren und „weder Ziel noch Zweck“ besaßen (AW 44), ferner ist das Pflastern eine Form des Kartographierens und damit ein weiteres Mal an Epsteins Schreibprojekte rückgebunden. Über Epsteins Bemerkung, dass die gepflasterte Wiese im Grunde ein „Film“ ist, „der alle menschlichen Bewegungen regis- 
,Wahrnehmungsorganen' absorbiert und abgelöst sind, sinnliche Wahrnehmung also durch eine rein technologische substituiert ist. ${ }^{59}$ Die Apparaturen des Sehens eliminieren das Subjekt keineswegs, sind sie es doch, die das Undarstellbare für das Subjekt in spezifischer Weise zur Darstellung bringen und damit das geistigimaginäre Sehen dessen, was „niemand [...] je mit eigenen Augen sehen“ würde, ermöglichen:

ma solo dalle tracce computerizzate di ciò che era decaduto avrebbe potuto intuire e immaginare, immaginare con rigore e prova, ciò che si era generato per trasformarsi subito in tutt'altro. $(\mathrm{AO} 70)^{60}$

Der Gipfel des Sehens markiert damit auch jenen Punkt, an dem die blinde sinnliche Anschauung in eine geistig-imaginäre umschlägt. Technik und Mensch sind nicht als disparate, streng voneinander geschiedene und unterscheidbare Größen ausgewiesen; vielmehr stehen die mit ihnen jeweils assoziierten Kompetenzen und Funktionen in einer komplexen Interdependenz-, Interaktions- und Komplementärbeziehung. Gemeinsam bilden sie ein integrales Ordnungs- und Organisationsgefüge, eine quasi-organologische Einheit. ${ }^{61}$

triert", wird das Gehen mit den Vorgängen des Beobachtens, Aufzeichnens und Speicherns von Teilchenspuren im CERN verbunden. Darüber hinaus ist mit Wiese (Natur) - Spur - Pflaster eine dreistellige Zeichenkonstellation beschrieben, die die Bezugspole der Repräsentation (wirkliche Wirklichkeit - Erscheinung/Bild - Darstellungsmedium/Abbild) abbildet, also Repräsentation repräsentiert und als ein literarisches wie epistemisches Verfahren problematisiert wird (dies vor allem über den von Epstein bedeuteten Einspruch gegen das Tun seines Dieners). - Die Zerstörungen, die Epstein im Garten beim Gehen hinterlässt, verweisen auf das Schwinden der Wirklichkeit und die allmähliche Auflösung des Außenraums; entsprechend ist das Pflastern ein Versuch des Konservierens, Materialisierens und Sichtbarmachens der vom Verwischen bedrohten Spuren, ein protestierendes Anpflastern gegen eine im Schwinden begriffene und technologisch usurpierte Welt. Nicht zuletzt ist das Gehen an Leiblichkeit und Bewegung, an die menschliche Anatomie und Physiologie und immer wieder auch an das Tierische, Instinktive und - literarisch konnotierte - Undisziplinierte und Autonome gebunden, das durch die Pflasterung gezähmt und kontrolliert werden soll (vgl. AW 74). Insgesamt tritt die Thematik des Gehens (wie bei dem analysierten Gang durch das Ersatzteillager) mit der zunehmenden Relevanz, die das Schwinden der Wirklichkeit und das neue Sehen für Epstein gewinnen, auf der inhaltlichen wie diskursiven Ebene zurück.

59 Vgl. auch Knorr-Cetina, die den Detektor als „eine Art ultimatives Wahrnehmungsinstrument" beschreibt (Knorr-Cetina: Wissenskulturen, S. 75).

60 „nur die vom Computer aufgezeichneten Spuren dessen, was vorgefallen war, erlaubten zu sehen und sich vorzustellen, streng beweisbar vorzustellen, was entstanden war, um sich sofort in etwas ganz anderes zu verwandeln“ (AW 97).

61 Das ,Schwinden der Sinne‘ ist nicht zu trennen vom allmählichen Verschwinden des anwesenden Körpers, der, wie Lyotard darlegt, „als materieller Sinnträger erscheint, auf dem mit 
$\mathrm{Zu}$ den Prozessen der Sichtbarmachung gehören schließlich auch all jene interaktiven und ästhetisierenden Eingriffe in die Bildschirmoberfläche, wie sie die raffinierten Programme der Bildbearbeitung zunehmend ermöglicht. Während die aktive Manipulation digitaler Bildschirmdarstellungen - ihre ,kathartische‘ Behandlung - im Roman eher beiläufig Erwähnung findet, ${ }^{62}$ steht die Fälschung einer Maschinenzeichnung im Mittelpunkt einer Begegnung zwischen Brahe und dem Nobelpreisträger Wang. Bei dieser Werkzeichnung, deren einziges Exemplar in Brahes Besitz ist, handelt es sich um den Entwurf einer Maschine, deren einzelnen Teile von verschiedenen Teams in verschiedenen Ländern entwickelt wurden. Da Brahe der Bitte Wangs, ihm 20 Zentimeter zu überlassen, nicht nachkommen kann oder will, beschließt er, „die Zeichnung zu fälschen“ („,contraffare il disegno“, AO 24 [36]), und zwar dergestalt, dass er mit dem von ihm konstruierten Teil

einer bestimmten Zahl von Codes (Gefühle, Bewegungen) Einschreibungen erfolgen“ (Lyotard: Immaterialität, S. 55). Die Beziehung zwischen Geist und Materie ist folglich „nicht mehr die zwischen einem intelligenten, seine Absichten verfolgenden Subjekt und einem leblosen, trägen Objekt. In der Familie der ,Immaterialien“ sind sie Vettern“ (ebd., S. 83). - Den Zusammenhang zwischen Mensch und Maschine beschreibt Knorr-Cetina ausführlich am Beispiel der im CERN durchgeführten Mega-Experimente. Wie (neben den epistemischen Objekten) auch die epistemischen Subjekte allererst konstruiert werden und damit als Komponenten und Produkte der technologischen und sozialen Maschinerien $\mathrm{zu}$ betrachten sind (vgl. KnorrCetina: Wissenskulturen, Kap. 7 u. 8), so werden umgekehrt die technologischen Maschinen als physiologische Organismen und sozial-moralische Wesen anthropologisiert und individualisiert (vgl. ebd., Kap. 5).

62 So geschieht die Suche nach einem neuen „Trigger-Niveau“, „indem sie eine Reihe von Signalen kürzten und andere hervorhoben“ (AW 143); gezielt „wählt Brahe Vorgänge aus, nimmt die spektakulärsten heraus“ (AW [188]), andernorts ist von den „inzwischen sehr reinen, sehr klaren“ Bildern die Rede (AW 192), die Brahe „wie Fotogramme“ erscheinen (AW 195). Dass Brahe sich der kosmetisch erzeugten Reinheit der Bilder durchaus bewusst ist und dieser Praxis auch Spuren des moralisch Unlauteren unterstellt, zeigt das Unbehagen, das er angesichts der Reinheit und Moralität wild lebender Tiere empfindet (vgl. AO 77 [107]). - Vgl. Heßler, die diese kosmetischen Verfahrensweisen ausdrücklich als „ästhetisches Handeln“ charakterisiert: „Dies meint, dass die wissenschaftliche Praxis von der Suche nach Mustern, nach Strukturen, nach Stimmigkeiten bzw. nach Herausfallendem geleitet ist und dass das, was gezeigt werden soll, hervorgehoben wird, indem es schärfer gemacht, eingefärbt, begradigt, betont und scheinbar Nebensächliches überdeckt und marginalisiert wird“ (Heßler: Einleitung, S. 23). - Was Bildbearbeitung konkret bedeutet, beschreibt Grube am Beispiel von Messungen atomarer Strukturen, deren bildliche Darstellung über ein Rastertunnelmikroskop erfolgt: Weder gibt es „sinnliche Erfahrungen mit atomaren Oberflächen“ noch gibt es ein realiter existierendes „Vorbild, [...], an dessen Gestalt die Bildbearbeitung orientiert“ und mit der das Bild verglichen und der Grad der Übereinstimmung bzw. Abweichung mit dem Objekt ermittelt werden könnte; „,was man über das abzubildende Objekt weiß, sind Messergebnisse und die sehen nicht aus“ (Grube: Digitale Abbildungen, S. 193 f.). 
vierzig Zentimeter in Wangs Refugium eindringt, um sich dann während der Verhandlung mit Wang großzügig zeigen und ihm die geforderten 20 Zentimeter überlassen zu können: „Però debbo fare finta di darglieli, senza darglieli in realtà“ (AO 32). ${ }^{63}$ Seine Kollegin Eileen, die dieses Vorgehen zwar nicht für korrekt hält, nimmt die Fälschung schließlich vor. Die Begegnung mit Wang - inszeniert als ein humoreskes Intermezzo - verläuft ganz nach Brahes Wunsch. Wang, so wird eindringlich suggeriert, durchschaut zwar das Täuschungsmanöver, spielt aber mit und überlässt Brahe den Sieg. Künstlerische performance, Manipulation, Täuschung und Betrug werden hier als ein selbstverständlicher Bestandteil des wissenschaftlichen Spiels ausgewiesen, ein Spiel, in dem es letztlich nicht um die persönliche Ehre des Gewinnens geht, sondern um den wissenschaftlichen Erfolg, der nur in Team-Arbeit erzielt werden kann. Refrainartig installiert Wang während der Begegnung mit Brahe die folgende Sentenz - und formuliert damit gleichsam die Goldene Regel des wissenschaftlichen Spiels:

„Per vedere [...] ci vogliono grande intenzione e grande energia, prima e dopo, perché ciò che è stato prodotto per poterlo vedere non lo si vede mentre accade: si vede prima come intenzione, si vede dopo come risultato“. Ha fissato Brahe negli occhi con intensità, ha detto: „Lei e io vediamo cosi““ (AO 39). ${ }^{64}$

Während die am Anfang zitierte Passage (vgl. AO 19 [29]) ihren Ausgang von der Bildschirmdarstellung nimmt und den Weg vom Wissenschaftsbild über dessen Interpretation hin zur wissenschaftlichen Erkenntnis skizziert, werden mit dem

63 „Ich muß jedoch so tun, als würde ich sie ihm geben, ohne sie ihm wirklich zu geben“ (AW 46).

64 „,Wenn man etwas sehen will, [...], braucht man große Willenskraft und große Energie, zuvor und danach, denn das, was hergestellt worden ist, um gesehen zu werden, sieht man nicht, während es geschieht: Man sieht es zuvor als Absicht und danach als Resultat.' Er hat Brahe nachdrücklich in die Augen geblickt, hat gesagt: ,Sie und ich, wir sehen das so.““ (AW 55). Evidenz wird als ein Produkt ausgewiesen, das aus der Verbindung von subjektiver Intention und Interpretation einerseits, technologischem Einsatz und Objektivität andererseits hervorgeht und damit als ein Modus der Beweisführung jenseits des epistemischen Diskurses. Vgl. auch Mersch, der die epistemische Funktion von Bildern als „Beglaubigung durch Sichtbarmachung“ beschreibt, die „Geltung nicht durch Gründe, sondern durch Evidenz“ erlangt. Evidenz aber ist - im Unterschied zum Argument - nicht falsifizierbar: die Evidenz des Visuellen beruht auf dem, „was durch sich selbst einleuchtet“, sie ist von schlagender Beweiskraft (Mersch: Naturwissenschaftliches Wissen und bildliche Logik, S. 416). Evidenz unterliegt - und auch das impliziert die von Wang formulierte Regel - aber auch historischen Bedingungen, d.h. „daß jede historische Formation all das sieht und sichtbar macht, was sie gemäß ihren Bedingungen der Sichtbarkeit zu sehen vermag, so wie sie alles sagt, was sie gemäß ihren Aussagebedingungen sagen kann“ (Gilles Deleuze: Foucault, Frankfurt/M. 1987, S. 85). 
Gang durch das Magazin und in Brahes inszeniertem Täuschungsmanöver die einzelnen Stationen bei der Erzeugung von Sichtbarkeiten (also jene Technologien und Interaktionen, die die wissenschaftliche Objektwelt generieren und untrennbar mit den epistemischen Prozessen zusammengeschlossen sind) abgeschritten und erinnert, ${ }^{65}$ und der Blick gleichsam auf das Bild-Innere - auf sein Anfängliches und Ursächliches ${ }^{66}$ - freigegeben. Sichtbar gemacht wird damit gerade das, was im (vorläufigen) Endprodukt - den „tracce computerizzate“ - und dessen Weiterverarbeitung unsichtbar bleibt, namentlich die instrumentellen, apparativen und zeichenprozessierenden Voraussetzungen seiner Herstellung. Indem der literarische Diskurs den Herstellungsprozess wissenschaftlicher Bilder - ihr unterirdisches Mycel - offen legt und die Relevanz dieser Bilder für die wissenschaftliche Erkenntnisgewinnung aufzeigt, arbeitet er dem die Ereignisebene dominierenden Thema, dem Verschwinden der Dinge, hier konkret: dem Verschwinden sowohl der Dinge als auch der Mechanismen ihrer Erzeugung im epistemischen Diskurs, entgegen. Ohne die Grenzen zwischen Naturwissenschaft und Literatur zu verwischen - und dies wird noch genauer zu analysieren sein -, wird über den fiktionalen Bilddiskurs der wissenschaftliche Bilddiskurs in seinen verborgenen technologisch-konstruktivistischen und virtuell-artifiziellen Zusammenhängen seziert und als ein unübersehbares Implikat des szientifischen Diskurses selbst ausgewiesen. Buchstäblich ans Licht gebracht wird die ,Viskursivität ${ }^{67}$, die den physikali-

65 Bekanntlich gehört das Magazin neben der Wachstafel zu den zentralen Memoria-Metaphern. Aus dem Umfeld der Sophistik und Rhetorik stammend, sind Magazinmetaphern überwiegend auf die Gedächtniskunst - auf die Lokalisierung bildhaft repräsentierter Gedächtnisinhalte - bezogen. Die Bilder, die in dem von Brahe und Rüdiger abgeschrittenen GedächtnisMagazin lagern, sind selbstreferentieller Natur: Bilder, welche die Bedingungen und Prozesse der Bilderzeugung abbilden und speichern. Zur Gedächtnismetaphorik vgl. Harald Weinrich: Metaphora Memoriae, in: ders.: Sprache in Texten, Stuttgart 1976, S. 291-294 sowie ergänzend Aleida Assmann: Zur Metaphorik der Erinnerung, in: Mnemosyne. Formen und Funktionen der kulturellen Erinnerung, hrsg. v. dies. u. Dietrich Harth, München 1991, S. 13-35.

66 Sichtbarkeit, so Mersch, wird letztlich aus Zahlenreihen modelliert: „Folglich haben wir es mit Transformationen von Theorien in Programme und von Programmen in Visualisierungen zu tun, an deren Anfang kein Wahrnehmbares oder eine markierbare Spur steht, sondern die Definition einer mathematischen Funktion“. Wissenschaftsbilder sind damit „Medium der Modellierung und Werkzeug eines internen wissenschaftlichen Konstruktivismus [...], welche jeden Ursprung im Anschaulichen verloren haben“ (Mersch: Naturwissenschaftliches Wissen und bildliche Logik, S. 410; vgl. auch S. 417).

67 „Viskurse“ bezeichnen nach Knorr-Cetina visuelle Darstellungen, welche die Bedeutung der ,rein' diskursiven Praxis für die Koordination des wissenschaftlichen Experiments zunehmend in den Hintergrund drängen: „Wo es Viskurs gibt, wird Diskurs schnell als ,bloßes Reden' abgetan, der keine experimentellen Ergebnisse ,zeigt‘ und keinen Nachweis für die Durch- 
schen Diskurs zunehmend prägt und elementarer Bestandteil seiner Selbstreferentialität ist. Dabei wird der epistemische Bildgenerierungsprozess wiederholt und überschritten zugleich, wobei hier die Transgression im Unterschied zu den bisher untersuchten Werken nicht auf ein Wissenschaftsexternes hin erfolgt, ${ }^{68}$ sondern auf die Wissenschaft selbst hin, auf ein ihr Immanentes. Für den Roman bedeutet dies konkret, dass er in der Wiederholung den epistemischen Viskurs auf einen Meta-Viskurs hin überschreitet, dessen epistemologische Funktion in der Selbstaufklärung des epistemischen Viskurses besteht. Auf diese Weise betreibt der Roman im besten Sinn des Wortes ,Archäologie des Wissens'. Zugleich, und dies wird noch zu zeigen sein, ist dieser Meta-Viskurs auch poetologisch relevant.

\subsection{Epsteins ästhetische Theorien}

Epsteins Darlegungen über seine Entwicklung als Schriftsteller etablieren eine fiktionsimmanente Poetik, der, so die diesem Kapitel zugrunde gelegte These, in Bezug auf die epistemologischen Zusammenhänge des Romans eine maieutische Funktion zukommt. Del Giudices Aussage, sein Roman thematisiere einen „mutamento di epoca sostanziale“, ist auch literarhistorisch zu verstehen: Epsteins künstlerische Biographie repräsentiert den Übergang der literarischen Moderne in die Postmoderne. Seine Poetiken, die von ihm in der Vergangenheit vertretene Poetik der Moderne und die von ihm in der Gegenwart experimentell entwickelte Poetik der Postmoderne, weisen dabei einerseits allgemeine, d.h. literaturwissenschaftlich kanonisierte Merkmale auf, sind jedoch andererseits auch extrem individualisiert. In Epsteins Retrospektive erscheint seine literarische Wandlung vom modernen zum postmodernen Schriftsteller auch nicht als ein fließender Übergang, sondern als der radikale Bruch zwischen einer literari-

führung bestimmter Arbeiten erbringt“ (Karin Knorr-Cetina: Viskurse der Physik, in: Konstruktionen Sichtbarkeiten, hrsg. v. Jörg Huber u. Martin Heller, Zürich, Wien u.a. 1999, S. 245-261, hier S. 249). Dabei werden Viskurse ihrerseits nicht nur apparativ-mathematisch, sondern auch diskursiv erzeugt. Der Begriff weist ferner ,auf die lateralen Bezugnahmen und Verknüpfungen der Darstellungen hin - die nicht isoliert sind, sondern immer in Zusammenhang mit vorherigen, gleichzeitigen, neuen Darstellungen stehen“ (ebd.); schließlich „entfalten Viskurse technische Objekte und haben eine interne Beziehung zu wissenschaftlicher Forschung“ (ebd.).

68 Transgressionen auf ein Wissenschaftsexternes hin verwandeln und semantisieren das wissenschaftliche Zeichen in ein wie auch immer konkretisiertes nicht-wissenschaftliches Zeichen. Dieses kann dann wieder sinnhaft auf die Wissenschaft selbst rückbezogen und als Teil ihres verdrängten Immanenten ausgewiesen werden. 
schen Moderne und einer ,nicht mehr literarischen', weil nicht mehr literarisierbaren Postmoderne. Dieser Bruch wird durch die Poetik, die dem Roman als Ganzes zugrunde gelegt ist, gekittet. Der implizite Autor bzw. Erzähler erhebt Einspruch gegen Epsteins Deutung und korrigiert diese dahingehend, dass er Moderne und Postmoderne in eine kontinuierliche, ja sogar in einem Bedingungsverhältnis stehende Beziehung bringt.

\subsubsection{Epsteins Ästhetik der Moderne}

Dal passato [so Epstein in einem Brief an seinen Verleger] mi interessa come è cambiato di libro in libro il mio rapporto tra l'etica e la forma [...]. Ma sono molto occupato dal presente (che non è la „vita“, io ho vissuto abbastanza): è una nota musicale lunga, tersa, consonante con tutte le altre in assoluta simultaneità, nella simultaneità totale della fantasia, del vedere oltre la forma. Forse è forma fluente. Ma è appena un'impressione. È una nota sospesa e compiuta e... (AO 29) ${ }^{69}$

Mit dem Terminus „l'etica“ umschreibt Epstein die komplexen Zusammenhänge zwischen den Menschen - ihren Erfahrungen, Gefühlen, Gedanken und Wahrnehmungen - und den Dingen. Diese Zusammenhänge herzustellen und ihnen in der Literatur Ausdruck und Form zu verleihen, war sein primäres Anliegen. ${ }^{70}$ Ausführlich schildert Epstein in einem Gespräch mit Brahe die besondere Beziehung, die er zu den Dingen unterhielt:

Ero capace di sentire come è fatta una cosa, ero capace di percepire la sua forma in un modo diverso da ciò che normalmente si intende per percepire: io sentivo come si sente il filamento di una lampadina nel vuoto d'aria della sua pera. Mi sembrava che ogni oggetto avesse una sua vita; non solo quella della materia, lavorata in forma, la sua vita era il pensiero che c'era dietro e il comportamento in cui si prolungava. [...] Cosí esisteva una relazione con gli altri, con molti altri, attraverso le cose che ci sono nel proprio tempo, attraverso il fare che non era soltanto fare gli oggetti, ma molto di più. Si poteva non essere

69 „Von der Vergangenheit interessiert mich, wie sich von Buch zu Buch mein Verhältnis zu Ethos und Form verändert hat [...]. Aber die Gegenwart beschäftigt mich so sehr (nicht das ,Leben', ich habe genug gelebt): Die Gegenwart ist ein langer, klarer Ton, der mit allen anderen Tönen in absoluter Simultaneität übereinstimmt, in der totalen Simultaneität der Phantasie, des Sehens jenseits der Form. Vielleicht ist es eine fließende Form. Aber das ist nicht mehr als ein Eindruck. Der Ton ist in der Schwebe und vollständig und ...“ (AW 42).

70 „Mein ganzes Leben und meine ganze Arbeit waren nichts anderes als der Versuch, die Menschen mit den Dingen in Zusammenhang zu bringen und die Dinge mit der Erfahrung und den Gefühlen, mit der Wahrnehmung ihrer selbst, mit den Gedanken“ (AW 81). 
d'accordo, ma c'era una possibilità di amicizia. Ogni oggetto era comportamento trasformato in cosa, e poi ritrasformato in comportamento. (AO 58-59) ${ }^{71}$

Epstein erscheinen die Dinge als je individuelle Manifestationen, ja geradezu als Narrative menschlicher Gedanken bzw. Verhaltensweisen und zwischenmenschlicher Verhältnisse. ${ }^{72}$ Solcherart personalisiert und ,entdinglicht' kommt ihnen eine mediale Funktion zu: Sie vermitteln zwischen jenen Menschen, die die Dinge herstellen, und ihm selbst, der die Dinge gebraucht. Herstellung und Gebrauch werden dabei allerdings nicht als Komponenten eines ökonomischen Kreislaufs gedeutet, innerhalb dessen die Dinge zur Ware degradiert würden, sondern als den Dingen selbst innewohnende Handlungen im Vollzug. Entsprechend sind die Dinge als Medien auch keine passiven Instrumente, sondern lebendige Akteure innerhalb eines sozialen Gefüges. ${ }^{73}$ In Epsteins anthropomorphisierender und entdinglichender Optik erscheinen die Dinge zugleich und paradoxerweise in ihrer gesteigerten Dinghaftigkeit, als materielle Behälter, in denen menschliches Denken und Handeln konserviert oder vielmehr zwischengelagert ist. Es sind gleichsam materielle ,Durchgangsstadien“ menschlicher Denk- und Handlungsprozesse, hybride Gebilde aus Objektivem und Subjektivem. ${ }^{74}$

71 „Ich vermochte zu spüren, woraus ein Ding besteht, ich konnte seine Form auf eine Weise wahrnehmen, die sich von der herkömmlichen Art der Wahrnehmung unterschied: ich spürte, was der Glühfaden einer Lampe im Vakuum der Birne empfindet. Für mich besaß jedes Ding ein Eigenleben, und zwar nicht nur das der zu Form verarbeiteten Materie; sein Leben bestand in dem dahintersteckenden Gedanken und in dem Verhalten, in dem es sich fortsetzte. (...) Auf diese Weise unterhielt ich eine Beziehung zu den anderen, $z u$ vielen anderen, und zwar durch die Dinge, die zu unserer Zeit gehören, durch das Tun und Herstellen, das nicht einfach ein Herstellen von Dingen war, sondern viel mehr. Man konnte anderer Meinung sein, aber darin bestand eine Möglichkeit der Freundschaft. Jedes Ding war in Objekt verwandeltes Verhalten, das sich wieder in Verhalten zurückverwandelte“ (AW 82-83).

72 Ähnlich auch die Deutung Dilmacs (vgl. Literatur und moderne Physik, S. 297). - Die Dingwelt umschließt für Epstein menschlich erzeugte Dinge, also Artefakte, ebenso wie die Gegenstände der Natur, im Grunde also die gesamte Welt der Phänomene.

73 Die ,Sozialität‘ der Dinge - dies suggeriert Epsteins Rede von den Dingen als ,possibilità di amicizia“ - kann so weit reichen, dass die Dinge die anderen Menschen substituieren. In diesem Fall sind sie nicht mehr Medien zwischen Menschen, sondern Stellvertreter.

74 Für Epstein sind die Dinge nicht - wie etwa im literarischen Symbolismus - Anlass und Vorwand für dichterische Selbstaussagen im Sinne Rilkes: „Im Grunde sucht man in jedem Neuen (Land oder Mensch oder Ding) nur einen Ausdruck, der irgendeinem persönlichen Geständnis zu größerer Macht und Mündigkeit verhilft. Alle diese Dinge sind dazu da, damit sie uns Bilder werden“ (Rainer Maria Rilke: Brief vom 27.05.1899 an Frieda von Bülow, in: ders.: Briefe und Tagebücher 1899-1902, Bd. 1, hrsg. v. Ruth Sieber-Rilke u. Carl Sieber, Leipzig 1931, S. 15-18, hier S. 17). Hingegen weist seine Bestimmung der Dinge durchaus Ähnlichkeiten mit Rilkes späteren ,Dinggedichten“ und der Lyrik des Imagismus auf: Auch hier erfolgt die 
Dieser Zugang zu den Dingen war Epstein nicht immer gegeben: Er musste ihren Gebrauch unter Zuhilfenahme von Anleitungen lernen. Jeder dieser Bildungsromane - „Ogni manuale era per me un libro di galateo applicato, un romanzo di formazione“ (AO 60) - verband sich für ihn mit einer „nuova nomenclatura“, einer „alfabetizzazione del corpo“ und eröffnete ihm eine Welt von Korrespondenzen zwischen Namen und Begriffen einerseits und Gesten, Gefühlen, Haltungen, Gedanken andererseits. Der Gebrauch der Dinge und der Gebrauch der Sprache waren letztlich untrennbar miteinander verschränkt die Dinge waren ihm Sprachkörper -, und der Zugang zu den Dingen ermöglichte ihm den Zugang zur Welt und zu den Menschen:

A me sembrava che la vita delle persone fosse unita a quella delle cose, fosse una lunga storia di sedie e di letti, di scarpe e di valige, di tavoli e di porte, di automobili e aerei e treni e navi e di cassetti e di scatole, cose che in genere non si vedono, che restano sullo sfondo di persone prese a pensare direttamente „io come sto?“ (AO 60) $)^{75}$

Sein Handwerk (mio mestiere, AO 59) als Schriftsteller bestand in nichts anderem als in der Wiederholung und Zurückverwandlung jener unsichtbaren und hintergründigen Metamorphosen, die das natürliche wie artefaktische Sein der Dinge konstituieren, in der Aktualisierung der ihnen eingeschriebenen narrativen Möglichkeiten, eben im Erzählen und Sichtbarmachen - in der ,Aisthetisierung - jener verborgenen Zusammenhänge zwischen Dingen und Menschen. In diesem Sinne folgte seine Poetik dem Programm einer ,imitatio rerum', das die phänomenologische ,Arbeit an den Dingen“ voraussetzte und sich mit der ethischen Zielsetzung verband, die Menschen aus der Knechtschaft ihrer Selbstbezüglichkeit zu befreien und auf diese Weise ihr Glück zu mehren (,,accrescere la felicità del genere umano“, AO 60).

Präsentation der Dinge gleichermaßen in ihrer gegenständlichen Eigenart wie in ihrer phänomenologischen Bezogenheit auf die Menschen, werden verborgene Analogien und Verwandtschaften aufgedeckt und die Bedeutung des Dinghaften über ihre Verweisungsvielfalt erschlossen („No ideas but in things“ lautet das Credo von W. C. Williams; vgl. William Carlos Williams: A sort of a song, in: ders.: The collected poems, Bd. 2.: 1939-1969, hrsg. v. Arthur W. Litz, New York 1988, S. 55). Er betrachtet die Dingwelt im Grunde als oikos, als ,Haus‘ oder ,Gehäuse' menschlicher Ideen und Handlungen. Sie in ihren Beziehungen zu den Menschen sehen bedeutet damit auch, sie in ihren ökologischen Strukturen sehen.

75 „Ich hatte den Eindruck, das Leben der Menschen sei mit dem der Dinge verbunden, sei eine lange Geschichte von Stühlen und Betten, Schuhen und Koffern, Tischen und Türen, Autos und Flugzeugen und Zügen und Schiffen und Schränken und Schachteln, von Dingen, die man für gewöhnlich nicht sieht, die im Hintergrund von Menschen bleiben, die damit beschäftigt sind, sich zu fragen: ,Wie geht es mir?““ (AW 84-85). 


\section{Exkurs}

Die ethische Fundierung von Epsteins Poetik ist freilich nicht auf die humanen Ziele seiner schriftstellerischen Tätigkeit beschränkt. Der Gebrauch der Dinge - das Sehen und Denken der Dinge in ihrer komplexen Verfasstheit und in ihren humanen Bezügen - meint ja gerade nicht ihre utilitaristische Verzweckung, sondern das Sehen und die (narrative) Sichtbarmachung dessen, was den Dingen als einem komplexen Beziehungsgefüge innewohnt. Dinge gebrauchen bedeutet für Epstein, sie aus dem ihnen von den Menschen zugewiesenen Dasein im Hintergrund (sullo sfondo) in den ihnen eigentlich zukommenden und angemessenen Vordergrund zu rücken, sie neben die Menschen und in ein Verhältnis zu den Menschen zu stellen „in pari dignità“ (AO 58). Dinge gebrauchen bedeutet folglich, sie in ihrer „reinen Selbstgegebenheit“ (Husserl) und damit auch in ihrer spezifischen Erscheinungsweise, die zugleich ihre spezifische Wahrheitsweise - ihre Evidenz ${ }^{76}$ - ist, perzeptiv und intellektuell zu durchdringen, um das, was sich an und durch sie zeigt, narrativ sichtbar zu machen und einer Evidenzerfahrung für andere zuzuführen. ${ }^{77}$ Dabei ist die „reine Selbstgegebenheit“ der Dinge, ihre Präsenz, dadurch ausgewiesen, dass sie das Andere - die menschlichen Denk- und Handlungsformen, deren Transformation die Dinge ja sind - einschließt: das Andere ist nicht das Andere zum Selbst der Dinge, sondern Implikat dieses Selbst. Implikat deshalb, weil sich die Selbstgegebenheit der Dinge nicht in ihrem humanen Anderen erschöpft, sondern ihnen durch ihre materielle Gestalt - ihre Objekthaftigkeit - auch eine vom Menschen unabhängige Eigenständigkeit zukommt (auch dann zukommt, wenn ihre Gestalt Produkt menschlicher Fertigkeiten ist). Daneben wird den Dingen eine zeitliche Struktur beigemessen: Sie sind in der Tat ,Durchgangsstadien', nämlich Ergebnis in der Vergangenheit aktualisierter und zugleich Ausgangspunkt von in der Zukunft möglicher humaner Denk- und Verhaltensweisen (vgl. AO 59). Ihre selbstgegebene Präsenz ist, um erneut eine Formulierung Husserls aufzugreifen, „stehendströmende Gegenwart “, ${ }^{78}$ die sich in die Vergangenheit ebenso erstreckt wie in die Zukunft. Die ,imitatio rerum - die Repräsentation der Dinge in den erzählten Geschichten - hat diese diffizile Selbstgegebenheit und Präsenz zur Grundlage, eine Grundlage, die ihrerseits in der wahrnehmenden und denkenden Zuwendung ${ }^{79}$ an die Dinge erarbeitet und hergestellt werden muss. Sehen und Denken sind für Epstein mit einer Art Dienstleistung an den Dingen verbunden, denn sehend und denkend wird den Dingen zu ihrer Präsenz verholfen (nicht zu ihrer

76 Wahrheit als aletheia im Sinne des Offenbarens und Ans-Licht-Bringens von Verborgenem.

77 Der Begriff der Form lässt sich, so Derrida, nicht trennen von dem des Erscheinens, des Sinns, der Evidenz, der Essenz: „Die Form ist die Präsenz selbst. Das Formhafte ist das, was sich allgemein von etwas präsentiert, sich sehen läßt, zu denken gibt“ (Jacques Derrida: Die Form und das Bedeuten. Bemerkungen zur Phänomenologie der Sprache, in: Randgänge der Philosophie, hrsg. v. Peter Engelmann, Wien 1988, S. 159-174, hier S. 160).

78 Edmund Husserl: Die Krisis der europäischen Wissenschaften und die transzendentale Phänomenologie. Eine Einleitung in die phänomenologische Philosophie, hrsg., eingel. u. mit Registern versehen v. Elisabeth Ströker, Hamburg 1996, S. 171.

79 Diese Zuwendung äußert sich vor allem in der Behutsamkeit und Zärtlichkeit, mit der Epstein die Dinge berührt (vgl. AO 123 [164 f.]). 
Präsenz an sich, sondern für die Menschen). ${ }^{80}$ Sehen und Denken sind damit auch Präsentationsvorgänge, im Zuge derer die Dinge räumlich und zeitlich angemessen positioniert und in ihren Beziehungen zu den Menschen geordnet werden. Sehen und Denken der Dinge heißt, sie in ihrem Eigenleben (vgl. AO 58) sehen und denken, heißt, ihren rechtmäßigen Stellenwert beglaubigen und stellvertretend für die Dinge bezeugen, ihnen im rechten Sehen und Denken, im rechten Gebrauch, gerecht werden. - Die kritischen Impulse dieser Position sind offensichtlich: Epstein steht ein für ein Denken, das mit dem rationalistischen, positivistischen und ökonomistischen Prinzip der Natur- und Dingbeherrschung bricht, ohne dabei den Anspruch auf die Möglichkeit authentischer Wahrheitsfindung über eine mimetische Annäherung an die Dinge preiszugeben. Seine Forderung nach einer paritätischen Dignität des Besonderen und Singulären gegenüber dem Allgemeinen und Systematischen kritisiert zugleich den Bruch zwischen Subjekt und Objekt, einen Bruch, dessen Pole nicht idealistisch synthetisiert, sondern nur im genauen Hinblick auf die Dinge und in der adäquaten Für-Sprache für sie in ihrer vielschichtigen Bezogenheit und Verwiesenheit aufeinander - und das meint zugleich: in ihrer Andersheit - gezeigt werden können.

Wenn Epstein die besondere ,Natur' der Dinge auf sein eigenes Schaffen und auf seine Bücher überträgt, dann stellt er sich und sein Werk in einen Produktions- und Rezeptionszusammenhang, innerhalb dessen auch seiner Arbeit und seinen Büchern eine mediale Funktion zukommt. Das Erzählen und Schreiben von Geschichten ist nichts anderes als eine Transformation von Verhalten (Epsteins Haltung zu den Dingen eingeschlossen), ein, wenn man so möchte, Dingerzeugungsprozess, der immer schon eingebunden ist in die Kontinuität ${ }^{81}$ jener

80 Dieser Zusatz erscheint notwendig vor dem Hintergrund jener konstruierten Sichtbarkeiten, mit denen Brahe im Experiment operiert. Im Unterschied dazu präsentiert Epstein nichts Abwesendes oder Unsichtbares oder Nicht-Präsentes, sondern anwesende, präsente Dinge, die lediglich von den Menschen ins Abseits, in den Hintergrund gestellt sind.

81 Die Kontinuität ist ein weiteres Leitmotiv des Romans, das auf der diskursiven Ebene genau das leistet, wovon der Begriff auf der inhaltlichen Ebene spricht: Es stiftet Zusammenhänge und Kontinuität zwischen Disparatem. Dabei erscheint die Kontinuität meist als ein Konstrukt, das, indem es einen scheinbaren Zusammenhang herstellt, zugleich auch immer Differenzen einebnet. Auch hierzu einige Beispiele: Kontinuität zwischen Natürlichem und Künstlichem/Technischem (so setzt das künstliche Lampenlicht scheinbar die Kontinuität des Tageslichts fort und kaschiert die „späte Stunde“, die „dramatische Stunde“ [un’ora drammatica] der Nacht, die, wie es heißt, „fehl am Platz war“, AO 50 [71]; vgl. auch die Beschreibung des Verhaltens der Luftteilchen beim Fliegen, die in die Zylinderrippen des Flugzeugs eindringen und eine „kalte Kontinuität“ schaffen, AO 100 [135 f.]); Kontinuität zwischen natürlichen Mechanismen und kognitiven Prozessen (so erscheint das von „Ungleichheit und Wechsel“ beherrschte Gehen, bei dem der Körper permanent „aus dem Gleichgewicht“ gerät, lediglich durch die rasche und natürliche Aufeinanderfolge und gekoppelt an eine „Absicht“ oder „Richtung “ als Kontinuität, AO 53 [75 f.]; auch die kontingenten Ereignisse der Vergangenheit lassen sich in der Erinnerung sinnvoll zu einer „Kontinuität der Veränderungen“ verfugen, AO 61 [86]; vgl. auch AO 108 [145]); schließlich müssten einer Überlegung Brahes zufolge auch extreme, 
langen Geschichte, die vom Leben der Menschen mit den Dingen erzählt (vgl. AO 60). Analog den Dingen ist das von ihm geschaffene ,Kunst-Ding“ in seiner Selbstgegebenheit gerade nicht selbstbezüglich-ästhetizistisch, sondern Anderen und Anderem zugewendet und auf Andere und Anderes ausgerichtet. - Was aber meinen ,Sehen` und ,Denken` im Kontext von Epsteins früher Ästhetik?

Guardando si vede solo lo sfondo, pensando si pensa solo la figura. Mai le due cose assieme. [...] Forse quello che ho inventato fin qui non è altro che una lente speciale, che permette di vedere lo sfondo e la figura nella loro relazione, in pari dignità. (AO 57-58) $)^{82}$

Das auf die dinglichen Phänomene im Hintergrund gerichtete Sehen ist physisch-sinnliche Wahrnehmung; das auf die Gestalt gerichtete Denken ist - und hier ist Epstein der platonisch-aristotelischen Philosophie verpflichtet - von Sinnlichkeit befreites, metaphysisch-geistiges Schauen, theorein im Sinne einer Anschauung dessen, was den Dingen in ihrer je besonderen Erscheinungsweise an allgemeinen Ideen, Formen oder Konzepten zugrunde liegt. Dabei erinnert Epsteins Intention, Sehen und Denken - und damit Sinnlichkeit und Vernunft, Besonderes und Allgemeines, Anschauung und Begriff - in ihrem Zusammenhang zu sehen, durchaus an die gemäßigten Varianten klassisch-aufklärerischer Philosophie und Ästhetik mit ihrer Forderung, den rational(istisch)en Weltbezug an einen sinnlich-empirischen rückzubinden. ${ }^{83}$ Dass es für Epstein

einander widersprechende Charaktereigenschaften nach dem physikalischen Vorbild der Komplementarität zum kontinuierlichen Ausgleich gebracht werden können, so, als würde es sich lediglich um zwei komplementäre Möglichkeiten (due modi complementari), zwei Punkte derselben Welle (due punti della stessa onda) handeln (AO 114 f. [154]). - Von diesen konstruierten Kontinuitäten unterscheiden sich zum einen jene, deren Status sich der Überprüfbarkeit entzieht (wenn Brahe an Epstein denkt, dann verbreitet sich der Gedanke in vielfache Linien und Fasern und verästelt sich „,come una continuità, nella quale gli sarebbe stato difficile distinguere un singolo evento“, AO 78 [107]; auch die unterirdische Kontinuität [sotteranea continuità] des Traums, die den Tag mit der Nacht verbindet, AO 95 [129], gehört zu diesen unbestimmten Formen der Kontinuität), zum anderen die wahren Kontinuitäten (für die es nur ein Beispiel gibt, nämlich die unerforschten Reserven und Zonen der automatischen Erinnerung, AO 61 [86]).

82 „Beim Sehen sieht man nur den Hintergrund, beim Denken denkt man nur an die Gestalt. Nie beides zusammen. [...] Vielleicht habe ich bisher nichts anderes erfunden als eine Speziallinse, die es ermöglicht, Hintergrund und Sehen in ihrem Verhältnis zueinander zu sehen, gleichberechtigt in ihrer Würde“ (AW 81).

$83 \mathrm{Zu}$ denken ist hier vor allem an Schillers Programm einer ästhetischen Erziehung des Menschengeschlechts, freilich auch an Kants erkenntnistheoretische Fundierung des Konnex von Anschauung und Begriff oder Baumgartens Rehabilitierung der Sinne, nicht zuletzt an Goethes 
eine theoriefreie Sinneswahrnehmung der Dinge und Tatsachen ${ }^{84}$ nicht gibt, sondern Sehen immer schon in gewisser Weise ,konzeptualisiert' ist, machen seine oben zitierten Ausführungen über sein Studium, die Dinge zu gebrauchen, deutlich: Der bloße Blick auf die Dinge gibt ihr „Eigenleben“ nicht preis; vielmehr offenbart sich ihm die ,Ordnung der Dinge“ erst unter Zuhilfenahme von Nomenklaturen, so dass das, was Epstein Ding oder Tatsache nennt, „immer schon in irgendeiner Weise theoretisch orientiert, [...] im Hinblick auf ein gewisses Begriffssystem und durch dasselbe implizit bestimmt“"85 ist. Seine Skepsis gegenüber der reinen Abstraktion (und diese Skepsis ist zugleich Kritik an den ästhetizistischen Tendenzen in der Kunst wie in der Philosophie und der Wissenschaft) ist auf ein zweifaches bezogen, nämlich zum einen auf die Ablösung der allgemeinen Eigenschaften der Dinge von ihren individuellen, ${ }^{86}$ zum anderen (und mit ersterem verbunden) auf die Ablösung des geistigen Sehens vom sinnlichen, folglich auf die Verselbständigung und Entleerung begrifflichen Denkens gegenüber der gegenständlichen Erfahrung. ${ }^{87}$ Beide Abstraktionsprozesse führen letztlich $\mathrm{zu}$ der bereits angesprochenen Spaltung von Subjekt und Objekt, der es - so Epsteins ästhetisches Programm - im Medium

Verteidigung der Sinnlichkeit gegenüber einer technologisch verstärkten und nurmehr mathematisch-abstrakt verfahrenden Wissenschaft.

84 Zur Gleichsetzung der Dinge mit den Tatsachen äußert sich Epstein im Gespräch mit Brahe: „Forse all'epoca degli oggetti corrispondeva l'epoca dei fatti; sí gli oggetti e i fatti andavano insieme [...], e uno come me, se gli avessero chiesto: lei si interessa di? ..., avrebbe potuto rispondere: di fatti, soltanto fatti, i puri fatti...“ (AO 137)./,Vielleicht entsprach der Epoche der Dinge die Epoche der Tatsachen; die Dinge und die Tatsachen gehörten zusammen [...], und wenn man einen wie mich gefragt hätte: Wofür interessieren Sie sich...? hätte er antworten können: Für Tatsachen, nur für Tatsachen, reine Tatsachen...“ (AW 184).

85 Ernst Cassirer: Philosophie der symbolischen Formen 3: Phänomenologie der Erkenntnis [1929], 1964, S. 477. Mit dieser Auffassung ist für Epstein, genauso wenig wie für Cassirer, kein radikaler Konstruktivismus verbunden; vielmehr ist dieses Bewusstsein von der Theoriehaltigkeit der Wahrnehmung vergleichbar mit Kants ,präkonstruktivistischer‘ Bestimmung, wonach die Dinge unserer Erkenntnis stets die Dinge unserer Erfahrung und Dinge für unser Bewusstsein sind, während die Dinge ,an sich' der menschlichen Erkenntnis entzogen bleiben.

86 Ausdrücklich spricht Epstein auch den serienmäßig hergestellten Dingen eine Individualität zu; entsprechend können auch sie in eine individuelle Beziehung zu ihm treten (vgl. AO 59 [82 f.]).

87 „Ratio ohne Mimesis negiert sich selbst.“ Mit diesem Wort Adornos kann auch Epsteins Position treffend beschrieben werden. Vgl. Theodor W. Adorno: Ästhetische Theorie. Gesammelte Schriften Bd. 7, hrsg. v. Gretel Adorno u. Rolf Tiedemann, Frankfurt/M. 1970, S. 489. Adornos Mimesis-Begriff orientiert sich dabei an Walter Benjamin: Über das mimetische Vermögen, in: Gesammelte Schriften Bd. 2.1: Aufsätze, Essays, Vorträge, hrsg. v. Rolf Tiedemann, Frankfurt/M. 1977, S. 210-213. 
einer mimetisch ausgerichteten Kunst entgegenzusteuern gilt. Epsteins Suche nach Verwandtschaften (vgl. AO 30 [44]) zwischen den Phänomenen sowie zwischen sprachlicher und dinglicher, dinglicher und menschlicher Welt entspricht im Literarischen seine Suche nach immer neuen Formen des Ausdrucks (,aver attraversato la scrittura in tutte le sue forme“, AO 27 [40]). In der narrativen Sprache manifestiert sich das sinnliche und geistige Sehen solcher Zusammenhänge, Korrespondenzen und Ähnlichkeitsbeziehungen konsequenterweise in der Form all jener Tropen, die sich aufgrund ihrer genuin relationalen Struktur zur adäquaten Abbildung der genannten Beziehungen eignen: Analogien, Allegorien, Vergleiche, Metaphern. ${ }^{88}$

Epsteins Poetik des Sehens - Sehen im beschriebenen Doppelsinn von intellektueller und sinnlicher Wahrnehmung und damit im Sinne der theoretischen Annäherung an die Phänomene bei gleichzeitiger Wahrung ihrer Besonderheit - entspricht einer der ,imitatio rerum‘ verpflichteten Poetik des Schreibens, welche auf die Selbstrepräsentation der Dinge zielt, in die, so ist zu erinnern, das Subjekt und mit ihm das Konzeptuelle und Schöpferische immer schon eingegangen sind. Als Phänomene der Literatur werden die Dinge zu referentiellen, der Lebenswelt zugewandten Zeichen der „menschlichen Intervention in die Dinge der Welt“ (Paul Valéry). Die Modernität von Epsteins Poetik ist dadurch gekennzeichnet, dass sie zwar einerseits an den Versöhnungsidealen der aufgeklärt-klassischen Ästhetik festhält, andererseits jedoch von Momenten der Negativität durchzogen ist, zu denen vor allem das Wissen um den utopischen Status einer auf Ganzheit, Harmonie und Identität gerichteten Ästhetik gehört. Wenn Epstein die Dinge in ihrer Selbstgegebenheit als „lauter Möglichkeiten“ wahrnimmt, „die sich von mir unterschieden, jedoch ähnlich waren“ (AO [84]), ${ }^{89}$ dann sind damit sowohl der Bruch und die Differenz als auch die Ver-

88 Als Brahe versucht, Epstein von seinem Experiment im CERN zu berichten, macht er sich auf die Suche nach „Wörtern, Bildern, Analogien“, nach körperlichen Gesten, nach „irgendein[em] Ding unter den Formen der Welt [...], mit dem er es [das, wofür es kein Bild gab] vergleichen konnte“ (vgl. AW 141). Dieser Versuch entspricht exakt der frühen Poetik Epsteins, von der er sich zum Zeitpunkt dieses Gesprächs längst verabschiedet hat. Doch ehe Brahe seine Ausführungen fortsetzen kann, wird er von Epstein unterbrochen: „,Nein, nicht so. So helfen Sie mir nicht. Das, wovon Sie sprechen, hat mit nichts Ähnlichkeit, das wissen Sie sehr gut. Ich möchte, daß man diesen Unterschied spürt. (...) Die Dinge, die es geben wird, kommen von dort, und es werden Nicht-Dinge sein. Warum soll ich sie mir als etwas vorstellen, was bereits existiert und was dabei ist, zu verschwinden? Warum soll ich sie ohne ihren Namen erhalten, auch wenn er noch so beliebig ist? Warum schicken Sie für jedes Ding den Zwillingsbruder voraus, den ich bereits kenne, und hindern mich dadurch, mir den anderen vorzustellen?““ (AW 141-142).

89 „Erano tutte possibilità diverse di me stesso, appena variate“ (AO 60). 
bundenheit und Kontinuität zwischen Subjekt und Objekt bezeichnet. Sehr drastisch werden dabei auch die Grenzen literarischer Repräsentation im Sinne der Aktualisierung jener den Dingen innewohnenden Möglichkeiten gezogen:

Pensò che il suo lavoro era stato pieno di cadaveri: una strage di possibilità a ogni pagina, cimiteri di oggetti e di gesti, immagini e pensieri smontati e appoggiati là, a terra di fronte a ciò che spuntava. Per questo rileggere era doloroso, perché quello che si vedeva era solo il positivo, mentre lui conservava ancora la memoria del calco. Poi piano piano se ne dimenticava, e rileggendo era tutto come voleva lui: scritto da un altro. (AO 96) ${ }^{90}$

Das, was im literarischen Werk reliefartig zutage tritt, sind lediglich Fragmente und Partikel aus einer Summe von Möglichkeiten, die das Sein der Dinge für das sehende Subjekt konstituiert, für das schreibende Subjekt jedoch nicht in toto darstellbar ist: Im Schreiben und Erzählen lassen sich die immanenten Möglichkeiten der Dinge lediglich partiell extrapolieren; hingegen vermag sich die Dingwelt als „Inbegriff des überhaupt Möglichen“ bestenfalls in der Erinnerung an das Gesehene als Negativ abzuschatten, um schließlich dem völligen Vergessen anheimzufallen. Epsteins ethisch fundierte Ästhetik - seine Suche nach immer neuen Formen um eines, dinggerechten' Schreibens willen - wird in der zitierten Passage auch von ihrer Kehrseite gezeigt: Schreiben und Erzählen als notwendig schuldbesetztes Unterfangen, als Unterdrückung und Massakrierung von Möglichkeiten und ungerechte Sprach-Behandlung der Dinge. Diese Schuld kann letztlich nur über Prozesse des Vergessens und Verdrängens, die mit der Abnabelung - der Abstraktion! - des literarischen Werks von seinem Autor einhergeht, kompensiert bzw. in der fortwährenden Anstrengung, immer neue dinggerechte Darstellungsformen aufzufinden, ${ }^{91}$,gesühnt' werden. Sehen und Schreiben bleiben in dieser Poetik zwar unabdingbar aufeinander bezogen das Schreiben orientiert sich am Ideal des Sehens -, doch stehen beide ebenso unausweichlich in einem konfligierenden, wenn nicht sogar aporetischen Verhältnis zueinander: Das mörderische Vokabular, mit dem das Verhältnis von geschriebenem ,Positiv‘ und gesehenem ,Negativ“ versehen wird, kritisiert den narrativen Diskurs als einen höchst defizitären, der permanent Gefahr läuft, in

90 „Er dachte, seine Arbeit sei voller Leichen gewesen: auf jeder Seite ein Massaker an Möglichkeiten, Friedhöfe von Objekten und Gesten, abmontierte Bilder und Gedanken, die auf dem Boden lagen, vor dem, was in die Höhe ragte. Aus diesem Grund tat es weh, eine Geschichte ein zweites Mal zu lesen, denn man sah dabei nur das Positiv, während er sich noch an den Negativabdruck erinnerte. Dann vergaß er ihn langsam, und beim erneuten Lesen war alles, wie er es sich wünschte: als hätte es ein anderer geschrieben“ (AW 130).

91 Diese Anstrengung meint auch den unablässigen Versuch, das sehende und das schreibende Subjekt einander anzunähern. 
einen Diskurs der Macht - einen Diskurs der gewaltsamen Subordination des dinggerechten Sehens - umzuschlagen und damit in eine jener Ideologien, welche die Dinge und Menschen auseinanderdividiert und sie in die hierarchische - hier spatialisierte - Scheinordnung von ,Hintergrund' und ,Vordergrund rückt. ${ }^{92}$ Die Wehmut, die Epstein bei der Relektüre seiner eigenen Werke empfindet - „questo rileggere era dolorosa“ - rührt aus der Einsicht, dass seine Literatur notwendig hinter den Forderungen seiner Ästhetik zurückbleibt, mehr noch: Resultat der permanenten Verletzung dieser Forderungen ist. Umgekehrt treibt gerade der defizitäre Status der Literatur gegenüber der Ästhetik immer neue literarische Formen hervor. Die Unmöglichkeit, Poesie und Poetik in Übereinstimmung zu bringen, stellt den Impetus seiner Bemühung dar, sich schreibend und erzählend den gesehenen Dingen fortwährend anzunähern.

\subsubsection{Epsteins poetologisches Experiment}

Epsteins poetologisches Experiment nimmt seinen Ausgang in dem von ihm mehrfach konstatierten Befund vom „Verschwinden der Dinge“ (la scomparsa delle cose, AO 62): „[L]e cose [...] cominciano ad essere non-cose“; sie sind im Begriff, „pura energia, pura luce, pura immaginazione“ (AO 68) ${ }^{93} \mathrm{zu}$ werden. Der diagnostizierte Verlust des Empirischen wird dabei - von der primären Erzählerinstanz explizit, von Epstein in wiederholten Andeutungen -, ursächlich auf den Vorstoß der Naturwissenschaften in den subatomaren Bereich und der damit verbundenen Irrealisierung der Objekte zurückgeführt. Dem gesamten im CERN angesiedelten Plot kommt in diesem Kontext eine argumentative und (zweifach) begründende Funktion zu: Die dortigen Vorgänge erklären Epsteins Rede vom

92 Erzählen ist für Epstein eine der möglichen Verhaltensweisen, in welche die Dinge - ihrerseits transformiertes Verhalten - transformiert werden können. Epstein ist sich zwar darüber bewusst, dass jedes Verhalten immer nur eines von vielen möglichen ist, gleichwohl leidet er unter der Diskrepanz zwischen den vielen Möglichkeiten, die den Dingen immanent sind, und dem Vermögen, nur eine davon realisieren zu können. Er überfordert die Literatur gewissermaßen, wenn er sie an einer Poetik des Sehens orientiert und beurteilt: Die Literatur als Positiv muss gegenüber dem Negativ notwendig Fragment bleiben. Die ,Schuld', die Epstein hier implizit eingesteht, besteht letztlich in der Tatsache, dass jede Transformation mit autoritären Eingriffen - Selektion, Kombination, kurz: mit allen Akten des Fingierens - verbunden und damit von herrschaftlichen Prozeduren der Ausschließung (vgl. Foucault) begleitet ist.

93 ,[D]ie Dinge [...] beginnen, Nicht-Dinge zu sein“ (AW 94). 
Verschwinden der Dinge und bilden zugleich das Fundament und den Ausgangspunkt („un dato di partenza“, AO 103) seiner neuen Ästhetik. ${ }^{94}$

Der Wandel der Materialien in „Immaterialien“95 erfordert eine grundsätzliche Neuorientierung in und Neuordnung der Wirklichkeit, eine - ganz wörtlich - neue Welt-Anschauung, die vor allem das veränderte Verhältnis

94 Die Formulierung „Verschwinden der Dinge“ fungiert im Epstein-Plot als formelhafte Verdichtung für das komplexe naturwissenschaftliche Gegenstands- und Tätigkeitsfeld im CERN. ,Aufgesprengt' und extrapoliert macht sie all jene Vorgänge sichtbar, die mit der dortigen Arbeit konnotiert sind. Als der markierte Ausgangspunkt für Epsteins ästhetisches Experiment weist diese Formulierung jedoch auch zurück auf den naturwissenschaftlichen Bildungsprozess, den Epstein durchlaufen haben muss und auf den in mehrfachen Anspielungen hingewiesen wird. So zum Beispiel in dem Seh-Experiment, das Epstein mit Brahe durchführt. Brahe, der einfach nur beschreiben soll, was er sieht, überrascht Epstein dadurch, dass er, der doch, wie Epstein sagt, „nell‘ assoluta di scomparsa delle cose“ (AO 68 [94]) arbeitet, im Hinblick auf die alltägliche Lebenswelt eine extrem konventionelle Sehweise an den Tag legt. Epstein weiß also durchaus, was sich mit den Arbeiten im CERN verbindet. Ein weiterer Beleg für seine naturwissenschaftliche Bildung findet sich während eines gemeinsamen Fluges, in dessen Verlauf Brahe erstmals von seinem Experiment berichtet. Noch ehe er mit seinen Ausführungen beginnt, erfährt der Leser in einer kurzen, personal erzählten Passage, wie Brahe seinen Freund wahrnimmt: „Sein [Epsteins] Blick ist aufmerksam, aber nicht übertrieben neugierig; er schaut, als würde er bereits alles wissen, oder als wäre dies nur ein Ausgangspunkt“ (AO 139 [103]). Bezeichnend für diese Episode ist, dass, wie schon im Falle Epsteins, nicht der Inhalt des Experiments, sondern lediglich das Wie des Erzählens über das Experiment erzählt wird.

95 „Immaterial“, so Lyotard, ,ist nicht immateriell; es bezeichnet eine Struktur, in der der herkömmliche Gegensatz zwischen Geist und Materie keinen Platz mehr hat“ (Lyotard: Immaterialität, S. 23). Mit dem Begriff „,immaterial“ ist lediglich ausgedrückt, „daß heute - und das hat sich in allen Bereichen durchgesetzt - das Material nicht mehr als etwas angesehen werden kann, das sich wie ein Objekt einem Subjekt entgegensetzt. Wissenschaftliche Analysen der Materie zeigen, daß sie nichts weiter ist als ein Energiezustand, d.h. ein Zusammenhang von Elementen, die ihrerseits nicht greifbar sind und von Strukturen bestimmt werden, die jeweils nur eine lokal begrenzte Gültigkeit haben. [...] Die zunehmende gegenseitige Durchdringung von Materie und Geist - gleichermaßen deutlich durch die Benutzung von Textverarbeitungsprogrammen - bewirkt nun, daß sich das klassische Problem der Einheit von Körper und Seele verschiebt“ (ebd., S. 25). An anderer Stelle definiert er den von ihm geprägten Neologismus „Immaterialen“: „Offenbar sind alle Fortschritte in den Wissenschaften, wahrscheinlich auch in den Künsten eng verbunden mit einer immer genaueren Kenntnis dessen, was man allgemein ,Objekt' nennt [...]. Wenn nun diese Objekte in Analysen zerlegt werden, wird klar, daß sie offenbar nur für den Menschen Objekte sind; aber in dem, was sie konstituiert, sind sie komplexe Agglomerate aus kleinen Energieteilchen, aus Partikeln, die als solche überhaupt nicht greifbar sind. Letztendlich gibt es keine Materie mehr, es gibt nur noch Energie; es gibt kein Material im ältesten Sinne des Wortes mehr, also ein Objekt, das sich einem Entwurf widersetzt, der es von seiner ersten Zweckbestimmung abbringen will...“ (ebd., S. 66). 
zwischen Mensch und ,Ding a auszuloten hat. ${ }^{96}$ Dass Epstein sein ästhetisches Experiment rückbindet und einbindet in ein Leben, das von diesen veränderten Bedingungen durchwirkt ist, und er seinen ,Versuch' gerade auf der Grundlage dieser radikalen Veränderungen unternimmt, zeugt von der Kontinuität seiner ethischen Gesinnung, Literatur und Leben nicht voneinander zu trennen, sondern in ihren konkreten Beziehungen zueinander einsichtig zu machen. Die Literatur, so ließe sich Epsteins Credo in die programmatischen Äußerungen Musils und Brochs fassen, bleibt zur „Anpassung an das naturwissenschaftliche Zeitalter“97 und damit zu „Zeitgerechtheit“98 verpflichtet. - Worin besteht nun Epsteins Experiment?

Però deve esserci un legame segreto tra la scomparsa delle cose e la visibilità, perché oggi io le mie storie le vedo, io comincio sempre piú a vedere le mie storie. [...] prima le vedevo raccontando, le vedevo nel momento in cui le scrivevo, adesso le vedo guardando, vedo una storia compiutamente dall'inizio alla fine semplicemente guardando. E questo, [...] è il mio esperimento. (AO 62-63) ${ }^{99}$

Mit dem Status der Dinge haben sich sowohl der Modus ihrer Wahrnehmbarkeit und Sichtbarkeit als auch die Möglichkeiten ihrer (literarischen) Darstellbarkeit grundlegend gewandelt. Hatten sich vormals die Dinge trotz ihrer verborgenen Verweisungskomplexität dennoch als Dinge gezeigt, so sind nun, da die Dinge im Verschwinden begriffen sind, Sichtbarkeit und Sehen nicht mehr sinnlichaisthetisch gebunden: Der Blick auf die non-cose ist kein Blick mehr, der sich auf ein dem Subjekt ,Äußerliches‘ richten würde, sondern es ist ein Blick epistemisch-technologischer Prägung, ein gleichsam wissensgeformter Blick auf ein seinerseits ungeformtes, gleichwohl existentes ,Nicht-Ding“: Sehen ist „pure immaginazione“, reine Vorstellung, „vede[re] mentalmente“ (AO 145), theoria, schauendes Denken.

96 Wie noch zu zeigen sein wird, ist Epsteins Vorhaben, einen „Atlas des Lichts“ zu schreiben, Signatur dieser Bemühungen, zugleich aber auch Signatur einer Krise, die geprägt ist von Orientierungslosigkeit und von der Suche nach Sinn.

97 Robert Musil: „Zu Kerrs 60.Geburtstag“ [1927], in: Gesammelte Werke in 9 Bänden, hrsg. v. Adolf Frisé, Reinbek bei Hamburg 21981, Bd. 8, S. 1180-1186, hier S. 1183.

98 Hermann Broch: „James Joyce und die Gegenwart. Rede zu Joyces 50. Geburtstag“, in: ders.: Schriften zur Literatur I./Kritik, Kommentierte Werkausgabe (= KW), Bd. 9/1, hrsg. v. Paul Michael Lützeler, Frankfurt/M. 1975, S. 63-94, hier S. 76.

99 „Es muß jedoch einen geheimen Zusammenhang zwischen dem Verschwinden der Dinge und ihrer Sichtbarkeit geben, denn inzwischen sehe ich meine Geschichten, ich beginne meine Geschichten immer mehr zu sehen. [...] Früher sah ich sie, indem ich sie erzählte, ich sah sie in dem Augenblick, in dem ich sie niederschrieb, jetzt sehe ich sie, indem ich schaue. Und das [...] ist mein Experiment“ (AW 88). 
In dieser Sichtweise treffen sich Brahe und Epstein, koinzidieren Wissenschaft und Kunst. ${ }^{100}$ Als „pura energia, pura luce“ und „pura velocità“ (AO 68) eignet der schwindenden Wirklichkeit keine Präsenz mehr; entsprechend ist sie, wie Brahe für seinen Bereich konstatiert, „,irrapresentabili“ (AO 145). Ihre Darstellbarkeit reduziert sich auf Formen reiner Virtualität und Artifizialität, auf die poietische Konstruktion von Zeichen, denen kein Bezeichnetes mehr korrespondiert, ${ }^{101}$ sondern jedes analoge Beziehungsgefüge aufgelöst ist „in quella strana e assoluta relazione in cui tutto era simultaneamente determinato e determinante, compreso lui“ (AO 77). ${ }^{102}$ Auch das alltägliche Leben erscheint in dieser spezifischen Optik nurmehr als Maske, hinter der sich kein Gesicht mehr verbirgt, als Inszenierung, die sich im referenzlosen Spiel der Andeutungen erschöpft:

regolato dal movimento degli sguardi che riguardavano esclusivamente l'abbigliamento, dal gioco di pure allusioni e rimandi a cose che non accadevano piú, e le avventure si risolvevano in questo travestimento misurato, in questa piccola messa in scena. (AO 79) ${ }^{103}$

Geradezu plastisch wird hier die ,Wirklichkeit' in ihrer textontologischen Verfasstheit gezeigt, einer Verfasstheit, die durch eine (ihrerseits theoretischzeichenhaft reglementierte) Perzeption reglementiert ist. ,Realität‘ erscheint poststrukturalistisch - aufgelöst in ein „Universum der Texte“, „in dem die einzelnen subjektlosen Texte in einem regressus ad infinitum nur immer wieder auf andere und prinzipiell auf alle anderen verweisen, da sie ja alle nur Teil eines ,texte général' sind, der mit der Wirklichkeit und Geschichte, die immer schon ,vertextete“ sind, zusammenfällt"..04 Die Formulierungen, deren sich Brahe und Epstein zur Beschreibung der sich wandelnden Objektwelt bedienen,

100 In dieser Sichtweise treffen sich entsprechend auch die Diskurse Brahes und Epsteins: Ihre Aussagen - diese Sichtweise betreffend - werden austauschbar: Sie kommentieren, ergänzen, erhellen einander, ohne sich aber zu einem einzigen Diskurs zusammenzuschließen.

101 Vgl. hierzu auch Dilmacs medienwissenschaftlich gestützte Interpretation (Dilmac: Literatur und moderne Physik, S. 300 f.).

102 „[...], in jener einzigartigen und absoluten Relation, wo alles gleichzeitig Determinat und Determinant war, er selbst nicht ausgeschlossen“ (AW 106).

103 „[...] bestimmt von der Bewegung der Blicke, die ausschließlich die Kleidung betrafen, vom Spiel der reinen Andeutungen und Verweise auf Dinge, die nicht mehr stattfanden, und die Abenteuer erschöpften sich in dieser unauffälligen Verkleidung, in dieser kleinen Inszenierung“ (AW 108 f.).

104 Manfred Pfister: Konzepte der Intertextualität, in: Intertextualität. Formen, Funktionen, anglistische Fallstudien, hrsg. v. Ulrich Broich u. Manfred Pfister, Tübingen 1985, S. 1-30, hier S. 9. 
weisen beide als reflektierte Vertreter einer postmodernen Wissenskultur aus, die durch die entsprechenden philosophischen - ihrerseits den naturwissenschaftlichen Diskurs aufnehmenden und auf diesen antwortenden - Theorien hindurchgegangen sind. So ist in Brahes und Epsteins Redepartien eine ganze Reihe von prominenten Theoremen aus dem Umkreis von Poststrukturalismus und Dekonstruktion integriert, deren Begriffe entweder direkt übernommen oder indirekt ihrer Sache nach paraphrasiert werden. ${ }^{105}$ Dazu im Folgenden einige Beispiele.

Die Feststellung der Identität von Signifikant und Signifikat trifft Brahe im Hinblick auf das Experiment im CERN:

Guardò i ponteggi e i cavi attorno al loro esperimento, come chiamavano il rivelatore, unendo in uno stesso nome la macchina e le intenzioni e forse i risultati, in quella strana e assuluta relazione in cui tutto era simultaneamente determinato e determinante, compreso lui. $(\mathrm{AO} 77)^{106}$

Der von Brahe gebrauchte Begriff des ,Experiments‘ ist heterotop, ${ }^{107}$ insofern er die Vielfalt möglicher, völlig heterogener und heterodoxer Bedeutungen unter einem einzigen Namen subsumiert; zugleich ist er autoreferentiell, insofern er keine externe Referenz, damit auch keine Sinnpräsenz besitzt und die genannten ,Referenten' wiederum nur Begriffe sind, die dem Begriff des ,Experiments‘

105 Hingewiesen wurde bereits auf die von Lyotard entlehnte Formulierung vom „Verschwinden der Wirklichkeit“ sowie die paraphrasierten thematischen Zusammenhänge im Kontext von Lyotards Befund der Immaterialität. - Die Anlehnung der Figurenrede an die poststrukturalistische Terminologie ist auch als Eingeständnis einer fehlenden, der neuen Wirklichkeit adäquaten Sprache zu verstehen. Explizit formuliert dazu Epstein: „Es ist ein Jammer, daß ich es nicht beschreiben kann, denn im Nicht-Beschreibenkönnen liegt etwas Amoralisches, so wie im übrigen in einer guten Beschreibung etwas durch und durch Moralisches liegt“ (AW 95).

106 „Er [Brahe] betrachtete das Gerüst und die Kabel rund um ihr Experiment, wie sie den Detektor nannten, wobei sie mit einem einzigen Wort Maschine, Intentionen und eventuelle Resultate bezeichneten, in jener einzigartigen und absoluten Relation, wo alles gleichzeitig Determinat und Determinant war, er selbst nicht ausgeschlossen“ (AW 106).

107 Unter Heterotopie (eine zur ,Ortlosigkeit‘ gesteigerte Unordnung) versteht Foucault jene „Unordnung, die die Bruchstücke einer großen Zahl von möglichen Ordnungen in der gesetzlosen und ungeometrischen Dimension des Heterokliten aufleuchten läßt.“ Es sind Heterotopien, die die „Sprache unterminieren, weil sie verhindern, daß dies und das benannt wird, weil sie die gemeinsamen Nenner zerbrechen oder sie verzahnen, weil sie im voraus die ,Syntax ‘ zerstören.“ Sie „trocknen das Sprechen aus, lassen die Wörter in sich selbst verharren, bestreiten bereits in der Wurzel jede Möglichkeit von Grammatik. Sie lösen die Mythen auf und schlagen den Lyrismus der Sätze mit Unfruchtbarkeit“ (Michel Foucault: Die Ordnung der Dinge, Frankfurt/M. 1971, S. 20). 
eingeschrieben sind, in die der Begriff des ,Experiments' sich zerstreut. ${ }^{108}$ Als Hetero-Topos ist der Begriff zugleich Chrono-Topos: Er verräumlicht die in seinem Namen und im Laufe seiner begrifflichen Geschichte vorgenommenen differentiellen Verschiebungen ${ }^{109}$ - die historisch gewachsene Polyvalenz seiner Einschreibungen. Er ,spatialisiert` Zeit als eine heterogene Simultaneität von vorher und nachher.

Komplementär zur Zerstreuung und Zersetzung der Sinngegenwart - und auch dieser Befund der Postmoderne ist in der zitierten Passage mitreferentialisiert - verhält sich auch die Dezentrierung des Subjekts und der Subjektivität. Wenn sich Brahe in das Experiment integriert weiß und sich ausdrücklich in den Begriff des Experiments einbegriffen sieht, dann ist der Begriff, den er von sich selbst hat, nicht logozentrisch-metaphysisch begründet - das Subjekt als sich selbst identische, autonome Instanz -, sondern Element des Experiments und dessen komplex vernetzter, ,randloser ${ }^{6}$ Struktur. ${ }^{110}$ Aufschlussreich für

108 Nach Derrida „re-präsentiert der Signifikant nicht zunächst schlicht ein abwesendes Signifikat, sondern er unterschiebt sich vielmehr einem anderen Signifikanten, einer anderen Ordnung von Signifikanten, die mit der fehlenden Präsenz eine andere Beziehung unterhält, um dann vom Spiel der Differenz aufgewertet zu werden“ (Jacques Derrida: Die Stimme und das Phänomen, Frankfurt/M. 1979, S. 146). „Es gibt also keine Phänomenalität, welche das Zeichen oder den Repräsentanten reduziert, um schließlich das bezeichnete Ding im Glanz seiner Präsenz erstrahlen zu lassen“ (Derrida: Grammatologie, S. 86); damit erweist sich bei näherer Betrachtung jede referentiell verbürgte, homogen-präsentische Signifikation als illusorisch. Entsprechend sind Zeichen auch nicht sinnidentisch wiederholbar, sondern jede Wiederholung verursacht eine erneute Sinnverschiebung und Sinnzersetzung, zeitigt also Differenzen, die nicht auf einen gemeinsamen begrifflichen Nenner zu reduzieren sind. Die iterabilité (Wiederholbarkeit) gewährleistet folglich nicht nur die strukturelle, von der Gegenwart einer ihm eingeschriebenen Bedeutung unabhängige Relektüre eines Zeichens, sondern ist zugleich ursächlich für die nicht begrenzbare dissémination (Zerstreuung) seiner Bedeutung (vgl. Jacques Derrida: Signatur, Ereignis, Kontext, in: Randgänge der Philosophie, S. 291-314, bes. S. 298 u. 301).

109 Mit dem Neologismus „différance“ verbindet Derrida semantische Verschiebung und zeitlichen Aufschub in Permanenz: „Und wenn die Bedeutung des Sinns (in der allgemeinen Bedeutung des Wortes Sinn, nicht aber von Bezeichnung) unendliches Einbegriffensein ist? Die unbestimmte Rückverweisung eines Signifikanten auf einen Signifikanten? Wenn seine Kraft eine gewisse reine und unendliche Mehrdeutigkeit ist, die dem bezeichneten Sinn keinen Aufschub und keine Ruhe lässt, die ihn in seiner eigenen Ökonomie auffordert, zum Zeichen zu werden und sich selbst aufzuschieben?“ (Jacques Derrida: Die Schrift und die Differenz, Frankfurt/M. 1976, S. 44 f.).

110 Deutlich spiegelt sich dies auch in Brahes Gefühl, seine Abwesenheit könnte dem Experiment Energie entziehen (,sua lontananza sottraesse energia“), weshalb er sich zwingt, selbst in seiner Freizeit gedanklich beim Experiment zu sein, ,als könnte er dadurch bewirken, daß 
diese Passage (und sie steht exemplarisch für eine Vielzahl solcher Belege) ist, dass darin gerade kein fiktives Wissenschaftsbild inszeniert wird, sondern umgekehrt gängige Forschungspraxis realistisch abgebildet wird. Damit ist auch angedeutet, worauf später noch präziser einzugehen sein wird, dass die Ästhetik des Romans (ungleich der Ästhetik Epsteins) gerade dadurch, dass sie die realiter praktizierte Episteme bis in ihre postmodernsten Verwinkelungen hinein spiegelt, paradoxerweise dem Programm eines poetischen Realismus verpflichtet ist. ${ }^{111}$

Noch entschiedener negiert Epstein die Grenzen zwischen den Dingen und den Menschen, wenn er sie durch „linee di forza“, Kraftlinien miteinander verbunden fühlt und beide auf übereinstimmenden Umlaufbahnen wähnt, „senza piú oggetti in mezzo“ („ohne dass ein Ding dazwischen wäre“), wie überhaupt die Grenzen zwischen Innen und Außen nicht mehr existieren im ununterbrochenen Kreislauf der Vorstellungen („fuori e dentro non esistono piú, nell'ininterrotto circuito dell'immaginazione“, AO 68 [94]). Mit dem Schwinden der Wirklichkeit zeigt sich die Welt in ihrer Verschränkung und Symmetrie, gehen Ding und Körper als Physis ununterscheidbar in den Zustand reiner Energie über, in ein - folgt man der aristotelischen Bedeutung des Wortes ${ }^{112}$ geistiges Tätigsein, das in der Deutung Epsteins nicht länger auf die Hervorbringung eines ,wirklichen“ Werkes (ergon) zielt, sondern selbstreflexiv auf Geist (Vorstellen, Denken und Fühlen) verwiesen bleibt. Immaterialisierung meint zugleich ,Despatialisierung': Entsprechend erfordern die non-cose nichts mehr, was sich im Außenraum abspielen würde - keine Bewegungen, keine Gesten, keine Handlungen (vgl. AO 68 [94]; 137 [185]) -, sondern „sentimenti“, „intelligenza“ und „percezione“ (ebd.). ${ }^{113}$

sich etwas offenbarte“ („si sforzava di essere nel pensiero dell'esperimento, di esserci con la tensione, come se questo aiutasse qualcosa a venire fuori“, AO 102 [138]).

111 Zur ,Postmodernität‘ der Hochenergiephysik vgl. Knorr-Cetina: Wissenskulturen, insbesondere die Abschnitte „Die Teilchenphysik und ihre negativen und liminalen Erkenntnisstrategien“ (S. 74-111), „Von Maschinen zu Organismen: Detektoren als physiologische und soziale Wesen“ (S. 163-193) sowie „Die Eliminierung des Individuums als epistemisches Subjekt in den Experimenten der Hochenergiephysik“ (S. 235-241).

112 Vgl. Martin Suhr: Artikel „Energeia“, in: Metzler Philosophie-Lexikon: Begriffe und Definitionen, hrsg. v. Peter Prechtl u. Franz-Peter Burkard, Stuttgart, Weimar 1996, S. 124-125.

113 Vgl. auch Lyotard, der mit der von ihm mitorganisierten Ausstellung „Die Immaterialien“ (Paris, 1985) das Ziel verbindet, „eine für die Postmoderne spezifische Sensibilität zu entdecken und zu erwecken [...]. Diese neue Sensibilität ist noch verborgen und sich ihrer selbst zweifellos noch nicht bewusst“ (Lyotard: Immaterialität, S. 24). 
Die Immaterialisierung des Materiellen ist für Epstein durch einen in allen Bereichen sich vollziehenden Vervielfältigungsprozess verbunden. Diese ,dissémination“ der Lebenswelt zeigt sich etwa im Blick durch das Schaufenster eines Werkzeugladens: die der Größe nach sortierten Werkzeuge sind ihm lesbar wie ein Alphabet, das über die Möglichkeiten ihres Gebrauchs informiert (,come un sillabario di tutto quello che si poteva fare“, AO 86):

Gli sembrò che i manici fossero sempre piú colorati, che si riducesse la porzione di ferro e la presenza del grigio. Gli piaceva che anche l'utile stesse diventando a colori, come le scarpe e i vestiti, gli sembrava che cosí fosse tutto piú leggero, meno importante. Anche il significato, pensò, sta diventando sempre piú leggero, probabilmente a colori. (AO 86) ${ }^{114}$

Die konventionellen Ordnungssysteme (Quantitäts- und Zeichenordnungen) erweisen sich als pure Oberflächenillusion. Der aufmerksame Blick sieht, dass die Dinge ihre materielle Substanz und ihren wohldefinierten Gebrauchswert zunehmend einbüßen, dass sie leichter und bunter werden, dass sie aus der ihnen beigemessenen Größen- und Relevanzhierarchie ausscheren und in ihrer Phänomenalität und Operationalität zersplittern in eine bunte und mannigfache Pluralität. Das Alphabet - Werkzeugkasten des Schriftstellers - und die aus ihm rekrutierten Namen und Begriffe verweigern sich einer definitorischbezeichnenden und ordnend-klassifizierenden Funktion und befreien sich von der Last ihres referentiellen Signifikats zugunsten des bunten Spektrums und freien Spiels der Signifikanten in einer sich unendlich verzweigenden ,bibliothèque générale“ (Grivel). ${ }^{115}$ Werden die Signifikanten hier noch sprachkörperlich aufgefasst, macht Epstein in einem Gespräch mit Brahe deutlich, ,wohin“ sich letztlich auch die Signifikanten zerstreuen:

114 „Er hatte den Eindruck, daß die Griffe immer bunter wurden, daß sich der Anteil des Eisens und der Farbe Grau verringerte. Es gefiel ihm, daß auch das Nützliche bunt wurde, wie Schuhe und Kleider, und es schien ihm, als würde auf diese Weise alles leichter werden und weniger bedeutsam. Auch die Bedeutung, dachte er, wurde immer leichter, womöglich bunt“ (AW 117).

115 Der Inhalt dieser personal erzählten Passage wirkt auf die Form zurück: Der in der Perspektive Epsteins unternommene Vergleich zwischen Werkzeugen und Alphabet (,come un sillabario“) wird in seiner Grundbeziehung - seinem tertium comparationis - durch die skizzierte Dekonstruktion der beiden Vergleichspole selbst dekonstruiert. Der Inhalt zerstört nicht nur die der Form eigene Semantik (die Ähnlichkeiten von Werkzeug und Alphabet), sondern die Form selbst (die durch das „come“ syntaktisch hergestellte Beziehung). Hier wird einsichtig, was Derrida mit dem „Entzug der Metapher“ meint (vgl. Jacques Derrida: Der Entzug der Metapher, in: Die paradoxe Metapher, hrsg. v. Anselm Haverkamp, Frankfurt/M. 1998, S. 197234, bes. S. 200). 
Potrei dirle: una storia è fatta di avvenimenti, un avvenimento è fatto di frasi, una frase è fatta di parole, una parola è fatta di lettere? E la lettera è irriducibile? È l',ultimo“? No, dietro la lettera c'è un'energia, una tensione che non è ancora forma [...]. (AO 129) ${ }^{116}$

Die Oberflächenordnung einer konventionellen Erzählung wird stufenweise in ihre einzelnen formalen Bestandteile zerlegt bis $\mathrm{zu}$ jenem Punkt, an dem sich die Form ins Formlose reiner Energie auflöst. ${ }^{117}$

\section{Exkurs}

Thema des Gesprächs, aus dem soeben zitiert wurde, ist erneut ihre Arbeit. Er, Brahe, beschäftige sich mit einer angewandten und speziellen Geometrie (una geometria applicata e particolare, AO 128), namentlich der Symmetrie: „Il mio lavoro è simmetria, una simmetria molto, molto spinta," und es sei immer wieder erstaunlich, dass es einem mit der Symmetrie gelinge, etwas von der Fluidität und Geschwindigkeit und Ungreifbarkeit zu erfassen. Als Brahe sich leicht vorwurfsvoll an Epstein mit den Worten wendet, er, Epstein, hätte ihn noch nie an den Ort der Produktion eingeladen, versucht der Schriftsteller nun seinerseits zu beschreiben, wie etwa die sprachliche Erzeugung eines Gefühls vonstatten geht. Dabei konfrontiert er Brahe allerdings lediglich mit einer Reihe ,semi-rhetorischer' Fragen, die die Wahrnehmung innerer sprachlicher Strukturen und die Ursprünge von Bildern, Gesten und Gefühlen tangieren. ${ }^{118}$ ,Semi-rhetorisch' sind diese Fragen deshalb, weil Epstein einerseits suggeriert, dass er selbst zwar um die Antworten weiß, sich aber nicht in der Lage sieht, sie Brahe adäquat zu vermitteln, andererseits aber am Ende seiner Ausführungen nicht nur die Erzeugung literarischer Werke, sondern jede Form authentischer Rede umgeben sieht von einer Aura des Geheimnisvollen und Wunderbaren. Dabei besteht die Authentizität von literarischer und alltäglicher Rede, gemäß Epsteins früher Poetik, in nichts anderem als im Wunder der unauflösbaren Entsprechung von individuellem Gefühl und Gedanke auf der einen und ebenso individuellem sprachlichem Ausdruck auf der anderen Seite. ${ }^{119}$ Geometrische und sprachliche Symmetrie werden - über

116 „Könnte ich Ihnen sagen: Eine Geschichte besteht aus Ereignissen, ein Ereignis besteht aus Sätzen, ein Satz aus Wörtern, ein Wort aus Buchstaben? Und der Buchstabe ist irreduzibel? Er ist das ,Letzte'? Nein, hinter dem Buchstaben verbirgt sich eine Energie, eine Spannung, die noch nicht Form ist [...]“ (AW [173]).

117 Epsteins Betrachtung der Sprache erfolgt analog seiner Betrachtung der Materie: Das Schwinden der Dinge geht einher mit dem Schwinden der Sprache. Der hier beschriebene Auflösungsprozess der Materialität der Sprache antizipiert bereits jenen Augenblick, in dem Brahe und sein Team die gesuchten Teilchen entdecken werden (s. u.).

118 „Kann ich sie je dazu einladen, die Zeiten der Verben zu besichtigen, die Gelenke, die die Sätze so verbinden, daß sie sich gegenseitig, wie durch Gegendruck festhalten? Kann ich Ihnen je den genauen Punkt anzeigen, an dem ein Bild entsteht, eine Geste, der Angelpunkt einer Geschichte, die Verflechtung eines Gefühls, und Sie auf den Unterschied zwischen Produkt und Produzenten hinweisen?“ (AW 173).

119 „Nein, hinter jedem Buchstaben verbirgt sich eine Energie, eine Spannung, die noch nicht Form ist, aber auch schon nicht mehr Gefühl, und wer weiß, welche Kraft notwendig wäre, um 
die von Epstein erzeugten Parallelen - in ihrer Funktionalität miteinander identifiziert: Beide machen das Unsichtbare - die flüchtigen, nicht fixier- und wahrnehmbaren Vorgänge im Detektor und die ebenfalls im ,Energetischen' aufgelösten Gefühle, Haltungen etc. - sichtbar, indem sie es figurativ binden, wobei der Figuration eine quasi-begriffliche Eigentlichkeit und Buchstäblichkeit im Sinne der adäquaten Vergegenständlichung des Seienden zugetraut wird. Ausdrücklich aber konstatiert Epstein, dass er dieses Stadium seiner literarischen Biographie - er sei im Grunde immer ein Autor von Abenteuergeschichten (uno scrittore di storie d'avventura, AO 129) gewesen - hinter sich gelassen habe, „[c]ome si esce da una fila per essere stati spinti in avanti (AO 129). ${ }^{120}$

Brahe wird Epsteins Sprach-Dekonstruktion erst in dem Augenblick nachvollziehen, als er gemeinsam mit seinen Kollegen jene neuen Teilchen, deren Auffinden das Experiment ausschließlich diente, zum ersten Mal ,sieht‘. Der Entdeckungs- und Wahrnehmungsvorgang ist dabei - darin die postmoderne Destabilisierung und Dezentralisierung des Subjekts ein weiteres Mal veranschaulichend - nicht nur auf die Mitglieder des Experiments verteilt, sondern darüber hinaus in einen seinerseits ,distribuierten' Erzählvorgang integriert. ${ }^{121}$ Von Brahe heißt es:

ma sopratutto sarebbe rimasto indimenticabile per Brahe l'attimo in cui passò, come di scatto, da ciò che vedeva con gli occhi a tutto ciò che vedeva mentalmente, la profondità di una materia nella quale le dimensioni non erano più quattro, ma dieci, o undici, e quelle sconoscuite e invisibili era cosí corte su se stesse, cosí curve, cosí veloci e irrapresentabili, cosí instabili, che sentí spaccarsi la parola „spazio“, sentí le lettere separarsi e ripiegarsi su se stesse come cilindri vorticanti, con all'interno altri cilindri e volumi aperti e chiusi istantaneamente, ma già volumi o cilindri o lacci o lembi o spirali non davano conto di alcunché, per tutto ciò che vedeva mentalmente in quel momento non esisteva im-

dieses Gefühl vom Wort abzuspalten, das es sichtbar macht, vom Gedanken, der es gleichzeitig denkt, und das Geheimnis zu verstehen, aufgrund dessen sich die Buchstaben auf eine bestimme Weise anordnen und auf keine andere und man sagen kann: ,Sie gefallen mir', und das Wunder, daß dies eine Entsprechung hat“ (AW 173).

120 „So wie man eine Menschenschlange hinter sich lässt, weil man nach vorn gestoßen worden ist“" (AW 173).

121 Auch die Erzählperspektive folgt dabei dem Prinzip der zunehmenden Vervielfältigung und Mehrfachdimensionierung: Der Primärerzähler erzählt, woran Mark, einer der Mitarbeiter, sich in diesem besonderen Augenblick immer erinnern würde, wobei sich das, was Mark niemals vergessen würde, wiederum auf das bezieht, was Rüdiger und Brahe niemals vergessen würden. Auf der Ebene des Erzählens wird der Vorgang des Sehens mit vollzogen: ein Vorgang, der von Außen/vom Zentralen/vom Eindeutigen nach Innen/ins Verästelte/ins Plurale geht. Die Polyperspektive vervielfacht sich zusätzlich durch mutuelle Spiegelungen: Rüdiger perspektiviert Mark und Brahe, Brahe perspektiviert Rüdiger usw. Zur Subjektivität als einer „Wirkung der différance“ vgl. Jacques Derrida: Positionen. Gespräche mit Henri Rose, Julia Kristeva u.a., Wien 1998, S. 70 f. 
magine, almeno finché ritornando a distanze e proporzioni piú grandi non percepí il riarrotolarsi delle dimensioni conosciute, dove tutto si manifestava ancora in modo puntiforme, campi onde particelle, comprese le particelle che loro vedevano per la prima volta quelle notte; [...] ed ebbe chiaro che da lí sarebbero venuti i nuovi oggetti, portando con sé comportamenti e percezioni e modi di essere e sentimenti, e capí di colpo ciò che aveva capito Epstein, e provò tenerezza per la pazienza con cui Epstein aveva voluto spingersi fin qui, fin nella gola del leone per prendergli la spina [...]. (AO 145-146) ${ }^{122}$

Das, was Brahe im epiphaniehaften Übergang ${ }^{123}$ vom sinnlichen zum geistigen Sehen sieht und von Rüdiger unmittelbar zuvor mit dem Ausruf „È cosí bello.

122 „[A]ber vor allem jener Augenblick würde für Brahe unvergesslich sein, in dem er schlagartig von dem, was er mit eigenen Augen sah, zu dem überwechselte, was er im Geiste sah, die Tiefe einer Materie, bei der es nicht mehr vier Dimensionen gab, sondern zehn oder elf, und die ihm unbekannten und unsichtbaren waren so kurz und gekrümmt, so schnell und so wenig darstellbar, so instabil, daß er geradezu spürte, wie das Wort ,Raum' zersplitterte, spürte, wie sich die Buchstaben voneinander lösten und sich wie wirbelnde Zylinder aufs neue zusammenfügten, und in ihrem Inneren befanden sich neue Zylinder und Volumen, die sich im selben Augenblick öffneten und schlossen, aber schon verwiesen Volumen und Zylinder und Bänder und Zipfel und Spiralen auf nichts anderes, denn für all das, was er in diesem Augenblick im Geiste sah, gab es kein Bild, zumindest so lange nicht, bis Abstände und Proportionen wieder größer wurden, und er sah, wie sich die Dimensionen zusammenrollten und innerhalb der vier bekannten Dimensionen verschwanden, wo sich alles noch in Punktform manifestierte, Felder, Wellen, Teilchen, auch die Teilchen, die sie in dieser Nacht zum ersten Mal sahen; [...] und es war ihm klar, daß von hier die neuen Dinge kommen würden und mit ihnen Verhaltensweisen und Wahrnehmungen und Seinsmöglichkeiten und Gefühle, und er verstand mit einmal, was Epstein bereits verstanden hatte, und er verspürte eine Zärtlichkeit für die Geduld, mit der Epstein bis zu diesem Punkt hatte gelangen wollen, bis in den Rachen des Löwen, um ihm die Gräte zu entfernen [...]“ (AW 195-196).

123 Es ist bezeichnend, dass der Augenblick der wissenschaftlichen Erkenntnis hier in der Form einer literarischen Epiphanie erzählt wird, hat sich diese doch gerade in der kritischen Reaktion auf wissenschaftlichen Empirismus und literarischen Naturalismus entwickelt. Ursprünglich als die irdische, materielle Erscheinung von Gottheiten definiert, hat sich die Epiphanie als eine der markantesten Stilfiguren der Literatur der klassischen Moderne zwar weitgehend von ihren konkreten konfessionellen und religiösen Inhalten emanzipiert, blieb jedoch mit ihrem Anspruch, ein Sinnganzes der Realität auszudrücken, gleichwohl metaphysisch konnotiert. Die literarische Epiphanie ist durch folgende Merkmale charakterisiert: 1 . durch den temporalen Aspekt der Plötzlichkeit als jener zentralen Anschauungsform des modernen Bewusstseins, die in der Beschleunigung der Lebenswelt ihre Entsprechung hat; dabei liegt dem Augenblick der Offenbarung die Doppelzeitigkeit des Vorübergehend-Flüchtigen einerseits, des Bleibend-Ewigen andererseits zugrunde; der Plötzlichkeit des Offenbarungsereignisses korreliert wiederum die Simultaneität des sich Offenbarenden: die Gegenwärtigkeit von Vergangenheit und Zukunft, von bereits konstituiertem Sinn und noch offenem, aber spürbar anwesendem Sinn, generell: die „Verbindung der Gegensätze und das Aufsteigen der allem zugrunde liegenden Einheit“ (Müller, s.u., S. 152). - 2. durch den perzeptiv-aisthetischen Aspekt 
der visuellen Wahrnehmung eines Gegenstandes, wobei sich dieser in einer Art Doppelgegenständlichkeit zeigt: er ist zugleich profanes Ding und „Gefäß für Offenbarungen“ (Hofmannsthal); - 3. durch einen erkenntnistheoretischen Aspekt, in dem wahrnehmendes, erkennendes Subjekt und wahrgenommenes, erkanntes Objekt ebenso zu einer ungeschiedenen Einheit verschmelzen wie philosophisch-analytische Erkenntnis und religiös-metaphysische Illumination. Die Erkenntnis erfolgt dabei im gegenwärtigen Augenblick der Wahrnehmung eines Dings und markiert den Durchbruch in die wesentliche, geistige Welt, die hinter der Maske der Dingoberfläche verborgen liegt. - Dabei sind Wahrnehmung und Erkenntnis, und damit wäre ein 4. Aspekt angesprochen, aus ihrem ästhetischen Zusammenhang nicht zu lösen: James Joyce, der den Begriff der literarischen Epiphanie geprägt hat, differenziert in terminologischer Anlehnung an Thomas von Aquins Lehre vom Schönen Ganzheit, Symmetrie und strahlender Glanz als die drei elementaren Eigenschaften des Schönen, denen die verschiedenen, gleichwohl augenblicklich-instantan sich vollziehenden Stufen der Wahrnehmung und Erkenntnis entsprechen. Fast immer wird das Erlebnis der Epiphanie „durch das Motiv der Unsagbarkeit eingeleitet“ (Ziolkowski, s.u., S. 605), wie überhaupt der narrative Kontext die strukturellen und hermeneutischen Bedingungen für das ,Funktionieren' der Epiphanie liefert, die Epiphanie mithin als „strukturgewordener Prozeß ihrer Genese“ (Geppert, s.u.) beschrieben werden kann. - Sämtliche Merkmale kehren in der zitierten Passage, die Teil einer kollektiven Epiphanie ist, wieder: das Moment der Plötzlichkeit im abrupten Wechsel vom sinnlichen zum geistigen Sehen, in dem die Oberfläche der Bildschirmdarstellungen durchbrochen wird hin zu einer „Vorstellung von einer Symmetrie, die so radikal und überraschend war, daß man das, was zuerst als Manifestation verschiedener und getrennter Kräfte erschienen war, unter dem einzigen großen Gesetz [...], das gleichzeitig ein Gesetz der Verschiedenheit und der Einheit war“ (AW 193), vereint sehen konnte. Die Erfahrung der Flüchtigkeit und Instabilität des darin Offenbarten, für das es kein Bild und kein Wort gab (vgl. AW 194 f.), paart sich mit der Erfahrung eines ursprünglichen Grundes, jener „Hundertstelsekunde hinter die große Exploxion, aus der alles entstanden war, als alles noch vereint war, nicht unterschieden und nicht in Dimensionen und Einheiten unterteilt“ (AW 196), einer Erfahrung, die zugleich als eine ästhetische - „Es ist so schön. So unglaublich schön“ - ausgewiesen ist. Auch das UtopischZukunftsweisende ist in diesen Blick in die „Tiefe der Materie“ (AW 194), in diesen - um eine treffende Formulierung Hugo von Hofmannsthals zu entlehnen - Augenblick des „ungeheuren Schauens des kosmischen Geschehens“ (s. u.) eingekapselt: Von hier, so heißt es, würden „die neuen Dinge kommen [...] und mit ihnen Verhaltensweisen und Wahrnehmungen und Seinsmöglichkeiten und Gefühle“ (AW 195 f.) und damit auch - wie ex negativo im Zersplittern des Wortes „Raum“ zum Tragen kommt (vgl. AW 195) - eine neue Sprache mit neuen möglichen Sinn- und Bedeutungskonstitutionen. Der sich geradezu aufdrängende Vergleich mit Hofmannsthals Chandos-Brief kann hier nicht geleistet werden; festzuhalten sei lediglich, dass ein- und dieselbe Erfahrung (die durch den Verlust der logisch-empirischen Weltwahrnehmung erlebte Atomisierung von Welt und Sprache) den einen Helden an den Rand des existentiellen Abgrunds treibt, dem anderen hingegen zum Auslöser einer Offenbarung gereicht; während Chandos vom Absturz in den Abgrund durch jene epiphaniehaften Augenblicke gehindert wird, die kontrapunktisch auf seinen Zustand der Krise bezogen sind und in denen sich ihm das Wesen der banalsten Dinge als die „restlose Vereinigung des Unvereinbaren“ erschließen, entdeckt Brahe gleichsam am Grund des Abgrunds selbst das physikalische Ge- 
Cosí incredibilmente bello“ kommentiert worden war (AO 143 f.), bezieht sich weder auf die Bildschirmdarstellungen noch auf eine von diesen repräsentierte Natur,

ma a quello che le tracce sparendo lasciavano immaginare, una simmetria cosí radicale e sorprendente per cui ciò che prima appariva come manifestazione di forze diverse e separate poteva essere considerato nell'unificazione di una grande legge, una sola e la piú semplice, una legge simultanea della differenza e dell' identità, di cui in quel momento vedevano, come erano abituati a vedere loro, la prova e il compimento. (AO 144) 124

Der gesehene ,Gegenstand‘ ist ein physikalisches Gesetz, möglicherweise eine Vorstufe der Weltformel, eine mathematische Formel, deren Symmetrie als Hinweis auf die Vereinigung zweier Kräfte gilt, die bisher als disparat angenommen wurden. Der Bezugspol des geistigen Sehens ist damit eine abstrakte

setz der Einheit. Das in epistemische Krise und poetisch-mythische Epiphanien sich spaltende Erleben des Chandos erscheinen in Brahes Epiphanie verschmolzen zu einem einzigen, naturwissenschaftliche Erkenntnis und ästhetische Erfahrung augenblicklich umfassenden Kontinuum. Die von Hofmannsthal, Musil, Virginia Woolf und vielen anderen Autoren der klassischen Moderne inszenierten Epiphanien nehmen die bei Del Giudice naturwissenschaftlich bewiesene und zugleich ästhetisch erfahrene Erkenntnis gleichsam als poetische Erkenntnis und Erfahrung vorweg. Die moderne Kluft zwischen Wissenschaft und Dichtung ist postmodern geschlossen. - Die skizzierte Theorie der Epiphanie orientiert sich an folgenden Darstellungen: Karl Heinz Bohrer: Plötzlichkeit. Zum Augenblick des ästhetischen Scheins, Frankfurt/M. 1981; Umberto Eco: Joyce und d'Annunzio. Die Quellen des Begriffs der Epiphanie, in: Materialien zu James Joyces „Ein Porträt des Künstlers als junger Mann“, hrsg. v. Klaus Reichert u. Fritz Senn, Frankfurt/M. 1975, S. 279-289; Hans Vilmar Geppert: Zur Semiotik der „epiphany“ bei Flaubert, d'Annunzio, Joyce und Hofmannsthal (unveröffentlichte Antrittsvorlesung an der Universität Augsburg); Walter Höllerer: Die Epiphanie als Held des Romans, in: Akzente 8, April u. Juni 1961, S. 125-136 u. S. 275-285; Klaus Peter Müller: Epiphanie. Begriff und Gestaltungsprinzip im Frühwerk von James Joyce, Frankfurt/M. 1984; Theodore Ziolkowski: James Joyces Epiphanie und die Überwindung der empirischen Welt in der modernen deutschen Prosa, in: Deutsche Vierteljahrsschrift für Literaturwissenschaft und Geistesgeschichte 35 (Dezember 1961), S. 594-616; das Hofmannsthal-Zitat stammt aus Hugo von Hofmannsthal: Der Dichter und diese Zeit, in: Gesammelte Werke in Einzelausgaben, Bd. II, hrsg. v. Herbert Steiner, Frankfurt/M. 1959, S. 229-258, hier S. 255; zum Chandos-Brief vgl. ders.: Sämtliche Werke. Bd. 31: Erfundene Gespräche und Briefe, hrsg. v. Ellen Richter, Frankfurt/M. 1991, S. 45-55.

124, „[...], sondern [auf die] Vorstellung, die die verblassenden Linien hervorriefen, [die] Vorstellung von einer Symmetrie, die so radikal und überraschend war, daß man das, was zuerst als Manifestation verschiedener und getrennter Kräfte erschienen war, unter einem einzigen großen Gesetz vereint sehen konnte, dem einfachsten und einzigen, das gleichzeitig ein Gesetz der Verschiedenheit und der Einheit war, und in diesem Augenblick sahen sie, so wie sie es gewohnt waren zu sehen, die Bestätigung und Erfüllung dieses Gesetzes“ (AW 193). 
Theorie, die auf der Grundlage computertechnisch erzeugter Spuren eines laboratisierten Naturvorgangs ihre experimentelle Bestätigung erfährt. Geistiges Sehen - wiewohl rückgebunden an eine technologisch hervorgebrachte und damit ihrerseits bereits erkenntnisgeprägte Spurenhaftigkeit, der kein natürliches Signifikat entspricht - ist hier wesentlich erkenntnisorientiert; die wissenschaftliche Erkenntnis selbst - eingebunden in die Zirkularität von mathesis und poiesis ${ }^{125}$ - erweist sich letztlich immer als ein auf Wissen zielendes Wissen aus Wissen.

\section{Exkurs}

Die sinnliche Wahrnehmung und Deutung der Bilder und das geistige Sehen im Sinne der ,eigentlichen' naturwissenschaftlichen Erkenntnis sind auf das engste miteinander verflochten und treten dennoch auseinander. Die Visualisierungen veranlassen und bestätigen zwar die wissenschaftliche Erkenntnis (dank ihrer Evidenz kann hypothetisches in positives Wissen überführt werden), doch ist diese Erkenntnis selbst nicht eine auf die Bilder gerichtete, sondern eine von diesen völlig abstrahierte. Die mathematisch-physikalische Erkenntnis gehört einer anderen Ordnung des Wissens zu. Ihr voraus liegt eine Theorie, welche die neuen Teilchen und deren Eigenschaften im Modus des Hypothetischen und Wahrscheinlichen beschreibt und antizipiert und im Idealfall, wie er im Roman ja eintritt, mit den Bildschirmdarstellungen, d.h. mit den ins Bildhafte übersetzten, auf nicht-sichtbaren Ereignissen bezogenen Messdaten übereinstimmt. Demgegenüber ist ein auf die Bilder selbst bezogener Verstehensund Erkenntnisprozess auf die oben beschriebenen Bilderzeugungsmaschinerien und prozeduren bezogen und analysiert den Weg von den ästhetischen Erscheinungen auf dem Bildschirm über die diesen zugrunde liegenden Programme bis hin zu den mathematischen Funktionen, die diese Programme definieren. „So bedarf es eines Wissens der zugrunde liegenden Programme und Modelle, um die Bilder angemessen verstehen zu können, das gleichwohl als Wissen ohne Korrelation erscheint, sondern der Erkenntnis apperzerpiert werden muß.“126 Dabei entscheidet „die Frage, ob im Erkenntnisprozeß Kurven, Diagramme, Zahlen, Text, Photographien oder digitale Bilder verwendet werden, darüber mit [...], was wir in wissenschaftlichen Bildern sehen“, ${ }^{127}$ eine Frage, die auch im Roman explizit gestellt wird: „,Wol-

125 Wobei die poiesis nicht mehr an die Natur des Genies gebunden, sondern ihrerseits bereits hochgradig automatisiert und virtualisiert ist. „Der kreative Prozeß ergibt sich eher aus einem Zustand höchster Komplexität als aus einer Handlung“ (Lyotard: Immaterialität, S. 15). Die Technologien sind damit auch nicht mehr vorrangig „Mittel zum Beweis von schon vorher aufgestellten Hypothesen“, sondern sind imstande, selbst Denkoperationen auszuführen und Ideen zu haben; sie „führen geradezu das Projekt durch, die ganze Welt zu einer Prothese der menschlichen Intelligenz zu machen (ein altes cartesianischen Projekt), die Wirklichkeit in eine Prothese zu verwandeln“. „Technologie ist [...] Wissenschaft inform von Apparaten“ (ebd., S. 58, vgl. auch S. 83).

126 Mersch: Naturwissenschaftliches Wissen und bildliche Logik, S. 418.

127 Heßler: Einleitung, S. 32. 
len Sie sie als Tabelle oder als Mikrofiches?' hat der Mann an der Ausgabestelle gesagt. ,Lieber als Tabelle, dann sehe ich sie sofort", hat Brahe gesagt“ (AW 187). Dem Objektpronomen „sie“ ist dabei kein bestimmbares Objekt zugeordnet; durch diesen höchst subtilen Kunstgriff wird nicht nur die heikle Fragen nach der Referenz erneut aufgeworfen, sondern auch die Frage, was an den Schnittstellen, also im Übergang von einer zur anderen Darstellungsform passiert. ${ }^{128}$ Vor allem aber rückt damit das erkenntnistheoretische Problem der Interrelation von Theorie und Bild ins Zentrum, also die Frage, welche Rückwirkungen die unterschiedlichen Arten medialer Repräsentation auf eine bereits bestehende oder im Entstehen begriffene Theorie zeitigen - ,jeder Übergang in eine andere Darstellungsform [...] verändert das Wissen“129 - und inwiefern umgekehrt die Wahl der Visualisierungstypen durch das hypothetische Wissen und der mit diesem verbundenen Erwartungshaltung gesteuert wird. Der Theorie und Bild trennende Hiatus einerseits, die komplizierten und vielseitigen Wechselwirkungen zwischen Theorie und Bild andererseits schleusen in das wissenschaftliche Erkennntnisresultat Elemente des Instabilen, Unsicheren und Aporetischen ein, die letztlich nur durch eine Erkenntnistheorie ,erfasst' werden können, welche sich gegenüber dem ,negativen', ,schwachen“ und ,liminalen“ Wissen nicht verschließt.

Die Schönheit der Symmetrie gründet in der angenommenen Übereinstimmung der physikalischen Theorie mit einem abwesenden ,natürlichen' Signifikat, dessen virtuelle Spuren seine Anwesenheit (scheinhaft) evident machen. Die naturwissenschaftliche Erkenntnis verschränkt sich mit einer ästhetischen Erfahrung, die von einer grundlegend modifizierten klassischen Ästhetik des Schönen geprägt ist: Einbildungskraft (der Sinn für Formen und Farben) und Verstand (das Vermögen rationaler Organisation) befinden sich zwar in freier Übereinstimmung, ${ }^{130}$ doch als technologische ,Werke“ sind die schönen Bilder, wie Lyotard am Beispiel der Fotografie darlegt, „unmittelbar von den Gesetzen der Erkenntnis geprägt“, d.h. alles Unbestimmte und Unreine - „und mit ihm auch das Gefühl“ - ist daraus entfernt. Entsprechend appelliert ein solches Bild „nicht ans Schöne des Gefühls, sondern ans Schöne von Verstand und Begrifflichkeit“; es „besitzt die Unfehlbarkeit dessen, was vollkommen geplant ist“, seine „Schönheit ist die des zweiten Blicks.“131 „Im Ergebnis ist es nicht schön,

128 Vgl. Heßler: Einleitung, S. 32. Exemplarisch sei auch auf die Studie von Hennig verwiesen, der am Beispiel von visuellen Darstellungen rastertunnelmikroskopischer Messungen aufzeigt, wie die „Übergänge von abstrakten Graphen zu figurativen Formen [...] die Grenzen zwischen den beiden Repräsentationsformen Graph und Bild erodieren lassen und die Bildhaftigkeit von Graphen deutlich machen“ (Jochen Hennig: Die Versinnlichung des Unzugänglichen, in: Konstruierte Sichtbarkeiten, S. 99-116, hier S. 102, vgl. v. a. S. 108-113).

129 Heßler: Einleitung, S. 32.

130 Vgl. Immanuel Kant: Kritik der Urteilskraft, hrsg. v. Wilhelm Weischedel, Frankfurt/M. $1974, \S 5$.

131 Lyotard: Immaterialität, S. 95. Der Adressat dieser Bilder „,ist nicht mehr das empfindsame Subjekt, das eine künftige Geschmacksgemeinschaft entwirft; es ist der Empfänger fertiger 
sondern zu schön.“ Dieses ,zu` zeigt, so Lyotard weiter, ein Unendliches an, das eben nicht mehr das Unbestimmte eines Gefühls ist, sondern die unendliche Realisierung von Wissenschaft und Technik: „Die Bestimmung der Realien wird durch die stets weiter zurückgehende Analyse und die Erfindung neuer Axiome unendlich aufgeschoben." ${ }^{132}$ Mit anderen Worten: Die Bilder verweisen auf die mannigfaltigen ,technowissenschaftlichen“ Prozesse ihrer Sichtbarmachung, ohne je auf den Ursprungsort ihrer Entstehung zurückzuführen und ohne je ihr Ziel, die Aktualisierung einer Referenz, zu erreichen. Mehr noch: Wissenschaft und Technik - selbst „matter of facts“ - erweisen sich ihrerseits als „Modi, das Unendliche der Ideen zu aktualisieren “133 und damit als Supplemente der Kunst. ${ }^{134}$

Am Höhepunkt des Experiments koinzidieren der naturwissenschaftliche Diskurs Brahes und der ästhetische Diskurs Epsteins im „Sehen hinter die Form“ - und treten zugleich an eben diesem Punkt auseinander, bleibt doch Brahes geistiges Sehen auf die veranschaulichende Beweiskraft der (virtuellen) Bilder und damit auf das sinnlich sichtbare Zeugnis einer ästhetisch vermittelten anästhetischen Natur angewiesen. Im Unterschied zur Wissenschaft, die das ,natürlich'Unsichtbare durch konstruierte Sichtbarkeiten kompensiert - kompensieren muss, will sie Wahrheitseffekte über das Unsichtbare erzeugen -,

Produkte, in denen er die Perfektion der sie bestimmenden Verfahren wiederzuerkennen weiß“ (ebd.).

132 Ebd., S. 95. Vgl. auch S. 101: „Die postindustrielle Welt der Technowissenschaften hat nicht zum allgemeinen Prinzip erhoben, daß etwas darzustellen sei, was darstellbar ist und demzufolge wiederzugeben ist; vielmehr gehorcht sie dem umgekehrten Prinzip: das Unendliche liegt in der Dialektik der Suche selbst.“

133 Ebd., S. 95.

134 Die Kunst verlagert sich von der Ästhetik des Schönen auf eine Ästhetik des Erhabenen, wie sie von Lyotard ausführlich dargelegt wurde. Die avantgardistische und postmoderne Ästhetik des Erhabenen ist jedoch nicht als das ganz Andere der Wissenschaft aufzufassen: Das Erhabene der Avantgarden ist „kaum nostalgisch“ im Sinne der Romantik: „[E]s richtet sich eher aufs Unendliche der durchzuführenden plastischen Versuche als auf die Vorstellung eines Absoluten, das verloren ist. Darin stimmt ihr Werk mit der zeitgenössischen Welt industrieller Technowissenschaft überein“ (ebd., S. 99 f.). Vgl. in diesem Zusammenhang auch Brahes Eindrücke unmittelbar nach der Entdeckung der neuen Teilchen: „ihm schien [...], daß Sehen nichts anderes bedeutete, als die Schwelle des Unsichtbaren ein wenig zu verschieben (che vedere significasse solo spostare un po' piú in là la soglia del non visibile, AO 146), sie mit einem einzigen Lidschlag abzureißen und wieder zu errichten, und ihm schien, eine Maschine, die so groß war, eine Geometrie, die derart kompliziert, und eine Mathematik, die derart komplex war, daß das wahre Problem in der andauernden Normalisierung des Unendlichen bestand, würden dabei helfen, strenge und konsequente Fragen zu stellen, die man solidarisch und konsequent beantworten musste... ,Ist dir heiß ' Ja, heiß`, ,Ist dir kalt?‘ ,Ja, kalt‘; und darin, in dieser Unerschöpflichkeit und Solidarität der Natur, lag die wahre Schönheit“ (AW 197). 
und auf die De-Ästhetisierung der Wirklichkeit mit deren Re-Ästhetisierung antwortet, wählt Epstein den asketischen, anti-poetischen Weg und unterwirft sich der Dominanz des (geistigen) Sehens.

Wie lässt sich nun Epsteins „Sehen jenseits der Form“ beschreiben, und welche Konsequenzen verbinden sich damit für seine neue Ästhetik? In seiner bisherigen Tätigkeit als Schriftsteller waren Ding- und Sprachwelt, Poetik des sinnlich-geistigen Sehens und Poetik des Schreibens eng aufeinander bezogen. Den Dingen selbst war, wie gezeigt, die Geschichte ihrer Entstehung und ihrer möglichen Fortsetzung eingeschrieben. Der Schreibprozess, aufgefasst als Dingerzeugungsprozess, war die Fortschreibung jener Geschichte, die den Dingen - und mit ihnen den Menschen - als bereits verwirklichte und noch zu verwirklichende Möglichkeiten innewohnen. Mit dem Schwinden der Dinge und damit dem Schwinden ihrer Präsenz - wird dem sinnlichen Sehen und dem auf dieses bezogene Schreiben seine materielle Grundlage entzogen: Das neue Sujet des Sehens und Schreibens ist nunmehr das Immateriale und damit das Formjenseitige, Unsichtbare und Undarstellbare. ${ }^{135}$

135 Epsteins Immaterialismus ist, und dies gilt es noch einmal hervorzuheben, naturwissenschaftlich und nicht - wie etwa der Immaterialismus Berkeleys - theologisch oder metaphysisch motiviert. Entsprechend ist auch das vom sinnlichen Sehen losgelöste geistige Sehen das ,Sehen hinter die Formen' - nicht auf die Schau höherer, übernatürlicher Seinsgründe (etwa im Sinne der platonischen Ideenwelt oder der mystischen Gottesschau) gerichtet. Schließlich ist auch das Licht, von dem später die Rede sein wird, kein ,lumen supranaturalis‘, das, wie bei Augustinus oder Thomas von Aquin, die Wahrheitsfähigkeit der menschlichen Vernunft (,lumen naturalis') ermöglichen und verbürgen würde oder dem sich, wie bei Plotin, der Mensch in der Anschauung der Gottheit nähern würde. Hingegen sind die strukturellen Ähnlichkeiten, vor allem in der Verbindung von Sehen und Denken, mit der abendländischen jüdisch-christlichen und philosophischen Tradition unverkennbar (vgl. hierzu Hans Blumenberg: Licht als Metapher der Wahrheit. Im Vorfeld der philosophischen Begriffsbildung, in: Studium Generale 10, 1957, S. 437-447; ferner: Bruno Snell: Die Entdeckung des Geistes. Stu-

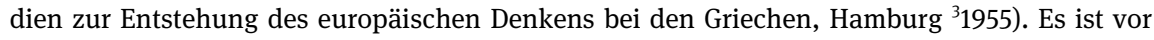
allem die Formulierung „vedere mentalmente“, welche die insbesondere im Umfeld der romantischen Dichtung und Philosophie relevant gewordene Kategorie der ,intellektualen Anschauung‘ evoziert. Gegen Kant gerichtet, der die Möglichkeit einer intellektuellen Anschauung unter Ausschluss der Sinne kategorisch ablehnt, halten Schelling, Hölderlin, Novalis, Schlegel und Schleiermacher im Rekurs auf Spinoza an der Möglichkeit einer scientia intuitiva - nach Spinoza die höchste und rein intellektuelle Erkenntnisform, die „durch die unmittelbare Teilhabe an der göttlichen Vernunft uns gegeben wird“ - fest (John Neubauer: Intellektuelle, intellektuale und ästhetische Anschauung. Zur Entstehung der romantischen Kunstauffassung, in: Deutsche Vierteljahrsschrift für Literaturwissenschaft und Geistesgeschichte, 46. Jg., 1972, S. 294-319, hier S. 297). So unterschiedlich deren Konzeptionen der intellektualen Anschauung jeweils sind (Schelling deutet sie als Augenblicke „mystischer Selbstanschauung“ [ebd., 301] 
Einer Literatur, deren Referenzbereich entleert ist, bleibt nur der Rückzug auf und in sich selbst: Der Blick auf die Welt wandelt sich in Selbstanschauung - in eine Ästhetik, die selbstreflexiv die Bedingungen des Sehens und die Bedingungen von Kunst in den Blick nimmt. Hierin der postmodernen Philosophie Lyotards durchaus verwandt, leitet Epstein aus diesem Befund nun aber gerade nicht eine Ästhetik des „immanent Erhabenen“ ab, der zufolge sich die Kunst verpflichtet weiß, in der ,Form“ negativ-abstrakter Darstellungen ,anzuspielen auf ein Undarstellbares, das nichts Erbauliches an sich hat, sondern im Unendlichen der sich wandelnden ,Realien“ liegt“ und damit „sehen zu lassen, daß es Unsichtbares im Sichtbaren gibt“; ${ }^{136}$ vielmehr leitet er daraus eine Ästhetik ab, die den Verzicht auf jegliche ,Form‘ künstlerischer Darstellung und damit das ,Ende von Kunst und Literatur postuliert. Es handelt sich um die reine Ästhetik eines ebenso reinen abstrakt-geistigen Sehens, dessen Gesehenes nicht mehr in Kunst übersetzt werden kann, sich also nicht mehr als Kunst zu manifestieren vermag. Epstein geht, wenn man so möchte, über Lyotard hinaus, indem er nicht nur die Möglichkeit einer positiv-repräsentativen Darstellung von ,Wirklichkeit“ negiert, sondern auch die Möglichkeit einer negativabstrakten Darstellung zur Unmöglichkeit erklärt. Waren (sinnlich-geistiges) Sehen und Schreiben in seiner frühen Ästhetik korrespondierend aufeinander bezogen, so wird nun jeglicher Zusammenhang zwischen Sehen und Schreiben - und damit auch zwischen Weltbetrachtung und literarischer Sprache -

des absoluten Ich, Hölderlin als die ,ästhetische Wiedergewinnung“ [303] eines als vollkommene Vereinigung von Subjekt und Objekt definierten Urzustandes, Friedrich Schlegel als „poetisches Wissen“ [307] von der Menschheit, Fichte als jene Tathandlung, in der sich das ursprüngliche Ich in einem Akt der Selbstanschauung konstruiert [vgl. 306], Novalis sieht sie durch einen frei gewählten und zugleich gegebenen Mittler ermöglicht, der sinnlich und zugleich übersinnlich angeschaut wird [309 f.], Schleiermacher spricht von der ,intellektualen Anschauung der Freundschaft“ [zit. n. ebd., 312], wobei die Anschauung des Freundes zur eigentlichen Selbstanschauung wird), so sehr treffen sie sich doch in deren Verankerung in einem transzendenten, transzendentalen oder immanenten Absoluten und (Fichte ausgenommen) vor allem in der Auffassung, dass die intellektuale Anschauung nur als ästhetisch objektivierte und damit in der Schönheit (und nicht im Verstandesbegriff) sinnlich-übersinnlich angeschaut werden kann: „Im Gegensatz zu Fichte bezeichnet die Romantik mit intellektualer Anschauung keine verstandesmäßige Operation sondern sinnliche, vor allem visuelle Begegnung, die eben durch die Intensität ihrer Sinnlichkeit übersinnlich wird. [...] Durch die äußerste Sinnlichkeit der Anschauung wird sie zum ästhetischen Erlebnis“ (ebd., S. 318). Im Falle Epsteins jedoch ist die intellektuale Anschauung weder sinnlich noch transzendent verwurzelt, sondern bestenfalls transzendental im Sinne eines radikalisierten Naturalismus, in dem reine Energie und reines Licht gleichsam als physiko-transzendentale Bedingung der Möglichkeit von (Nicht-)Welt und (Nicht-)Ich gedeutet werden.

136 Lyotard, Immaterialität, S. 98 u. 101. 
aufgekündigt: Das kunsttheoretische Prinzip des, vedere le storie raccontando e scrivendo“ ist abgelöst durch das philosophisch-ästhetische Prinzip des ,vedere le storie guardando'. Das (nurmehr geistige) Sehen erscheint als ein vom Schreiben vollkommen abstrahierter und emanzipierter eigenständiger Vorgang, der zum ausschließlichen Gegenstand der neuen Ästhetik avanciert. Entsprechend gehen Epsteins literarische Geschichten nicht, wie vormals, aus den sinnlich wahrgenommenen Dingen und den in ihnen verborgenen ,Geschichten' hervor und gelangen erzählend-schreibend zu ihrer wahrnehmbaren (d.h. auch lesbaren und deutbaren) Sichtbarkeit, sondern werden geistig-sehend erzeugt und für das geistige Auge sichtbar gemacht. ${ }^{137}$ Von der ,Natur dieser Geschichten erfährt der Leser nur wenig: Es sind Geschichten, in denen zeitliche Sukzessivität und Prozessualität ${ }^{138}$ zugunsten einer „pure simultaneità“ aufgehoben scheint, Geschichten, in denen die Möglichkeiten nicht mehr um eines fragmentarischen ,Positivabdrucks' willen massakriert werden, sich hingegen alles auf einmal - „compiutamente dall’inizio alla fine“ (vollständig vom Anfang bis zum Ende, AO 63 [88]) - zeigt; ${ }^{139}$ es sind Geschichten, die keinen

137 Es sei noch einmal das entsprechende Zitat angeführt: „prima le [le storie] vedevo raccontando, le vedevo nel momento in cui le scrivevo, adesso le vedo guardando, vedo una storia compiutamente dall'inizio alla fine semplicemente guardando. E questo, [...] è il mio esperimento“(AO 62 f.).

138 Und damit alles, was der Zeit und der Prozessualität unterworfen ist: schöpferische Arbeit, Handlung, Wachstum usw.

139 Unverkennbar kehren hier verschiedene Merkmale der Epiphanie wieder: die Hypostasierung des gegenwärtigen Augenblicks und die damit verbundene Aufhebung der zeitlichen Sukzessivität in einer räumlichen Simultaneität sowie die Vision von Ganzheit, Vollständigkeit und Einheit. Allerdings handelt es sich im Falle Epsteins um eine kupierte Epiphanie: Sie nimmt ihren Ausgang eben nicht mehr in der sinnlichen Wahrnehmung eines materiellen Gegenstandes, dessen wahrhaftes Wesen sich im geistigen Sehen ,epiphanisieren` würde, sondern in den immaterialisierten non-cose, die nurmehr als geistige Vorstellungen des Subjekts zu begreifen sind. In einer solchen, von aller Empirie, aber auch von allen narrativen Kontexten abstrahierten Epiphanie wird dann auch nicht mehr die „faktische Wirklichkeit des Dings zu metaphysischer Symbolhaftigkeit [gesteigert]“ und „das Ding gleichsam aus seiner empirischen Starre zu poetischem Leben erweckt“ (Ziolkowski: James Joyces Epiphanie, S. 603), sondern eine geistig-symbolische Wirklichkeit in eine ,höher- und höchstgeistige potenziert. Die Epiphanie wäre letztlich Gegenstand ihrer selbst; sie wäre nicht mehr poetische und zugleich metapoetische Figur, die der freien sprachlichen Imagination bzw. der „Entautomatisierung der künstlerischen Zeichen prinzipielle wirklichkeitsbildende Funktion“ zuspräche (Geppert: Zur Semiotik der „epiphany“), sondern eine ausschließlich metatheoretische Figur, die in einer referenzlosen Leere um sich selber kreist. Obwohl Epstein mehrfach betont, er stehe erst am Anfang seines Experiments - „Ich bin Anfänger in meinen eigenen Verhältnissen“, diese Worte von Rilkes Romanheld Malte könnten auch von Epstein stammen -, so deu- 
Außenraum mehr beanspruchen, sondern sich im geistigen Innenraum labyrinthisch verzweigen („ovunque nello spazio, determinato dalla storia stessa“), in alle Richtungen des Raums, der wiederum von der Geschichte selbst bestimmt wird (AO 68 [94]); es sind letztlich non-storie, deren Sujet das Sehen selbst ist und mit ihm das Licht, jenes Licht, in das Epstein alles verwandelt sieht und das er gerne als Ding - als das einzige ihm verbleibende Ding überhaupt ${ }^{140}$ - beschreiben möchte. ${ }^{141}$ Die einzige Gestalt aber, in der Epsteins Lichtgeschichten nach außen strahlen, ist die einer abstrakten, rein formalen Ästhetik, die se-

tet doch nichts darauf hin, dass sein Schreibverzicht ein lediglich vorübergehender ist. Entsprechend sind auch seine epiphaniehaft offenbarten ,Geistgeschichten' utopisch entleert: In ihnen deuten sich keine neuen (ästhetischen) Sprach- und Seinsmöglichkeiten mehr an; sie zielen - man möchte fast sagen: gespenstisch - in Richtung Leere, Dunkelheit und Tod. Vgl. auch den Schluss des von Epstein ausführlich beschriebenen Feuerwerks: „[...] e luce e luce e luce e luce - Buio“ (und Licht und Licht und Licht und Licht - Dunkelheit, AO 134 [180]). Auf Dunkelheit und Tod verweist auch der polysemantische Titel Atlante occidentale: im Westen geht die Sonne unter, ebenso ist der Westen traditionelles Symbol für Vergangenheit und Tod.

140 Vgl. AO 137 [184]. War ihm das Licht in seiner frühen Schaffensphase „sforno e contorno delle cose“ („Hintergrund und Rahmen der Dinge“), oder hatte sich ihm das Licht in Gegenstände verwandelt (AO 96 [130-131]), so ist es nun umgekehrt: Im neuen Sehen verwandeln sich ihm die Dinge in Licht, das Licht selbst ist ihm Ding (vgl. ebd.). Vgl. v.a. Epsteins Beschreibung des Feuerwerks (AO 130-134 [174-180]), die eine ,eruptive‘ Entfaltung seiner Überzeugung von der Verwandlung der Materie in Licht (,la materia diventava luce“, AO 130 [174]) ist. Analoges gilt für Brahes Arbeitswelt, wo „ogni luce era circostanziata e significativa“ (,jedes Licht genau umrissen und bedeutungsvoll [war]“), „non tanto lo sfondo di un'azione, ma l'azione stessa“ („,nicht so sehr der Hintergrund einer Handlung als die Handlung selbst“): „ogni luce era una domanda, o una risposta, non piú contorno delle cose, forse le cose stesse dopo il loro progressivo farsi piccole e sparire“ (,jedes Licht war eine Frage oder eine Antwort, nicht mehr Umriß der Dinge, sondern vielleicht die Dinge selbst nach ihrem unaufhaltsamen Kleinerwerden und Verschwinden“, AO 48 [68]). Vgl. ein weiteres Mal Lyotard, der in Bezug auf die postmoderne Malerei sagt: „Änderung des Sujets, des Materials. Neues Sujet: Licht. Neues Material: Licht. So begründen sich die Werke, die aus Licht und durch Licht geschaffen sind, Werke, die sich selbst zum Sujet haben. Schwindelerregende Selbstreferenz“ (Lyotard: Immaterialität, S. 14). Die avantgardistische Malerei sei wesentlich reflexiv geworden, d.h. auf das Hinterfragen der Regeln der Kunst selbst konzentriert (vgl. ebd., S. 38 u. 39); entsprechend sucht sie auch das Undarstellbare, das immanent Erhabene ,in den Bedingungen künstlerischer Arbeit selbst“ (ebd., S. 99). Diese Suche bezeichnet Lyotard als „Aufgabe des Experimentierens" (ebd., S. 101).

141 Die non-storie sind damit pure Wahrscheinlichkeit. Vgl. AW 124 f.: „Vielleicht ist die Wahrscheinlichkeit eine große Form des Respekts und dem sehr nahe, was bis zur Übereinstimmung geschieht, und dennoch davon getrennt.“ Mit dem Verlust ihres Ding-Status (vgl. die Ausführungen zu Epsteins früher Ästhetik) verlieren Epsteins Geschichten auch jegliche kommunikative und hermeneutische Funktion; sie können nicht gelesen, nicht gedeutet, nicht in pragmatisches oder kognitives Handeln fortgesetzt werden. 
hend in die Gesetzmäßigkeiten des geistigen Sehens einzudringen versucht, eine Ästhetik, die nicht mehr - weder positiv noch negativ - Theorie der Kunst ist (deren integraler Bestandteil die Theorie der Wahrnehmung immer schon war), sondern Theorie des geistigen Sehens - reine Schau des reinen Sehens. ${ }^{142}$

Welcher Status kommt diesen Geschichten ,im Kopf', diesen reinen Vorstellungen („pure immaginazione“) zu? Ist diese vollkommen immateriale - deliteralisierte - ,Literatur' noch Kunst? Auf diese Fragen antwortet nicht die fiktionsimmanente Ästhetik Epsteins, sehr wohl aber die im Erzähldiskurs von Atlante occidentale realisierte Poetik. Der implizite Autor unternimmt am Ende des Romans den Versuch, Epsteins Ästhetik ins Ästhetische einer mise en abyme zu übersetzen und auf diese Weise den Kunst- und Darstellungsnihilismus seines Protagonisten zu überwinden. ${ }^{143}$ Nimmt man Epsteins radikal philosophische Ästhetik und die aus ihr resultierende Konsequenz einer absoluten literarischen Askese - eines freiwilligen poetischen Schweigens, das eben nicht einmal mehr nach (s)einer ,negativen' Darstellung drängt - ernst, dann ist jeder Versuch, diese Ästhetik zu applizieren, als ein entschiedener Einspruch gegen eben diese Ästhetik zu deuten. ${ }^{144}$

142 Mehrmals weist Lyotard darauf hin, dass es Aufgabe der Postmoderne sei, das Werk der modernen Avantgarde-Bewegung fortzuführen, freilich ohne sich durch deren Ideale zu legitimieren. Was die Avantgarde auszeichnet ist, dass sie nicht versuchte, „das schon Dagewesene [...] $\mathrm{zu}$ wiederholen, sondern weiterzugehen im Hinterfragen der Kunst“. Die Avantgarden „mochten die etablierte ,Moderne“ lediglich, um sich von ihr abzusetzen, ins Exil zu gehen. Dieses Exil, das ich Experimentieren nenne, mache ich als Kraft im Postmodernen geltend“ (Lyotard: Immaterialität, S. 39; vgl. auch S. 30). Epstein löst dieses Postulat in denkbar radikalster Weise ein: Er begegnet der Exilierung der Wirklichkeit - ihrem Hinschwinden an einen (noch?) nicht erfahrbaren Ort - mit der Exilierung der Literatur aus seinem persönlichen Leben und dem Rückzug in ein inneres, geistiges Exil, in jenes mit der Formel „Sehen jenseits der Form" umschriebene Experiment.

143 Vordergründig (und wie gezeigt werden soll nur scheinbar) stellt sich der implizite Autor gleichsam in den Dienst seiner Figur: Stellvertretend für Epstein führt er das Experiment zu Ende, indem er es literarisch erprobt.

144 Vgl. Lyotard: „Denn darstellen heißt relativieren, heißt in Zusammenhänge und Bedingungen der [...] Darstellung bringen. Das Absolute kann man also nicht darstellen. Man kann jedoch darstellen, dass es Absolutes gibt“ (Immaterialität, S. 98). Epsteins Ästhetik geht jedoch genau an diesem Punkt über Lyotard hinaus: Er macht nicht nur die positive Darstellung (nach Lyotard alle „feststehenden Symbole“ für das Absolute) zum „Märtyrer“ (vgl. ebd.), sondern Darstellung überhaupt. Epstein opfert die Darstellung zugunsten der „Dinge ohne Grab“ („,cose senza sepoltura“, AO 85 [115]). - Obgleich Regns Argumentation, wonach in der mise en abyme Epsteins experimentelle Poetik des „vedere storie compiute“ literarische Gestalt gewinne, und zwar „nicht in der Form einer idealtypischen Realisierung, sondern im Modus allusiver Annäherung“, sehr plausibel erscheint (vgl. Regn: Nach der Moderne, S. 347), so bedeutet - mit Blick auf 
Der extradiegetische Erzähler weist die mise en abyme, allgemein definiert als die „Spiegelung der Makrostruktur eines literarischen Textes in einer Mikrostruktur innerhalb desselben Textes“, ${ }^{145}$ als das von Epstein geistig Gesehene aus: ${ }^{146}$ Er sieht, was Epstein sieht, und teilt es mit. Das, was sich dem Erzähler

Epsteins Ästhetik - jeder Darstellungsversuch nicht lediglich die Relativierung des Absoluten, sondern die Negation und Liquidierung eben dieser Ästhetik selbst. Die mise en abyme, die, wie Regn darlegt, als ,avantgardistische Spatialisierung der Geschichte [...] deren vorgängige Entfaltung auf der Achse temporaler Abfolge voraus[setzt]“, in ihr also das postmodern Experimentelle im modern Konventionellen abgestützt wird (vgl. ebd., S. 349), ist vor dem Hintergrund von Epsteins Ästhetik lediglich als eine von jenen literarischen Formen zu werten, die Epstein seiner frühen Ästhetik folgend stets gesucht hat. Mit seiner neuen Ästhetik hat sie nur im Modus des Alsob zu tun: Der implizite Autor insinuiert, dass die mise en abyme das wiedergibt, was Epstein sieht. Das Verfahren der mise en abyme ist vergleichbar mit jenem Spiel der Täuschung, das Brahe mit Wang spielt: Ist es hier eine Maschinenzeichnung, die gefälscht wird, um den Kontrahenten Wang auszutricksen (dieser durchschaut das Spiel und gibt nach, weil er das Spiel affirmiert), so handelt es sich bei der mise en abyme um eine spielerische Volte des impliziten Autors gegen die Ästhetik seines Protagonisten; vor allem ist sie jedoch Figur eines klugen Spiels mit dem Leser, der erst, nachdem er, wie Wang die Zeichnung, den Text gegen das Licht hält, erkennt, dass es sich bei der mise en abyme gerade nicht um die approximative Realisierung von Epsteins Ästhetik handelt, sondern um eine geniale Fälschung.

145 Werner Wolf: Ästhetische Illusion und Illusionsdurchbrechung in der Erzählkunst, Tübingen 1993; vgl. ferner: Ders.: Art. „Mise en abyme“, in: Metzler Lexikon Literatur- und Kulturtheorie, hrsg. v. Ansgar Nünning, Stuttgart 2004, S. 442f.; Michael Scheffel: Formen selbstreflexiven Erzählens, Tübingen 1997, bes. S. 71-90.

146 Die exzessiv eingesetzte Formel „vede“ (er sieht) wird in dem knapp zweieinhalbseitigen mise en abyme-Text (vgl. AO 150-151 [200-203]) 15 Mal angeführt. - Das Ereignis des geistigen Sehens ist auf dem Flugplatz kurz vor Epsteins Abreise nach Deutschland und damit kurz vor dem letzten Wiedersehen mit Brahe situiert. Auf der Achse der Erzählzeit wird dieses Ereignis unmittelbar nach dem Bericht von der sensationellen Entdeckung im CERN erzählt, auf der Achse der erzählten Zeit fällt es jedoch mit dem Augenblick der Entdeckung zusammen („In quello stesso istante Ira Epstein [...]“, AO 147). Diese Parallelisierung der Ereignisse verweist auf ihre Affinitäten und zugleich auf ihre Differenzen: Analog zur Entdeckung im CERN wird auch das geistige Sehen der Geschichte durch die sinnliche Wahrnehmung eines Modells und damit eine virtualisierte Realität evoziert: Epstein betrachtet durch ein Schaufenster eine Modelleisenbahn, die wiederum in ein Modell der Stadt Genf (den „grande anello“ des CERN und den alten Flugplatz, an dem sich die beiden Freunde kennen gelernt haben und die Geschichte ihren Ausgang nahm) eingepasst ist. Die in der mise en abyme erzählten Ereignisse erstrecken sich dabei bis zu jenem Augenblick, in dem Brahe am Flughafen eintrifft, um seinem Freund Lebwohl zu sagen. Die mise en abyme geht also unmittelbar in das Ende der Romanhandlung über. - Die Parallelgestaltung ist jedoch eine vom Erzähler ,konstruierte‘, und es ist eben höchst fraglich, ob der Erzähler wirklich jene Geschichte wiedergibt, die Epstein geistig sieht. Parallelisiert werden bei genauer Betrachtung nicht Epsteins Sehen mit Brahes Sehen, sondern das Sehen des Erzählers mit Brahes Sehen. 
von dem zeigt, was Epstein sieht, ist die Geschichte, die im Roman Atlante occidentale erzählend hervorgebracht und - darin Epsteins früher Ästhetik folgend - für den Leser sichtbar gemacht wurde. Der Erzähler fungiert als Augenzeuge dessen, was sich in der geistigen Vorstellung seiner erzählten Figur abspielt. Indem er diese Vorstellungen stellvertretend für Epstein verbildlicht und versprachlicht, bezeugt er darüber hinaus gegenüber dem Leser die Glaubwürdigkeit seiner Figur und deren Experiment des „,vedere una storia compiuta“. Bei der Gestaltung der mise en abyme orientiert er sich durchaus an den theoretischen Grundlagen der Epstein'schen Ästhetik: So wird etwa durch die „Aussparung von grammatikalischen Funktionswörtern, die eine temporale Abfolge indizieren könnten“, aber auch durch die „Kaskade anaphorisch gereihter ,vedere“-Formeln“ der „Eindruck extremen Akzelerierens der Diskursbewegung "147 und damit der Eindruck von Simultaneität des gesehenen Geschehens suggeriert. Der „Effekt einer Verräumlichung des Temporalen“ ergibt sich ferner aus der durchgängigen Verwendung des Präsens, das mit den Vergangenheitstempora des vorausliegenden Erzähldiskurses kontrastiert, sowie aus der Projektion der von Epstein gesehenen Geschichte auf ein von ihm gerade betrachtetes Modell der Stadt Genf. ${ }^{148}$ Auf der Ebene der histoire wird die von Epstein behauptete ,Vollständigkeit‘ seiner Geschichten (Vollständigkeit definiert sowohl als die Total-Ansicht einer Geschichte „vom Anfang bis zum Ende“ als auch als Inbegriff des Möglichen und Wahrscheinlichen) dadurch insinuiert, dass einzelne Orte und Ereignisse des Romangeschehens parataktisch aneinandergereiht werden, darunter auch Situationen, die weder von Epstein erlebt noch überhaupt im Laufe der Romanhandlung thematisiert worden sind und sich deshalb einer chronologischen Zuordnung verweigern. ${ }^{149}$

147 Regn: Nach der Moderne, S. 348.

148 Vgl. ebd., S. 347 u. 348.

149 Zum Beispiel findet die in der Romanhandlung sich anbahnende Liebesgeschichte zwischen Brahe und Gilda in der mise en abyme ihre Erfüllung (,li vede entrambi che dormono“/,er sieht sie beide schlafend“, AO 150 [202]). Entgegen Regns Deutung, dass der „sekundäre handlungsvermittelnde Diskurs“ der mise en abyme „das Ausgesparte retrospektiv ins Bewusstsein“ rücke (Regn: Nach der Moderne, S. 333), scheint es mir gerade im Zusammenhang mit Epsteins neuer Ästhetik plausibler, die mise en abyme nicht nur als eine reduzierte Reproduktion und Retrospektion der erzählten Romanhandlung auszulegen, sondern auch als produktives und prospektives Verfahren der amplificatio im Sinne einer noch nicht erzählten, aber im Kontext der erzählten Handlung möglichen und wahrscheinlichen künftigen Handlung. Dass Epstein (in der Sicht des Erzählers) mehr sieht als er sinnlich wahrgenommen hat, ist ferner Indiz dafür, dass er dem geistigen Sehen eine quasi-metaphysische, eine hellseherische Qualität beimisst. 
Indem der Erzähler aber das poetische Schweigen Epsteins bricht - und Epstein wählt den Weg des Schweigens nicht aus Unvermögen, sondern aus Gründen der Authentizität -, widersetzt er sich gleichsam dem Willen seiner Figur und autorisiert sich als deren literarische Stimme: In der Gestalt einer mise en abyme verfasst er jenen „Romanautorroman“150, den der Romanautor Epstein nie zu schreiben beabsichtigte. ${ }^{151}$ Auf diese Weise macht er den von Epstein etablierten Bruch zwischen geistigem Sehen und narrativem Schreiben wieder rückgängig: Er rehabilitiert das Schreiben und Erzählen von Geschichten. Indem er seine ,Erzählung، als ungebrochene, authentische Wiederholung dessen anzeigt, was Epstein sieht, erhebt er das geistige Sehen zum Fundament seiner narratio; indem er jedoch mit der Erzählaskese Epsteins bricht, dementiert er zugleich die Selbstgenügsamkeit, die Epstein dem geistigen Sehen beimisst - „Non aver bisogno di raccontare è l'unica cosa che incrina la felicità del vedere oltre la forma“ (AO 68) ${ }^{152}$-, und damit die radikalen Konsequenzen, die dieser daraus zieht. Kritisch formuliert der Erzähler - allein dadurch, dass er erzählt - sein Missfallen an einer Ästhetik, die als Theorie einer ins Geistige versenkten Kunst keine Kunst mehr neben sich duldet und in der Folge zu einem Solipsismus des Denkens verpflichtet. Über das narrative, selbstreferentielle Verfahren der mise en abyme hält der Erzähler seinem Helden den Spiegel vor (genauer: der Erzähler suggeriert, dass es Epstein selbst ist, der sich den Spiegel vorhält) und rückt die Schattenseiten dieser ,schwindelerregend selbstreferentiellen' (Lyotard), in den intellektuellen Autismus mündende Ästhetik ins Licht, ohne deren ästhetisches Potential zu negieren. ${ }^{153}$

150 Jutta Zimmermann: Metafiktion im angloamerikanischen Roman der Gegenwart, Trier 1996, S. 53.

151 Eine argumentativ zwar anders unterlegte, im Ergebnis jedoch ähnliche Gegenläufigkeit konstatiert auch Richter: „Das entgrenzende visionäre Sehen, Epsteins Wahrnehmungsprojekt, [...], akzentuiert - innerhalb der histoire - jenen Aspekt des Atlanten, der maximale Zulassung von Kontingenz verspricht. Doch steuert Del Giudice dieser Bewegung auf der Ebene des discours entgegen, indem er der erzählten Welt mittels eines Repräsentationsmodells noch eine Form verleiht. Die Form [...] begründet nicht nur die ethische Dimension seines Schreibens, sie begrenzt auch Kontingenz" (Steffen Richter: Trauerarbeit der Moderne. Autorenpoetiken in der Gegenwartsliteratur, Wiesbaden 2003, S. 220).

152 „Es nicht nötig haben zu erzählen, trübt als einziges das Glück, hinter die Form zu sehen“ (AW 95).

153 Der Erzähler entwirft gleichsam eine dritte Ästhetik, die an Epsteins frühe Ästhetik - und damit an die sinnliche Wahrnehmung der Dinge und ihre komplexe Vernetzung mit den Menschen anknüpft, zugleich aber der postmodernen Verfasstheit der Welt - ihrer Deästhetisierung - Rechnung trägt. Im Grunde synthetisiert er die Ästhetiken Epsteins: Er affirmiert dessen Befund vom „Schwinden der Dinge“ und die damit verbundenen ästhetischen Herausforderungen, doch er negiert die von Epstein gezogene Konsequenz des Schweigens und damit des ,Schwindens` von 
Kunst und Literatur, indem er der deästhetisierten, formlosen Welt mit ästhetischen Mitteln Gestalt verleiht. Für diese Annahme spricht auch, dass er über das reproduktiv-produktive Verfahren der mise en abyme eine Ähnlichkeitsbeziehung zur bisher, im Modus von Epsteins früher Ästhetik erzählten Geschichte herstellt, ja mit der Kategorie der Ähnlichkeit eines der wichtigsten Theoreme dieser Ästhetik appliziert, zugleich aber eine ,postmoderne' Sprache wählt, die den (ihrerseits aus den naturwissenschaftlichen Erkenntnissen resultierenden) Postulaten der neuen Ästhetik - Simultaneität und Wahrscheinlichkeit - gerecht zu werden versucht. Die Gestaltung der mise en abyme folgt damit jenem Gesetz von Identität und Differenz, wie es von Brahe und seinem Team formuliert worden ist. Mit anderen Worten: Sie folgt dem für die Poetik der poetica scientiae charakteristischen Prinzip von Wiederholung (Wiederholung der Romanhandlung, zu deren Bestandteil die poetologischen Diskurse Epsteins gehören) und Transgression (Überschreitung der fiktionsimmanenten Wirklichkeit auf mögliche und wahrscheinliche Wirklichkeiten hin sowie Überschreitung der Diskurse auf eine neue, dritte Ästhetik, zu der wesentlich die kritische Revision der von Epstein vertretenen Ästhetik des reinen Sehens gehört). Diese Beobachtung bestätigt sich vor allem im Hinblick auf die zeitliche Struktur: Sowohl das erzählende Subjekt als auch der erzählte Gegenstand sind in der mise en abyme in einer Vorzukunft verortet. Diese Zeitform wird bereits im vierten Kapitel explizit in einem ganz anderen Zusammenhang eingeführt: Brahe beobachtet seine Kollegin Eileen, die gerade dabei ist, in seinem Auftrag eine Werkzeichnung zu fälschen. „Er [Brahe] trinkt stehend, an das Fenster gelehnt: Die blauen Pünktchen auf dem Entwurf, das Mädchen mit den brünetten, üppigen Haaren, das Licht und die Situation und er selbst erschienen ihm wie Dinge, die er in diesem Augenblick und gleichzeitig in der Zukunft wahrnahm, von der aus er sich an sie würde erinnern können und sich vielleicht doch nicht mehr erinnern würde; von einer Vorzukunft aus“ (AW 49) (,[...] percepite in questo istante e nello stesso tempo da un futuro in cui avrebbe potuto ricordarle e magari non se ne sarebbe ricordato piú, da un futuro anteriore“, AO 34, Hervorhebung B.M.). Während hier Zeit-Erleben und Zeit-Reflexion zusammenfallen, wird Brahe an anderer Stelle von einer „plötzlichen Sehnsucht“ nach dem Standort einer Vorzukunft erfasst (vgl. AW 146). Im sechsten Kapitel, gestaltet als innerer Monolog Epsteins, stellt der Romancier theoretische Reflexionen über die Zeitstruktur der von ihm gesehenen Geschichten an: „Und wie lange dauerte diese Zeit [gemeint ist der Augenblick des Sehens], da doch die äußere Zeit stillstand, Nullzeit [tempo zero, AO 68], und die Zeit im Inneren einer gesehenen Geschichte sich weder nach vorne noch zur Seite bewegte, sondern in alle Richtungen des Raums, der wiederum von der Geschichte bestimmt wurde?“ (AW 94). Alle diese Passagen antizipieren und erläutern das Zeitereignis der mise en abyme (wie im übrigen auch der Epiphanien), wie dieses umgekehrt auf diese ,unscheinbaren` Textabschnitte zurückstrahlt, sie gleichsam in den Rang eigenständiger mise en abymes erhebt, ein Verfahren, das an unzähligen weiteren Beispielen erläutert werden könnte und das den Text als Ganzes in ein wahres Spiegelkabinett wechselseitig sich kommentierender, deutender, rekurrierender Reflexionen und Erlebnisse verwandelt. Dabei folgen die Spiegelungen dem Prinzip von Wiederholung und Transgression, d.h. sie gewährleisten ein Wiedererkennen des/der wiederholten Zeichen(s), ohne jedoch eine semantische Konsolidierung und damit die Übersetzung in eine Bild-Abbild-Relation zu ermöglichen; als iterierende Zeichenkomplexe unterliegen die Spiegel vielmehr einer unaufhörlichen Verzeitlichung, genauer: sie sind der Effekt der „différance als Temporisation“, die jede aktuale, identifikatorische Signifikation und damit auch die Aktualisierung einer Referenz aufschiebt. Nach Derrida setzt dies voraus, „dass das Zeichen, welches die Präsenz aufschiebt (différant), nur von der Präsenz, die es aufschiebt, ausgehend und im Hinblick auf die aufgeschobene Präsenz, nach deren 
Ungeachtet der Frage nach der reliability des Erzählers ${ }^{154}$ - gibt er tatsächlich das wieder, was Epstein sieht oder liefert er dem Leser nicht vielmehr ein Trugbild oder eine Möglichkeit dessen, was Epstein sehen könnte? - wird die mise en abyme vorrangig zu einer Figur der Kritik, die das Abgründige des Epstein'schen Ästhetizismus offen legt. ${ }^{155}$

Wiederaneignung man strebt, gedacht werden kann“ (Jacques Derrida: Die différance, in: ders.: Randgänge der Philosophie, hrsg. v. Peter Engelmann, Wien 1988, S. 29-52, hier S. 35). „Postmodern“, so auch Lyotard, sei „als Paradox der Vorzukunft (post-modo) zu denken“ (Lyotard: Beantwortung der Frage: Was ist postmodern?, S. 48), insofern die postmodernen Künstler bei ihrer Arbeit nicht „durch bereits feststehende Regeln geleitet“ sind, sondern umgekehrt: „sie arbeiten, um die Regel dessen zu erstellen, was gemacht worden sein wird. Daher rührt, daß Werk und Text den Charakter eines Ereignisses haben. Daher rührt auch, daß sie für ihren Autor immer zu spät kommen, oder, was auf dasselbe führt, daß die Arbeit an ihnen immer zu früh beginnt“ (ebd.). Dieses regellose Arbeiten beansprucht auch Epstein für seine narrativen Visionen (vgl. AO 67 [93], wo er die „regole“ als „la forma di ciò che accadeva“, als die „Form der Geschehnisse“ selbst bezeichnet), wobei diese im Unterschied zu Lyotard - ,textloser` Text, ,werkloses` Werk sind, deren materiellen, schriftlichen Generierung sich Epstein ja systematisch verschließt. Vor diesem Hintergrund kann der Aufenthaltsort der Vorzukunft, von dem sich die geschilderten Episoden herschreiben, immer nur aktuell und virtuell zugleich eingenommen werden; entsprechend ist auch das, was sich dort ereignet - die augenblickshafte Restitution des Ursprungs und der Einheit, die Begegnung mit der Sache selbst Wirklichkeit und Fiktion zugleich.

154 Vgl. in diesem Zusammenhang auch Richters Ausführungen zu Del Giudices „Poetik der Wahrscheinlichkeit“, in: Richter: Trauerarbeit der Moderne, S. 198-203; zur quantentheoretischen Fundierung der probabilità in Atlante occidentale, S. $207 \mathrm{f}$.

155 Während, abyme', ein Begriff aus der Heraldik, das Wappen im Wappen bezeichnet und somit den Aspekt der Wiederholung anzeigt, bedeutet ,abime‘ Abgrund; diese Doppelbedeutung ist der im Übrigen von André Gide in die Literatur eingeführten - Figur der mise en abyme im Sinne von „in den Abgrund unendlicher Wiederholung werfen“ eingeschrieben. - Anders deuten Klinkert und - auf ihn rekurrierend - Dilmac das Verhältnis von Erzähler und Figur: Nach Klinkert verschmilzt Epsteins „Bewusstsein mit dem des außerhalb der Geschichte stehenden Erzählers“ (Klinkert: Daniele Del Giudice: Literatur und Erfahrung, S. 301), ein Kunstgriff, mit dem Del Giudice die im Falle einer internen Fokalisierung bzw. eines personalen Erzählens gegebene Richtung der Verschmelzung von Erzähler und Figur umdrehe (vgl. ebd.). Erst durch diese „paradoxe ,mise en abyme“ des Produktionsvorgangs“ (ebd.) wird „das von Epstein erlebte simultane Sehen auch für den Leser erfahrbar“ (ebd., S. 306 f.). Dass jedoch trotz dieser Verschmelzung von Erzähler und Figur zugleich deren Differenz erhalten bleibt, macht auch Klinkert deutlich: „Im paradoxen Verhältnis zwischen Epsteins Verstummen und dem Diskurs des Textes äußert sich der prekäre Status eines Textes, dessen Gegenstand die Grenzen des Sichtbaren und somit letztlich die Nichtdarstellbarkeit sind“ (Klinkert: Die Grenzen des Sehens und der Kommunikation: Del Giudices ,Atlante occidentale‘ und ,Staccando l'ombra da terra', in: ders. Epistemologische Fiktionen. Zur Interferenz von Literatur und Wissenschaft seit der Aufklärung, Berlin, New York 2010, S. 316-325, hier S. 322). 


\subsection{Widerstreit: Moderne Anthropologie und condition postmoderne}

Auch wenn Brahe und Epstein dem Verlust des Empirischen in Wissenschaft, Kunst und Leben mit Faszination, Neugier und Gelassenheit begegnen - „Non ho nostalgia per la scomparsa delle cose“, behauptet Epstein (AO 62) -, so ist beiden jene romantische Sehnsucht der Moderne, die nach Lyotard postmodern überwunden ist, ${ }^{156}$ alles andere als fremd. Dieser sehr unaufdringlich gestaltete Gegendiskurs ist nicht nur auf der Erzählebene, sondern in den Protagonisten Brahe und Epstein selber angelegt. Zweimal ist von Brahes Sehnsucht nach der „solidità degli oggetti“, nach der „Festigkeit der Dinge“ (AO 23 [35]) die Rede. Einmal im Zusammenhang mit seinem eigenen Experiment: Er liegt mit geschlossenen Augen auf dem Bett, wird aber von den ,visualizzazioni con le tracce“ (ebd.), den Bildschirmdarstellungen mit den Spuren, heimgesucht. Ein weiteres Mal im Kontext eines Feuerwerks, ${ }^{157}$ das die Stadt Genf unter Brahes Mitwirkung Epstein zu Ehren organisiert hat: Nachdem das Feuerwerk erloschen ist, gibt Epstein eine ausführliche Beschreibung dessen, was er gesehen hat, und nachdem auch dieses sprachliche Feuerwerk abgeklungen ist, heißt es von Brahe, er versuche

di trattenere le forme che ha appena visto, o creduto di vedere; vorrebbe che gli restassero con la limpidezza con cui le ha percepite mentre ascoltava, vorrebbe che avessero la solidità di un punto esterno contro cui rimbalzare, vorrebbe isolarle una per una, disporle con un certo ordine, toccarle; ma c'è un circuito di assoluta fluidità, di scorrimento veloce, di continua trasformazione nel quale gli sembra di essere immerso, dove è difficile stabilire un qualunque punto fisso; (AO 135) $)^{158}$

156 Vgl. Lyotard: Immaterialität, S. 38.

157 Vgl. hierzu ausführlich Dilmac, die dem Feuerwerk eine „Stellvertreterfunktion für die ausgesparte Darstellung jener Computersimulation“ zuweist, „die Brahes Experiment erfolgreich abschließen wird“ (Dilmac: Literatur und moderne Physik, S. 295 sowie S. 318-321). Zu einer facettenreichen, insbes. den zeitlichen und erzähltechnischen Aspekt berücksichtigende Analyse von Brahes Experiment vgl. ebd., S. 324 f. Zur „Idee der verzweigten Zeit“ vgl. auch Fendt, Wissenschaft und Imagination, S. 68 f. u. S. 72 f.). Dem Lichtspektakel weist Fendt die Funktion einer „Entfaltungsplattform imaginativer Energien“ zu (ebd., S. 86).

158, ,...] versucht Brahe die Formen zu behalten, die er eben gesehen hat oder die er geglaubt hat zu sehen; er möchte, daß sie sich ihm mit derselben Klarheit einprägen, mit der er sie beim Zuhören wahrgenommen hat; er möchte, daß sie die Festigkeit eines äußeren Punktes besitzen, von dem man abprallen kann, er möchte sie der Reihe nach isolieren, sie in einer bestimmten Reihenfolge anordnen, sie berühren; aber da ist ein absolut flüssiger, schnell dahin- 
Der Wunsch - durch den syntaktischen Parallelismus in seiner Eindringlichkeit gesteigert -, den imaginär gesehenen Bildern Festigkeit und Stabilität zu verleihen, sie als Bilder $\mathrm{zu}$ isolieren und $\mathrm{zu}$ ordnen, die non-cose gleichsam in cose zurückzuverwandeln und sie als objektives Gegenüber im Außenraum positioniert zu wissen, ist hier weder ästhetisch noch naturwissenschaftlich motiviert, sondern anthropologisch: Er ist Symptom der Überforderung angesichts einer im Schwinden begriffenen, sich (buchstäblich) liquidierenden Wirklichkeit, aus der es offenbar kein Entrinnen gibt (die parallelistisch erzeugte Spannungssteigerung wird durch das adversative „ma“ jäh unterbrochen und in ihr krasses Gegenteil, die Ernüchterung, verkehrt). Es ist Brahe selbst, der für dieses ,metaphysischlogozentrische' Verlangen an anderer Stelle eine evolutionstheoretische Begründung liefert: Alles, die unsichtbaren Vorgänge im Experiment eingeschlossen, wäre auf natürliche Weise sichtbar, hätte sich nicht im Laufe der Phylogenese „una misura standard della percezione e della sensibilità“, ein „Standardmaß der Wahrnehmung und Sensibilität“ entwickelt (AO 106 [143]), entwickelt möglicherweise sogar dadurch, dass Atom- und Schwerkraft einst zwar zu den menschlichen Sinnesvermögen zählte, jedoch ,an irgendeinem Punkt der Evolution zugunsten der Standardwahrnehmung geopfert" worden war (sacrificato in chissà quale punto dell'evoluzione, AO 145 [195]) und gegenwärtig nur durch eine gigantische Prothese wie den Detektor substituiert werden kann. ${ }^{159}$ Werden in diesen Passagen Mensch und Technik in ein Kontinuum gebracht - die Technik, die jene dem Menschen widerfahrenen Evolutionsschäden kompensiert, erscheint als die sinnliche Linienverlängerung des sinnamputierten Menschen -, so markiert die Sehnsucht nach einer der Standardwahrnehmung adäquaten ,standardisierten“ Welt einen Bruch zwischen Mensch und Technik, natürlicher und virtueller Wahrnehmung: Der sinnlich wahrnehmende Mensch hinkt in seiner phylo- wie ontogenetischen Entwicklung gewissermaßen der von ihm selbst produzierten technologischen Wahrnehmungsmaschinerie und deren Rückwirkungen auf die natürliche, gleichwohl immer auch theoretisch mitgeprägte Sinneswahrnehmung hinterher. Und, sofern man Brahes evolutionstheoretische Vermutungen ernst nimmt: Der Mensch lässt sich offenbar nicht nahtlos an eine frühere Evolutionsstufe anschließen. Wenn Epstein seinen Freund Brahe anfangs einmal einen „Metaphysiker“ nennt, hat er damit nicht ganz unrecht: Nicht ohne Bewunderung

strömender, in ständiger Veränderung begriffener Kreislauf, in den er eingefügt zu sein scheint und in dem es schwierig ist, einen Fixpunkt auszumachen“ (AW 181).

159 Der wissenschaftlich-technologische Fortschritt kompensiert die durch die Evolution verursachten Opfer und Verluste; es ist ein vergangenheitsorientiertes Fortschreiten mit dem Ziel, Erkenntnisse über den Ursprung der Welt zu gewinnen. 
und Respekt nämlich denkt Brahe an dieses Standardmaß der Wahrnehmung „come al senso comune, alla sua straordinaria forza e confortevolezza e intolleranza“ (AO 106), wie an einen zwar eingeschränkten, aber in seinen Kräfteverhältnissen äußerst ausgeglichenen und damit funktionstüchtigen Gemeinsinn, einen, wie es in der Übersetzung treffend heißt, „Hausverstand“, der es dem Menschen möglich machte, sich in der Welt und in Übereinstimmung mit der Welt einzurichten. ${ }^{160}$ Die Sehnsucht, von der Brahe gelegentlich erfasst wird, ist eine Form der Trauer über die - auch metaphysische - Unbehaustheit.

Die Aporie, in die Epsteins Experiment einer neuen Ästhetik mündet, wurde dahingehend beschrieben, dass eine adäquate und authentische ,Darstellung der non-cose nurmehr im entsinnlichten, rein geistigen Sehen möglich ist, seine neue Ästhetik also letztlich gegen Kunst und literarische Sprache überhaupt zielen muss. In seinem geplanten Vorhaben, einen „Atlante della luce“ zu verfassen, deutet sich jedoch eine Gegendiskursivität zu dieser radikal mit der Literatur brechenden Ästhetik an, ein Selbstwiderspruch, der zwar nicht zu einer Relativierung seiner Position - etwa im Sinne des Erzählers - führen wird, sehr wohl jedoch deren anthropologische Problematik sichtbar macht. Einen versteckten, nur ganz leise anklingenden Hinweis darauf, dass auch Epstein den Verzicht auf die (poetische) Sprache als eines elementaren Aspekts des menschlichen Wohnens in der Welt potentiell mit der Gefahr von Schutzlosigkeit und Unbehaustheit assoziiert, findet sich im letzten Abschnitt des siebten Kapitels: Geschildert werden die Eindrücke, die Brahe bei der Lektüre eines von Epstein verfassten Romans hat. ${ }^{161}$ Am Ende wird der Satz eines Protagonisten dieses Romans zitiert, ein Satz, der das Ende der frühen Ästhetik und damit das Ende von Epsteins literarischem Schaffen antizipiert, und deshalb als eine gedankliche Projektion des Autors Epstein auf die von ihm erzählte Figur gedeutet werden kann: „,Lui [Epsteins Ro-

160 Eine ganz ähnliche Forderung nach Normalität formuliert Brahe nach der Entdeckung der neuen Teilchen: „ihm schien [...], daß Sehen nichts anderes bedeutete, als die Schwelle des Unsichtbaren ein wenig zu verschieben (che vedere significasse solo spostare un po' in là la soglia del non visibile, AO 146), sie mit einem einzigen Lidschlag abzureißen und wieder zu errichten, und ihm schien, eine Maschine, die so groß war, eine Geometrie, die derart kompliziert, und eine Mathematik, die derart komplex war, daß das wahre Problem in der andauernden Normalisierung des Unendlichen (rinormalizzare continuamente l'infinito, AO 146) bestand, würden dabei helfen, strenge und konsequente Fragen zu stellen, die man solidarisch und konsequent beantworten musste“ (AW 197).

161 In diesen Eindrücken - und hier wäre ein weiteres Beispiel für die zahllosen Parallelisierungen und Spiegeleffekte des Romans - bestätigt sich, was Epstein selbst über seine frühere Ästhetik gesagt hatte, letztlich also der unabdingbare Zusammenhang von Poetik und Poesie, die gelungene Übersetzung der Regeln der Kunst in das literarische Werk. 
manheld] sapeva che non avrebbe piú potuto accucciarsi tra le parole come un animale nella tana““ (er wußte, daß er sich nicht mehr zwischen die Wörter kauern konnte wie ein Tier in seinen Bau, AO 81 [111]). Doch in eben diesen „Bau“ der Sprache, der nach Epsteins neuer Ästhetik seine Funktion als oikos des Menschen eingebüßt hat, nimmt Epstein mit seinem Atlas-Projekt Zuflucht:

Scriverò un Atlante della luce, forse sarà l'ultimo cosa che scriverò... [...] Lo scriverò soltanto per me, un libretto da portarmi appresso, in tasca. Lo userò come gli ornitologi usano quelli per riconoscere e distinguere gli uccelli, o come i geografi usavano le carte. Certe volte mi sembra che la geografia sia la scienza piú fondamentale, legata com'è alla terra per via del nome, e cosí legata alle persone per via dell'orientamento... Forse il vero centro del pensiero e del sentimento è nell'orecchio, dove ci sono gli ossicini dell'equilibrio... Chissà, [...] forse alla fine imparerò una geografia diversa, in cui uno, sollevando gli occhi dalla carta che ha in mano, guarda e vede davanti a sé, attorno a sé, un'enorme carta a grandezza naturale, e nonostante questo è capace di mettere il dito in un qualsiasi punto e dire „qui“ e dire „io“... (AO 138)

Epsteins Atlas-Projekt ist ein solipsistisches - sein Autor adressiert es an sich selbst - und nicht ein auf Kommunikation und Dialog mit anderen gerichtetes. Dennoch handelt es sich bei diesem Vorhaben um ein Schreibprojekt und damit um ein heimliches Vergehen an dem von Epstein selbst etablierten und autorisierten ,anästhetischen' Gesetz der poetischen Sprech- und Schreibaskese. ${ }^{163}$ In dem Wunsch, das Licht - „la cosa piú comune [...] eppure [...] la piú privata“ (AO 137 [184]), vor allem aber das schnellste, flüchtigste, wandelbarste und

162 „Ich werde einen Atlas des Lichts schreiben, vielleicht ist es das letzte, was ich schreibe... [...] Ich werde ihn nur für mich schreiben, ein Brevier, das ich immer bei mir in der Tasche trage. Ich werde es so benutzen, wie die Ornithologen die Handbücher benutzen, mit deren Hilfe die verschiedenen Vögel bestimmt und unterschieden werden, oder wie die Geographen ihre Karten benutzen. Manchmal habe ich den Eindruck, die Geographie sei die grundlegendste aller Wissenschaften, da sie schon aufgrund ihres Namens so sehr an die Erde gebunden ist, und an die Menschen aufgrund der Orientierung... Vielleicht liegt das wahre Zentrum des Denkens und Fühlens im Ohr, wo die Gleichgewichtsknöchelchen sind... Wer weiß, [...] vielleicht werde ich am Schluß eine andere Geographie erlernen, bei der man, wenn man den Blick von der Karte in der Hand erhoben hat, um sich blickt und vor sich und rund um sich eine riesige Karte in natürlicher Größe sieht und trotzdem in der Lage ist, den Finger auf einen bestimmten Punkt zu legen und ,hier‘ und ,ich‘ zu sagen..." (AW 185).

163 Als Epstein sein Atlas-Projekt gegenüber Brahe ankündigt, blickt ihn dieser überrascht an, woraufhin Epstein lächelnd den Kopf schüttelt und erklärt, dass er den Atlas nur für sich selbst schreiben wird. Brahes Blick kann übersetzt werden: ,Sie werden also doch wieder schreiben?', ebenso Epsteins Reaktion: ,Nein, ich bleibe meinem Experiment treu, ich schreibe den Atlas nur für mich selbst, werde ihn in die Tasche stecken, verstecken und ihn vor anderen verbergen'. 
diffuseste aller Dinge - kartographisch $\mathrm{zu}$ vermessen und in seinen für den Menschen unendlichen phänomenalen Ausprägungen $\mathrm{zu}$ ordnen, $\mathrm{zu}$ differenzieren und sprachlich festzuhalten, spiegelt sich die Kehrseite jener im Schwinden begriffenen, unendlich vervielfältigten, partikularisierten und atomisierten Welt als ein unbeherrschbares Chaos, innerhalb dessen dem seinerseits nicht mehr identifizierbaren Subjekt jegliche Orientierung abhanden gekommen zu sein scheint. ${ }^{164}$ Epstein projiziert an dieser Stelle die physikalische Doppelnatur des Lichts in die ebenso ethisch wie erkenntnistheoretisch aufgeklärt-modern konnotierte Semantik von ,Licht' und ,Finsternis‘: Die allgegenwärtige Herrschaft des Lichts - „una cosa fuori misura, fuori del tempo, ovunque nello spazio, non circoscritta, senza solidità“ (ein Ding, für das es kein Maß gibt, das außerhalb der Zeit ist und überall im Raum, das keine Grenzen kennt und keine Festigkeit; AO 137 [184]), das die Konturen der Wirklichkeit und mit ihnen die Möglichkeit sinnlicher Wahrnehmbarkeit und ästhetischer Gestaltbarkeit ,absorbiert - führt in eine Dunkelheit, der (zumindest solange, bis aus der neuen Wirklichkeit der non-cose die neuen Tatsachen und mit ihnen die neuen Wahrnehmungs-, Erkenntnis-, Seinsweisen hervorgegangen sein werden; vgl. AO 146 [195 f.]) nur über eine zeichenhafte und wie auch immer ästhetisch und aisthetisch vermittelte Ordnung beizukommen ist. Liest man die von Epstein getroffene Feststellung, dass das Licht stets dasselbe bleibe und nur die Gefühle es seien, die sich verändern (,la luce resta sempre uguale a se stessa, cambiano soltanto i sentimenti“, AO 137 [184]), im Zusammenhang mit seiner Angst, mit dem Schwinden der Dinge könnte ihm auch das Gefühl abhandenkommen (AO 62 [87]), dann erscheint seine Sicht auf die Postmoderne als eine zutiefst ambivalente: So sehr er die Buntheit, Vielfalt und Leichtigkeit der immaterialen Wirklichkeit begrüßt, so kritisch wendet er sich auch gegen eine Postmoderne, deren Differenzierungsmanie in die Uniformierung von Denken und Fühlen zu kippen droht. ${ }^{165}$ Der Maßlosigkeit des Lichts setzt Epstein die kartographische

164 Vgl. hierzu auch Richter: Trauerarbeit der Moderne, S. 211 f.: „Wer wie die versierten Hobbypiloten Brahe und Epstein seine Identität gemäß dem Modell der Navigation - also relational zu den umgebenden Objekten - bestimmt, wird in einer Welt des Übergangs dieser Objekte in Dinge des Lichts die größte Schwierigkeit geraten, noch Ich zu sagen.“

165 Zur Abgrenzung der „veritablen Postmoderne“ von der „postmodernen Einäugigkeit“ einer „Pseudo-Postmoderne“ vgl. Wolfgang Welsch: Die Postmoderne in Kunst und Philosophie, S. 48-49 u. 59-61. - In diesen Kontext müsste Brahes und Gildas Besuch des Schloss Voltaire einbezogen werden. Der Führer, kein anderer als der zukünftige Erbe des Schlosses, genealogisch also zum Stammbaum Voltaires gehörend, zeigt sich als typischer Repräsentant der Aufklärung (vgl. das Candide-Zitat, AW 149). Die völlige Dunkelheit, die im Schlossinneren herrscht, die Beschreibung, wie Brahe und Gilda sich in der Dunkelheit des Raumes über Tast-, 
Vermessung des Lichts entgegen - und behauptet sich damit, wie virtuell auch immer, als Autor(ität).

Unter der Prämisse, dass alles Materielle in seiner elementarsten Form als nicht-dinghaft und damit als reine Licht-,Substanz' erscheint, das Licht also Integral für schlechterdings alles ist, erweist sich Epsteins Vorhaben, einen „Atlas des Lichts“ zu verfassen, als ein enzyklopädisches Projekt. Indem Epstein überdies die mannigfaltigen qualitativen Erscheinungsweisen des seiner Natur nach immer gleichen Lichts ursächlich an den - seinerseits durch das Schwinden der Dinge bedingten - Wandel der menschlichen Gefühle und Perzeptionen rückbindet, charakterisiert er seinen „Atlas des Lichts“ zugleich als einen Atlas menschlicher Emotionen und Wahrnehmungsweisen. Thema des Atlas wäre demnach das immaterielle Licht, in das alles Materielle transformiert und das untrennbar mit den immateriellen Gefühlen und Wahrnehmungen verschränkt ist. Was es kartographisch und enzyklopädisch zu erfassen gälte, wäre das eine Ding ,Licht' in seiner pluralen und polysemantischen Phänomenologie, die zugleich einer Phänomenologie der Wahrnehmungen und Empfindungen entspräche. Ins Linguistische übersetzt würde dies die qualitative Erfassung des einen Substantivs ,Licht' mittels unendlich vieler Adjektive bzw. Attribute bedeuten (vgl. AO 137 [184]). Die Korrelation von Lichtattributen und Empfindungen ist jedoch keine generalisierbare, sondern eine zutiefst individuelle: Im Akt der Kommunikation bzw. im Akt des Lesens würde sich jedes dem Licht zugeschriebene Attribut seinerseits in eine Pluralität der Vorstellungen disseminieren und dadurch letztlich seine Klassifikations-, Beschreibungs- und Orientierungsfunktion einbüßen (vgl. AO 137 [184]). Die „schwindelerregende

Gehör- und Geruchssinn orientieren (die Umkehrung der Sinneshierarchie, die Ausschaltung des Gesichtssinns als aufklärerische Metapher für die Vernunft), die metaphorische Wegsemantik („es gibt keinen Anhaltspunkt mehr für den Rückweg“, AW 150) und schließlich das restlos entfernte, weil verlorengegangene und „immer weniger gebrauchte“ Mobiliar, von dem nur noch „Spuren“ an Wänden und Tapeten zeugen, all dies zeigt das Ende der Aufklärung an. Die Fensterläden, so der Führer, müssten wegen der Möbel geschlossen bleiben, genauer: wegen des „Abdrucks“, des „Umrisses“ und der „Spuren“, welche die Möbel auf den Wänden und Tapeten hinterlassen haben, „denn das Licht könnte mit der Zeit alles gleichmachen, den Abdruck der Gemälde und Schränke tilgen, und Stofftapeten und Wände würden einheitlich gelb werden, so daß man keine Spuren mehr sehen würde“ (AW 152). Im Namen der Aufklärung wird hier das Licht - zentrale Metapher der Aufklärung - ins Negative verkehrt: Das Licht der kritisch-differenzierenden Vernunft hat sich - so die Einschätzung des Voltaire-Erben gewandelt in einen universalen Licht-,Immaterialismus', der die Vernunft unter die Herrschaft der Technik stellt und sie zur Blindheit verdammt. Entsprechend ist der Führer auch der einzige, der sich kritisch über das CERN äußert: Eines Tages, so heißt es, werde ihm das ganze Anwesen gehören, „wenn die vom Ring nicht alles in die Luft jagen“ (AW 149). 
Selbstreferentialität“" (Lyotard) des Lichts würde zwangsläufig auf das Schreiben und Lesen des Atlas übergreifen. ${ }^{166}$

Mit seiner Wahl der ,Text'-Sorte „Atlas“ knüpft Epstein gattungspoetologisch an sein Erstlingswerk Atlante delle andature (Atlas der Gangarten, AO 58 [82]) an und setzt ferner das professionelle Erbe seines Vaters - „mio padre era un geografo“ (AO 123 [165]) - fort. Definiert als eine „Zusammenstellung von Karten in Buchform oder eine Folge von Einzelkarten, die eine sachliche Einheit bilden“, ${ }^{167}$ ist der Atlas durchaus mit einem enzyklopädischen Wörterbuch vergleichbar, das in der alphabetischen Reihung von Einzelartikeln die einheitliche Ordnung des Wissens oder eines Wissensgebiets abbildet. Ihrem epistemischen Inhalt, aber auch ihrem auf Bildung und Wissensvermittlung gerichteten Zweck entsprechend, werden sowohl Atlanten als auch Enzyklopädien vorrangig mit wissenschaftlichen Schreib- und Darstellungsweisen, also mit solchen Formen rationaler Wissenskonfiguration assoziiert, die auf Definition, Klassifikation und Systematik ausgerichtet sind. Wenn der Romancier Epstein auch wissenschaftliche Darstellungs- und Gattungsformen bedient, so steht zu vermuten, dass er an jene neuzeitlich-aufgeklärte Tradition der ,artistischen Enzyklopädie“ anschließt, die „an der Möglichkeit einer Trennung von mathesis und poiesis gerade zweifelt“ und die Literatur nicht als „,das Andere“ des Wissens, die Sphäre außerhalb seiner Ordnungs- und Begriffswelten“ ausgrenzt, sondern sie - „gerade als Schreibweise“ - als ein „Dispositiv des Wissens“ anerkennt. ${ }^{168}$ Für diese Annahme einer wie auch immer konkret gestalteten Verschränkung von Literatur und Wissenschaft sprechen mehrere Indizien. Zunächst sind es die exotischen, in wissenschaftlicher Perspektive keine eigenständigen disziplinären Wissensgebiete formatierenden Themen der Epstein'schen Atlas-Projekte: Sowohl die „Gangarten“ als auch das „Licht“ werden durch die ,atlantisch-

166 Er könnte, so Epstein gegenüber Brahe, von jeglichem Typ Licht erzählen, doch würde Brahe sich sicher ein anderes vorstellen als er selbst (AW 184). In dieser Unmöglichkeit, das Licht qualitativ so zu erfassen, dass die Beschreibungen ähnliche oder gar identische Vorstellungen bei einem anderen hervorrufen, liegt auch der ganz pragmatische Grund für Epsteins Vorhaben, den Atlas nur für den Eigengebrauch zu verfassen. Der Atlas wäre zwar für andere durchaus lesbar, doch wären diese Lektüren aufgrund der fehlenden phänomenologischen Vergleichsmöglichkeiten radikal partikularisiert und singularisiert und damit nicht mehr integrierbar in einen gemeinsamen Vorstellungs-, Kommunikations-, Deutungs- und Orientierungszusammenhang.

167 Heinz Musall: Art. „Atlas“, in: Lexikon der Geographie in vier Bänden, Bd. 1: A bis Gasg, hrsg. v. Ernst Brunotte, Hans Gebhardt u.a., Heidelberg, Berlin 2001, S. 88.

168 Andreas B. Kilcher: mathesis und poiesis. Die Enzyklopädik der Literatur 1600 - 2000, München 2003, S. 18 u. 19. 
enzyklopädische‘ Darstellung gleichsam vom Rang eines Phänomens und Begriffs in den Rang einer Disziplin erhoben; entsprechend verlangt ihre adäquate Erfassung nicht mehr die Teilform des Artikels oder der Einzelkarte, sondern das Ganze einer Enzyklopädie oder eines Kartenwerks. Ein weiterer Hinweis auf den Synkretismus von Literatur und Wissenschaft ist Epsteins Hervorhebung der Geographie als der grundlegendsten aller Wissenschaften: Gleichermaßen an die Erde und die Menschen gebunden ist die Geographie eine ,Interdisziplin“ mit natur- und humanwissenschaftlicher Ausrichtung, die sich mit der „Erdoberfläche in ihrer räumlichen Differenzierung, ihrer physischen Beschaffenheit sowie als Raum und Ort des menschlichen Lebens und Handelns“ beschäftigt. ${ }^{169}$ In der Konnexion von Mensch- und Dingwelt, von nomologischen und ideographischen Erkenntnisinteressen, von positivistischen und hermeneutischen Methoden sowie von begrifflichen und ikonisch-symbolischen Ausdrucksmit$\operatorname{teln}^{170}$ weist die Geographie eine unübersehbare Affinität zu Epsteins früher Ästhetik, vor allem aber - wie noch zu zeigen ist - zur Ästhetik des Romans auf. - Die Bezeichnung seiner Atlanten als „sillabario“, der wie ein ornithologi-

169 Hans H. Blotevogel: Art. „Geographie“, in: Lexikon der Geographie in vier Bänden, Bd. 2: Gast bis Ökol., hrsg. v. Peter Meusburger u.a., Heidelberg, Berlin 2002, S. 14. Die von Epstein angesprochene Doppelbindung der Geographie an Erde und Menschen entspricht der Zweiteilung der Geographie in die naturwissenschaftliche Physische Geographie einerseits, in die gesellschafts- und kulturwissenschaftlich ausgerichtete Humangeographie andererseits. Entsprechend dieser Differenzierung folgt die Physische Geographie dem methodologischen Prinzip, „dass der reale Gegenstand der Geographie (Ausschnitte der Erdoberfläche usw.) unabhängig vom Beobachter existiert und wahr und unverzerrt in den Ergebnissen der wissenschaftlichen Arbeit (Texte, Karten usw.) repräsentiert werden soll“, während die $\mathrm{Hu}$ mangeographie, ,deren Gegenstände immer (auch) der sozialen und geistigen Welt angehören und insofern nicht als außerhalb unseres Denkens und unserer Sprache existent angenommen werden können“, ihre Ergebnisse als „Rekonstruktion“ und „Repräsentation“ begreift, „die einerseits von ihrem realen Gegenstand, andererseits von den [...] Erkenntnisvoraussetzungen der Geographen bestimmt wird“ (ebd., S. 16). Der Zusammenführung der beiden relativ eigenständigen Zweige in einer ,übergreifende[n] ökologischen Betrachtungsweise des GesellschaftUmwelt-Verhältnisses“ (ebd., S. 15) ebenso wie einer „wertorientierten geographischen Bildung, in deren Zentrum neben dem geographischen Wissen die geographische Handlungskompetenz steht“ (ebd., S. 16), kommt aufgrund der menschlichen Eingriffe in die natürliche Umwelt zunehmende Bedeutung zu.

$170 \mathrm{Zu}$ den wichtigsten kartographischen Zeichen gehören Positions-, Linear- und Flächensignaturen, aber auch ikonische Signaturen, deren Ikonizitätsgrad „,von abstrakt-geometrisch bis assoziativ-bildhaft“ reicht, sowie symbolische und indexikalische Signaturen. In der Legende werden die Kartenzeichen „mit dem zugehörigen Begriff identifiziert bzw. verbal erläutert“ (vgl. Wolf G. Koch: Art. „Kartenzeichen“, in: Lexikon der Geographie in vier Bänden, Bd. 2, S. 214). 
sches Handbuch oder eine geographische Karte $\mathrm{zu}$ benutzen sei, vernetzt seine Atlas-Projekte mit dem geradezu leitmotivischen Vorkommen von Ordnungssystemen, allen voran dem Alphabet. ${ }^{171}$ Dieses dritte Indiz dafür, dass die AtlasProjekte einer poetica scientiae zuzurechnen sind, indiziert ebenfalls eine Kontinuität mit seiner frühen Ästhetik - und damit ein gegendiskursives Moment zu seiner Ästhetik des reinen Sehens - und verknüpft ein weiteres Mal den literarischen Diskurs des Romans mit dem naturwissenschaftlichen.

Mit der Einführung des Alphabets als eines „enzyklopädischen Schreibparadigmas“ - als einer „literarischen Praxis der Enzyklopädie“ - wird die „Ordnung der Dinge“ (im Sinne des systematisierten Wissens) der „fragmentarischen und arbiträren Ordnung der Sprache überantwortet“, ${ }^{172}$ dies mit dem Effekt, dass das Wissen selbst eine Versprachlichung und Arbitrarisierung erfährt. ${ }^{173}$ Im Roman ist es Brahe, der auf diesen Zusammenhang unmissverständlich hinweist, wenn er die wissenschaftlichen und erst Recht populärwissenschaftlichen Bilder von Dingen, die sich jeglicher Form der Repräsentation verweigern, als gleichsam phantasmatographisch erzeugte imagines entlarvt, „die sich im Hinblick auf die Dinge so willkürlich und allmächtig verhielten wie das Alphabet“ (,arbitrarie e potenti [...] come un alfabeto“, AO 79 [109]). Wie beim Alphabet handelt es sich bei diesen Bildern um eine „Ordnung der Unordnung“, eine „nichtmotivierte Ordnung“, die, obzwar in ihrer Arbitrarität ungeordnet und bedeutungslos - „sie löscht alles aus, verdrängt alle Herkunft“174 -, dennoch einen Zusammenhang in der Abfolge der Buchstaben von A bis Z bzw. in der Schichtung eines Sandwiches (vgl. AO 79 [109]) suggeriert und dazu verleitet, „die atomisierten Fragmente erneut zu einer Totalität zu synthetisieren und Nachbarschaften und Sinnbezüge herzustellen“. ${ }^{175}$ Und wie für die Alpha-

171 Vgl. noch einmal AO 60 [84], 71 [98], 86 [117].

172 Kilcher: mathesis und poiesis, S. 178. Die Säkularisierung des Wissens ist die wissenschaftsgeschichtliche Voraussetzung dieses „geradezu kopernikanische[n] Paradigmenwechsel[s] in der Schreibweise der Enzyklopädie“: „Als Säkularisierung des Wissens nämlich erweist sich der Wechsel von einem metaphysisch und ontologisch disponierten Wissen, das sowohl die theologisch zentrierte Enzyklopädik des Mittelalters als auch die rationale Enzyklopädik der Frühen Neuzeit regulierte, zu arbiträren Wissensformen seit dem letzten Drittel des 17. Jahrhunderts“ (ebd.).

173 Vgl. ebd., S. $178 \mathrm{f}$.

174 Diese und die vorausgehenden Formulierungen aus Roland Barthes: Über mich selbst, München 1978, S. 160, hier zitiert nach Kilcher: mathesis und poiesis, S. 200, der sich ausführlich mit Barthes Theorie des Alphabets im enzyklopädischen Zusammenhang auseinandersetzt.

175 Kilcher: mathesis und poiesis, S. 200. Mit dem Hinweis auf die Arbitrarität des Alphabets negiert Brahe erneut den repräsentativen Status wissenschaftlicher Abbilder; darüber hinaus 
betisierung der Enzyklopädie, so ist auch für ikonographisch oder kartographisch gestaltete Atlanten das Kriterium der „Nützlichkeit“ bestimmend: „Die Wahrheit im Gehalt weicht der Nützlichkeit in der Darstellung des Wissens. “176 Die ausgewiesene ,Benutzerfreundlichkeit“ von Atlanten und Enzyklopädien hängt damit aufs engste zusammen: Die Arbitrarität der alphabetischen und kartographischen Aufschreibe- und Darstellungspraxen und der dadurch hervorgetriebene Effekt einer Arbitrarisierung und Partikularisierung sowohl des Textes als auch des Wissens bedingt den Wandel im Lektüreverhalten vom ,linearen' Lesen zum Nachschlagen. ${ }^{177}$

Mit seinem Vorhaben, einen „Atlas des Lichts“ zu schreiben, reagiert Epstein auf seine eigene Sicht auf die Welt als einer in die Immaterialität des Lichts aufgelösten. Diese konturlose, formjenseitige, rein geistige Welt, der keine natürliche Außenwelt mehr entspricht, ist jene Geosphäre, die es kartographisch abzubilden gilt. Sein „Atlas des Lichts“ ist damit ein Atlas, dessen Gegenstand die Geographie seines Geistes ist und der deren Mangel an Formen, Konturen und Differenzen kompensieren soll. Intendiert als Gegenprojekt zum theoretisch-abstrakten „Sehen jenseits der Formen“, zielt das kartographische Schreiben darauf ab, die Welt des Geistes zu ,erden“, sie also physiognomisch zu dimensionieren, zeichenhaft nach außen zu projizieren, ihr ein geographisches Design zu verleihen, sie ganz buchstäblich $\mathrm{zu}$ designieren und sie auf diese Weise wieder für eine sinnliche Anschauung und sprachlich-hermeneutische Erfassung zu öffnen. Epsteins Vorhaben entspringt dem Wunsch, gegen das „Schwinden der Dinge“, gegen ihre Immaterialisierung ins rein Abstrakte anzuschreiben, indem er die non-cose zeichenhaft (in der Materialität des Sprachkörpers) zu rematerialisieren und in der

erinnert er abermals den Bildherstellungsprozess, denn digitale Bilder „sind im Wortsinn, unter Verwendung eines Alphabets, geschriebene Bilder“ (Grube: Digitale Abbildungen, S. 188). Dabei geht Grube von einem „notationellen Schriftbegriff“ aus, der (im Unterschied zum reduzierten „phonographischen Schriftbegriff“) das „Spezifische der Schrift“, nämlich ihre „Operativität“ berücksichtigt. Entsprechend fungiert hier der Terminus „Alphabet“ als Oberbegriff für eine Pluralität von Schriftcodes und umfasst z.B. auch „Notenschriften, Tanzschriften und mathematisch-logische oder formale Schriften“ (ebd., S. 188 f.).

176 Kilcher: mathesis und poiesis, S. 227. Das Kriterium der Nützlichkeit rückt das Kriterium der Wahrheit in den Hintergrund: „Das Alphabet organisiert ein Wissen, das nicht mehr ontologisch und rational, sondern praktisch und pragmatisch ist. Als entscheidendes Kriterium der Alphabetisierung der Enzyklopädie wurde deshalb die Nützlichkeit hervorgehoben, und eben nicht mehr eine wie auch immer metaphysisch verstandene Wahrheit“ (ebd., S. 216).

177 Vgl. ebd., S. 227, v.a. 265-275. - Atlanten und Enzyklopädien stehen von jeher im Dienst von Bildung und Ausbildung, was sich im Falle der Enzyklopädie nicht zuletzt in ihrer etymologischen Verwiesenheit auf die paideía im Sinne der Lehre, Ausbildung und Erziehung spiegelt. 
Topographie der atlantischen Karten $\mathrm{zu}$ verorten intendiert. ${ }^{178}$ Dieser Absicht wohnt auch ein wissenschaftskritisches Moment inne, geht es doch nicht zuletzt auch darum, den unendlich kleinen Maßstab, mit dem die Technowissenschaften operieren, um Informationen über das äußerst Große zu gewinnen, wieder auf einen menschlichen, sinnen- und sinngerechten Maßstab zu bringen. ${ }^{179}$ Diese kartographische ,Rettung der Phänomene' geht notwendig mit Prozessen der Ästhetisierung einher: mit einer Re-Aisthetisierung im Sinne der Wiederversinnlichung einer sinnlich nicht mehr wahrnehmbaren, sinnlich enteigneten Welt, mit einer Re-Ästhetisierung im Sinne der vorübergehenden Aufhebung jenes von Epstein erklärten programmatischen Endes von Kunst und Literatur, vor allem aber im Sinne der bildhaft-kartographischen Darstellung des Undarstellbaren und der fiktionalen Erzeugung von Dingen, die es als Dinge nicht (mehr) gibt. Nicht zuletzt verweist der kartographische Darstellungsmodus auf einen Begriff des Schönen, der sich vom klassischen Ideal der Ordnung, der geregelten Relation und Übereinstimmung der Teile zu einem Ganzen und der Symmetrie her bestimmt ${ }^{180}$ und sich darin mit dem naturwissenschaftlich-mathematischen Verständnis von Schönheit trifft. Das rein formal definierte Schöne ist hier jedoch

178 Das Atlas-Projekt ist durch die Paradoxie gekennzeichnet, dass der von jeder Sinnlichkeit abstrahierten geistigen Welt über das seinerseits abstrahierende Schreibverfahren der Kartographie eine konkret-sinnliche Gestalt gegeben werden soll. Diese kartographisch und damit virtuell erzeugte konkrete Gestalt ist Abstraktion der Abstraktion, weist also, obwohl sie die gestalthafte Annäherung an die natürliche Welt bedeutet, einen höheren Abstraktionsgrad auf als jene abstrakte Welt des Geistes, deren Abbildung sie ist. Wollte man - entgegen seiner ,Ästhetik ohne Kunst und Literatur ‘ - Epsteins ,Sehen jenseits der Form‘ bildhaft darstellen, wäre dies nur in der abstrakten ,Form‘ eines weißen Blattes bzw. einer weißen Fläche denkbar. Die kartographische Übersetzung dieser weißen Fläche wäre dann die Auflösung der ,NichtFarbe‘ Weiß in ihre farblichen ,Bestandteile‘. Abstraktion bezeichnet hier also, um auf ein Bild Epsteins zurückzugreifen, einen Vorgang der Re-Positivierung des Negativs (das Weiß, das Licht, das Negativ als Inbegriff aller Farben und aller Möglichkeiten).

179 Vgl. dazu auch Lyotard: Immaterialität, S. 82.

180 Wesentliches Kennzeichen eines geographischen Atlas ist, „dass die Karten hinsichtlich Format, Begrenzung, Maßstäben, Inhalt und Graphik aufeinander abgestimmt sind“ (Musall: Art. „Atlas“, S. 88). Analog gehören zu den Merkmalen einer Karte, definiert als ein „abstrahierendes und zugleich anschauliches Modell aus graphischen Zeichen“: die mathematisch definierte, nie verzerrungsfreie Verebnung (Kartennetzentwurf) und Verkleinerung (Maßstab), eine hohe Anschaulichkeit infolge der geometrischen Ähnlichkeit zur Erdoberfläche und der damit verbundenen Wahrung von Lagebeziehungen, die Verwendung graphischer Zeichen (= Kartenzeichen) und spezifischer Methoden der graphischen Abstraktion, mit der eine begriffliche Abstraktion einhergeht und schließlich die Verwendung von benennender und erklärender Schrift (geographische Benennungen, Namen, Zahlen). Vgl. Konrad Großer: Art. „Karte“, in: Lexikon der Geographie in vier Bänden, Bd. 2, S. 207-208. 
weder Spiegel einer schönen Natur noch Kennzeichen einer autonomen schönen Kunst, sondern ausschließlich funktional bestimmt, d. h. der praktischen Zweckmäßigkeit des Gebrauchs unterstellt. ${ }^{181}$

Auf die Praktikabilität deutet bereits Epsteins Absicht hin, den Atlas immer bei sich in der Tasche zu tragen. Das Taschenformat bezieht sich nicht nur auf die Größe des Atlas, sondern mehr noch auf seine einfache Handhabung: Es ermöglicht die ökonomische Lektüre des Nachschlagens und Nachschauens und gewährleistet die jederzeitige Verfügbarkeit - das jederzeitige „Zur-HandHaben“ - des kartographisch und lexikographisch organisierten Wissens. ${ }^{182} \mathrm{Zu}$ gebrauchen wie ein ornithologisches Handbuch, mit dessen Hilfe „die verschiedenen Vögel bestimmt und unterschieden werden“ (AO [185]), soll der Atlas vor allem die definitorische Identifikation und Differenzierung jener indifferenten Licht-Welt leisten, die potentiell zwar alles ist, in der aber nichts mehr sinnlich und sinnhaft unterschieden werden kann. ${ }^{183}$ Als Kartenwerk ermöglicht der

181 Auch in diesem Zusammenhang erweist sich die Brauchbarkeit des Design-Begriffs: Das Design verbindet Ästhetik (Gestaltung eines Gegenstandes), Technologie (industrielle Gestaltung) und Funktionalität (Gebrauch). Alle diese Faktoren binden den produzierten Gegenstand an den gesellschaftlichen Kontext zurück: Die Produktion von Designer-Gegenständen orientiert sich an der gesellschaftlichen Nachfrage. Die „Krise des Design“ sieht Lyotard darin, dass sich die ,industrielle Produktion in bezug auf die gesellschaftlichen Bedürfnisse [...] verselbständigt hat“, der Designer deshalb auch seiner „utopischen Aufgabe“, an der Verbesserung der Gesellschaft mitzuwirken, nicht mehr nachkommt (Lyotard: Immaterialität, S. 28 u. 31; vgl. auch S. 33). Epstein verweigert sich dieser sozialen Forderung in denkbar radikaler Weise. Seine ethisch motivierte Preisgabe der Literatur - die authentische Darstellung der non-cose ist der Verzicht auf Darstellung überhaupt - erweist sich in gesellschaftlich-sozialer Hinsicht als geradezu unethisch.

$182 \mathrm{Zu}$ erinnern ist in diesem Zusammenhang noch einmal an die Szene, in der Brahe und Rüdiger das Maschinenlager aufsuchen. Auch hier wird die im Magazin herrschende systematische Ordnung mit dem Aspekt der Verfügbarkeit verknüpft und mit einem Wörterbuch verglichen („ordinate e disponibili, come un vocabolario“ [AO 71]). Darüber hinaus bindet die Magazin-Metapher die Aspekte der Ordnung und Verfügbarkeit an den memoria-Diskurs zurück.

183 Das Schreibprojekt „Atlas des Lichts“ ist eingebunden in eine zyklische Struktur von Weltvernichtung und Weltschöpfung: In einer Umkehrung des biblischen Schöpfungsaktes gehen die Dinge zunächst in der Indifferenz des Lichts unter; der „Atlas des Lichts“ lässt die Dinge im Akt des Schreibens wieder aus dem Licht hervortreten. Das Schreiben (Kartographieren und Lexikographieren) ist - nun in Analogie zur göttlichen Rede - mit den Akten des Unterscheidens und Benennens verbunden. Darüber hinaus finden sich Merkmale der Johannesoffenbarung: Der Untergang der Welt ist im Roman zwar völlig entdramatisiert und ins Schöne und Gute gewendet - das „Schwinden der Dinge“ ist Welt-Nichtung, nicht WeltVernichtung! -, doch ist mit Brahes und Epsteins wiederholtem Hinweis, dass von dort, von der genichteten Welt, die „neuen Tatsachen“, Wahrnehmungs- und Seinsmöglichkeiten kommen werden (,Le cose che ci saranno vengono da lí“, AO 104 [141]; vgl. auch 146 [195 f.]), ein 
Atlas geographische Ortsbestimmungen und dient dem Benutzer ganz allgemein der Orientierung und Navigation; als Kartenwerk der menschlichen Emotionen, Wahrnehmungsweisen und Gedanken (s.o.) dient Epsteins Licht-Atlas vor allem aber der inneren Orientierung. Dabei verbindet sich mit der topographischen und lexikographischen Registrierung von Emotionen, Kognitionen und Perzeptionen eine psychotherapeutische Funktion: Wie sich die Dinge im Schwinden zunehmend pluralisieren und vereinzeln und schließlich in ein homogenes Licht auflösen, so verästeln sich auch die Gefühle, werden zunehmend richtungslos und drohen schließlich ganz zu erlöschen (Vgl. AO 30 u. 62 [44 u. 87]); ihre kartographische Aufzeichnung ist folglich nichts anderes als der Versuch, jene mit der De-Aisthetisierung und De-Ästhetisierung der Wirklichkeit drohende Gefahr einer Anästhetisierung des Menschen im Sinne der Einbuße jeglicher Sensibilität und Empfindsamkeit abzuwehren. ${ }^{184}$ Epsteins Hoffnun-

adventistisch-messianistisches Element eingeführt. Der Roman folgt dabei der apokalyptischen Zeitstruktur (Zeit des Untergangs - Interimzeit des tausendjährigen Reiches - Ewiges Reich Gottes), wobei die erzählte Zeit im Übergang von Welt-Nichtung und Interimzeit angesiedelt ist, auf die Zukunft hingegen lediglich ,prophetisch“ verwiesen wird); ferner erscheint der apokalyptische Mythos (Weltzerstörung - tausendjähriges Reich - Herabkunft des neuen Jerusalem bzw. Etablierung des Reiches Gottes) im Roman nicht nur als eine säkularisierte, sondern als eine dezidiert szientifizierte Variante: Die Wissenschaft ,nichtet‘ die Welt und lässt zugleich eine neue Welt entstehen. Welt-Nichtung und Welt-Schöpfung werden dabei als Kontinuum ausgewiesen, letztlich als eine durchgängig optimistisch gewertete Fortschrittsgeschichte. Lediglich in der Tatsache, dass auf Mythen zurückgegriffen wird, kann als latente Kritik am Wahrheitsanspruch der Wissenschaft gelesen werden: Der Mythos der Religion wird durch den Mythos der Wissenschaft abgelöst; was diese Mythen zu erkennen geben, ist letztlich eine Frage des Glaubens.

184 In dieser Intention ist Epsteins Projekt vergleichbar mit der Licht-Kunst etwa eines James Turrell. Auch hier geht es um das Sehen des Sehens, um die Wahrnehmung der Wahrnehmung, um die sinnlich-körperliche Erfahrung des Lichts in objektlosen und semantisch entleerten Räumen. Vgl. dazu Hartmut Böhme: Das Licht als Medium der Kunst. Über Erfahrungsarmut und ästhetisches Gegenlicht in der technischen Zivilisation. Antrittsvorlesung an der Humboldtuniversität Berlin am 2. November 1994 (im Folgenden zit. nach http://edoc.huberlin.de/humboldt-vl/boehme-hartmut/PDF/Boehme.pdf; letzter Zugriff: 26.09.19): „Die semantisch leere, doch feinstoffliche Fülle des Lichts schafft eine Raumpräsenz, die zur Präsenz des Betrachters wird. Er erfährt sich räumlich und als räumlich: denn das leibsinnliche Bewusstsein ist von einer eigenen Räumlichkeit. Damit, nicht mit Dingen der Natur, beginnt Naturästhetik“ (S. 28). Der Weg, den der Rezipient von/in Turrells Licht-Räumen zurücklegt, ist der „vom minimalen Licht zu einer maximalen Bewusstheit der eigenen Wahrnehmungsrealität. [...] Das Minimum bezeichnet [...] die geringstmögliche Differenz, welche Wahrnehmung allererst konstituiert, zum anderen den zur Objektlosigkeit gereinigten Raum oder die Farbfläche. Gerade dadurch, daß keinerlei ,objektive‘ Differenz vorliegt, wird eine eigenaktive Differenzierung der Wahrnehmung in Gang gesetzt [...]. Die objektive wie die subjektive Seite des 
gen gehen aber noch weiter: Sein Atlas soll nicht nur die labyrinthische Struktur der Gefühle, Gedanken und Wahrnehmungen und damit den gefährlichen Umschlag in die absolute Uniformität des Struktur- und Konturlosen - die menschliche Eindimensionalität ${ }^{185}$ - verhindern, sondern überdies den Weg weisen $\mathrm{zu}$ einem Zentrum des Fühlens und Denkens, das, so Epsteins Vermutung, im Ohr liegt, dort, „wo die Gleichgewichtsknöchelchen sind“ (AO [185]). Von diesem sinnlich-kognitiven Sinnzentrum her wäre eine „geografia diversa“ (AO 138) zu denken: eine Geographie, die nicht primär vom Sehen, sondern vom Hören bestimmt wäre - genauer: die den Blick akustisch ausrichten und deren kartographische Partituren die Positionierung, Identifizierung und Benennung eines ,Ich“ in einem Hier und Jetzt auf der „riesigen Karte in natürlicher Größe“ erlauben würde; eine Geographie, welche die Tondominante der Gegenwart, ihr vorsprachlich gestaltloses Gestimmtsein - „[la presente] è una nota musicale lunga, tersa, consonante con tutte le altre in assoluta simultaneità“ (AO 29) - , in die logischaffektive und mathematisch präzise Zeichenordnung eines Kartenwerks zu übersetzen und sie nachträglich mit Sinn und Gehalt auszustatten hätte. ${ }^{186}$ Die Rei-

ästhetischen Geschehens zielen auf einen Prozeß, bei dem die Erfahrung des Lichts oder des Farbfeldes ununterscheidbar mit der Selbstwahrnehmung des Rezipienten wird“ (ebd., S. 29). Dabei zielt die Licht-Kunst auf „Reinigung der ästhetischen Kompetenz“, das „Gewahrwerden des eigenen Sehen-Könnens“ und vermittelt solcherart „Formen der Ästhetik selbst“ (ebd., S. 30). Epsteins Licht-Atlas ist, wie gezeigt wurde, nicht primär Kunst, sehr wohl aber Dokumentation seiner eigenen lichtästhetischen Erfahrungen. - Zum ästhetischen Postulat einer neuen Art von Sensibilität in der postmodernen Kunst vgl. auch Susan Sontag: On Culture and the New Sensibility, in: dies.: Against Interpretation and Other Essays, New York 1967, S. 293-304.

185 Vgl. Herbert Marcuse: Der eindimensionale Mensch, Berlin, Neuwied 1967.

186 Diese von Epstein suggerierte akustische Weisung des Sehens und deren Bedeutung für die menschliche Kommunikation erinnert an das Alte Testament. Dort ist das Hinhören und Hören-auf (im Sinne des Gehorsams) Voraussetzung sowohl für das rechte Sehen als auch für das rechte Sprechen. Vgl. exemplarisch Psalm 38, Jes. 43,8-13, Hiob 4,12-15, Prv 18,13 u. 28,9. Epsteins Verortung des Sinnzentrums - und ineins damit des Gleichgewichts - im Ohr und nicht zuletzt die angedeutete Korrelation von Gehör und Sprache begegnet auch bei Herder, der das Gehör im Hinblick auf Deutlichkeit, Klarheit, Lebhaftigkeit, Zeit und Ausdrucksbedürfnis als den „mittleren der menschlichen Sinne [...] und also Sinn der Sprache“ bestimmt (Johann Gottfried Herder: Abhandlung über den Ursprung der Sprache, in: Sprachphilosophische Schriften, ausgew., eingel. u. komm. v. Erich Heintel, Hamburg 21960, S. 41-44). In der Literatur ist es vor allem die Lyrik der europäischen Spätromantik und des (maßgeblich von der Poetik E. A. Poes beeinflussten) französischen Symbolismus, die die Klangkraft der Sprache über ihren semantischen Gehalt stellt. Keats' Ode to a Nightingale inszeniert geradezu dramatisch den Übergang vom Sehen zum Hören und die buchstäbliche Todesgefahr, der sich das lyrische Ich in der idealisierten Hingabe an eine rein musikalische Lyrik, verkörpert im Gesang der Nachtigall, aussetzt und es schließlich zur Rückkehr ins Reich des Sehens und des Logos 
hung Ohr - Auge - Sprache, die Epsteins Rede über sein Projekt inhaltlich strukturiert, beschreibt zugleich die Methode der „neuen Geographie“, in deren Atlas die zentralen Signaturen abendländischer Philosophie (Subjekt, Identität, Begriff, Präsenz) reliefartig herausragen. Das Atlas-Projekt erweist sich damit als eine im Medium der Schrift vorgenommene Revision einer Ästhetik des rein geistigen Sehens, eine Revision, die in jenen ontologisch begründeten Phonozentrismus, Logozentrismus und Subjektzentrismus zu münden scheint, der mit der postmodernen episteme und der dieser entsprechenden neuen Ästhetik gerade erst überwunden worden war. Aber: Die „riesige Karte in natürlicher Größe“, deren Lesbarkeit und Zugänglichkeit die „Karte in der Hand“ ermöglichen soll, ist nicht mehr die natürliche, unabhängig vom Menschen existierende Welt, sondern ihrerseits theoretisches Konstrukt, kartographische Rekonstruktion einer Landschaft des Geistes. Sie ist jener (in Auflösung begriffene, seine Positionssignaturen verlierende) Positiv-Abzug vom Negativ der geistigen ,Licht'-Welt, die im „Atlas des Lichts“ - der „Karte in der Hand“ - zum Zwecke der Positionierung und Orientierung erneut in ein Positiv übersetzt werden soll. Der dem „Atlas des Lichts“ eingeschriebene bzw. aus der kartographischen Schrift deduzierte Phono-, Logo- und Subjektzentrismus ist deshalb ein hochgradig virtueller, seine Logik der Identität, Präsenz und Wahrheit eine nurmehr fingierte, seine Methode ein Privatweg, seine Begriffe individuelle Chiffren ohne eine inter- oder transsubjektive Sicherung. Das eigentlich gegendiskursive Moment dieses Projekts liegt in der anthropologischen Relevanz, die der Materialität Schrift und einem auf Gestaltung und Strukturierung - und damit auf sinnliche Wahrnehmung - ausgerichteten (epistemischen wie narrativen) Schreiben zukommt. ${ }^{187}$ Ausgelagert in die

zwingt. Mallarmé spricht von seiner Dichtung als „Laboratorium“, in dem er als „Techniker“ die „Geometrie der Sätze“ erzeugt, und er radikalisiert die poésie pure zu einem „schweigenden Aufflug ins Abstrakte“, deren Ideal das „schweigende Konzert“, das „schweigende Gedicht, aus lauter Weiß“ wäre (Mallarmé, zit. n. Hugo Friedrich: Die Struktur der modernen Lyrik. Von der Mitte des neunzehnten bis zur Mitte des zwanzigsten Jahrhunderts, Reinbek bei Hamburg ${ }^{22} 1996$, S. 114 u. 118). Bei allen Unterschieden in den Voraussetzungen, der Konzeption und der poetischen Realisierung sind die Gemeinsamkeiten zwischen Epsteins Ästhetik des reinen Sehens und der symbolistischen Tradition mit ihrer Poetik der Entdinglichung und Entpersönlichung, des von allem Konkreten abstrahierten, rein geistigen „regard absolu“ (Mallarmé) und der Idealisierung von Nichts, Leere und Schweigen unübersehbar.

187 Gegenüber Epsteins früher Ästhetik erweisen sich Schrift und Schreiben als die einzig verbleibenden Medien der Gestaltung und Wahrnehmung: Schrift und Schreiben heben die non-cose in die Sichtbarkeit, lassen sie aus der indifferenten Finsternis des Lichts dinghaft hervortreten. Wahrheit im Sinne der aletheia, des Entbergens und Heraus- bzw. Hervortretens, ist damit kein primär erkenntnistheoretisch (d.h. auch unsinnlich) motivierter Begriff mehr, 
Zukunft und ausgewiesen als ein rein privates, nicht publikationsfähiges Projekt ${ }^{188}$ negiert es jedoch umgekehrt die kommunikative und orientierungsstiftende transsubjektive Funktion einer zeichenhaft vermittelten Literatur und Wissenschaft. Der Atlas wird damit zur Signatur einer Krise: Er indiziert die Aporie einer dem Bedürfnis nach Kommunikation und Orientierung Rechnung tragenden Anthropologie und der Unmöglichkeit, dieser unter den Bedingungen eines auf die Spitze getriebenen Immaterialismus - die Diktatur eines alles, nicht zuletzt auch alle differenzierenden, kommunikationsermöglichenden Zeichensysteme, absorbierenden Lichts - gerecht zu werden.

\subsection{Poetologie als Epistemologie: Die doppelte Ästhetik des Atlante occidentale}

Brahes und Epsteins anthropologisch motivierter Wunsch nach einer ,Ordnung der Dinge، findet in der diskursiven wie handlungsbezogenen Ordnung der Erzählung seine Erfüllung. Der implizite Autor antwortet seinen Helden mit einer doppelten Ästhetik, die ihrer in der Postmoderne verankerten Wissenschaft und Ästhetik ebenso gerecht zu werden versucht wie ihrer (noch) in der Moderne wurzelnden Psychologie. Der Titel des Romans, „Atlas des Westens“, ist eine Abbreviatur dieser doppelten Ästhetik, der implizite Autor ein Kartograph, der - ungleich seinem Helden Epstein - die Welt der Dinge und NichtDinge in Ordnungen des Narrativen einträgt und auf diese Weise eine wegweisende, orientierende, auf Partizipation und Kommunikation gerichtete Lektüre ermöglicht. Die Analysen haben gezeigt, dass in der Optik des Romans der Übergang von der geordneten materiellen Oberfläche der Wirklichkeit über ihre zeichenhaft-labyrinthische Struktur hin zu ihrer ,energetisch' immateriellen Tiefenstruktur durch den jeweiligen Blick auf die ,Dinge' konditioniert ist. Diese Annahme ist für die ,histoire (als Thema) und den ,discourse“ (als Strukturprinzip) gleichermaßen zentral: Den Ordnungen des Sehens korrelieren Ordnungen der Wirklichkeit, und sie treiben jeweils andere Wissensformationen und jeweils andere Ästhetiken hervor. In der Kartographie des „Atlas des Westens“ erscheinen diese Wahrnehmungs- und Wirklichkeitsordnungen nicht zusammenhanglos separiert, sondern eingelagert in ein textuelles Schichtenmodell,

sondern ein ästhetisch (d.h. sinnlich) motivierter: Wahrheit ist, was ästhetisch hervorgebracht und solcherart hervorgehoben Wahrnehmung ermöglicht.

188 Die Arbitrarität und Leere der Zeichen ist lediglich solipsistisch zu durchbrechen; in seiner publizierten Form würde sich der Atlas in potentiell unendlich viele Singularitäten seines Gebrauchs zerstreuen, d.h. in kommunikativer Hinsicht wäre er nichts als eine asignifikante Textur. 
das in einem von Brahe imaginierten geologischen Profil geradezu paradigmatisch veranschaulicht wird:

Saliva, e immaginava dietro la parete di metallo e dietro la parete di beton il primo strato di molassa, spaccato in verticale dal suo salire, e la consistenza delle piccole scaglie di quarzo e di feldspato e forse l'impronta fossile di un animaletto, un lytoceras loricatum o qualche altro radiolare o echinoderma del giurassico, periodo che prendeva nome dal Giura alle cui falde stava risalendo, e poi lo strato successivo di morena con rocce e limo rastremati nel tempo dai ghiacciai, e piú su ancora lo strato di superficie con tuberi e erbe e radici delle latifoglie e delle conifere che spuntavano dal bosco nelle prime luci dell'alba. $(\mathrm{AO} 22)^{189}$

Sowohl der naturwissenschaftliche als auch der literarisch-ästhetische Diskurs folgen dieser vertikal-diachronen ,Geologik', wobei die einzelnen stratisphärischen Schichten beider Diskurse durch ein komplexes Netz von Similaritäts-, Analogie- und Korrespondenzbeziehungen jeweils auch auf einer horizontalsynchronen Ebene miteinander verschränkt sind. Exemplarisch sei noch einmal auf die horizontal-parataktisch gefügte, mit einem Wörterbuch verglichene Ordnung des Maschinenlagers verwiesen, die durch eine vertikale, den Bedeutungsgrad der einzelnen Teile für das Sehen anzeigende Achse durchkreuzt wird oder die vertikale Schichtung naturwissenschaftlicher Bilder, die zugleich den diachronen Prozess ihrer Generierung und die unterschiedlichen Modi ihrer Wahrnehmbarkeit anzeigt; diese Passagen sind strukturell wiederum mit der von Epstein vorgenommenen Dekonstruktion einer Geschichte und mit dem von ihm eingeführten Vergleich zwischen Positiv- und Negativabdruck, in einem gröberen Maßstab aber auch mit der Raumsemantik (oberirdisch - unterir$\operatorname{disch}^{190}$ ) und den damit jeweils verbundenen Wahrnehmungsweisen (sinnlich -

189 „Er fuhr [mit dem Aufzug im CERN] nach oben, und im Geiste sah er hinter der Metallwand und hinter der Betonwand die erste Schicht Molasse, die von seiner Aufwärtsbewegung durchschnitten wurde, die kleinen Quarz- und Feldspatsplitter und vielleicht den fossilen Abdruck eines kleinen Tierchens, eines Lytoceras loricatum oder sonst eines Strahlentierchens oder Stachelhäuters des Juras, eines Zeitalters, dessen Name vom Juragebirge herrührte, das zu dieser Zeit entstanden war, und dann die darauffolgende Moränenschicht aus Felsen und Schlick, die im Lauf der Zeit durch den Druck der Gletscher nach oben hin zusammengeschoben worden waren, und noch weiter oben die Deckschicht mit Knollen und Gräsern und den Wurzeln der Laub- und Nadelbäume, deren Wipfel im ersten Licht der Morgendämmerung aus dem Wald ragten“ (AW 33-34).

190 Diesem binären Raummodell folgt nicht nur das unterirdische CERN im Unterschied zur überirdischen Stadt Genf; auch Genf ist in eine mit der Vergangenheit, Geschichte und Krieg konnotierte Altstadt und in eine mit Internationalität, Wissenschaft, Frieden, Neutralität und Freiheit konnotierte moderne Stadt gegliedert; nicht zuletzt stehen auch einzelne Gebäude in 
geistig) parallelisiert und analogisiert. ${ }^{191}$ Nicht zuletzt folgt auch das Kompositionsprinzip des Romans dieser vertikal-horizontalen Ausrichtung, etwa indem dezidiert moderne Motive (die futuristische Motivik der „velocità“, des Fliegens, des Autofahrens, der Männerfreundschaft ${ }^{192}$ ), Darstellungsfiguren (Epiphanie, mise en abyme) und Problemzusammenhänge (Darstellung des Undarstellbaren, Momente der negativen Ästhetik) aufgegriffen und mit postmodernen Theoremen („Spiel“, „Spur“, „Verweis“, Referenzlosigkeit, Immaterialität) und Verfahren (Dekonstruktion, dissémination, Täuschung) variiert und synkretisiert werden. Dieses artistische Arrangement des Romans konstituiert einen Hypertext, der - und darin besteht seine eigentliche Provokation - primär epistemologisch funktionalisiert ist. Was heißt das?

Opposition zueinander, so etwa das abgedunkelte Schloss Voltaire und die gläserntransparente „foresteria“ des CERN, über die auch eine zeitliche Opposition und zugleich eine historische Kontinuität erzeugt wird.

191 Diese Beispiele ließen sich um viele weitere ergänzen. Vgl. z. B. AO 13 [20 f.], wo eine alltägliche Situation - Epstein beobachtet die Menschen in einer Flughalle in ihren räumlichen Beziehungen zueinander - zum Anlass wird, über die ,Schichten' des Menschen nachzudenken, darüber, wie die situativ artikulierte Sprache eben dieses bildhafte Wahrnehmen und Wahrgenommenwerden maskiert und solcherart - noch mehr als die Gesten - als ein Gerüst fungiert, ohne das die Menschen zusammenbrächen ,wie jemand, der im Laufen geköpft wird und dessen Körper noch ein paar Schritte macht, bevor er zusammenbricht“ [20 f.]. Oder AO 105 [142], ein Passus, in dem erneut die ,Vertikalstruktur‘ der Sprache aufgezeigt wird: Brahe versucht Epstein sein Experiment zunächst laizistisch mittels Wörtern, Bildern, Analogien und Gesten zu erklären; erst auf Epsteins Bitte hin beschreibt er das Experiment professionell und „nannte alles bei seinem richtigen Namen, nannte die Abkürzungen, nannte die Formeln; er machte auch nicht sehr viele Gesten; nur hin und wieder nahm er die Hand vom Steuer, aber eher um etwas dazulegen, als um es zu illustrieren, so als holte er aus einer unterirdischen Welt [sottomondo] Dimensionen und Begriffe und Bewegungen und Zustände und Richtungen hervor, die sich aus einer perfekten mathematischen Konstruktion ergaben und nur dort galten“ [142]. - Dieser doppelten Logik folgen auch die im Roman angesprochenen Ordnungsmodelle (Magazin, Alphabet, Wörterbuch, Nomenklatur, Atlas usw. und mit ihnen das ganze semantische Feld von funktional festgelegten Begriffen, von fixierten Positionen der Dinge in Raum und Zeit, von klaren Definitionen, präzisen Unterscheidungen etc.), die mit den im Roman ebenfalls thematisierten und praktizierten ,ordnungsdekonstruierenden' Verfahren kollidieren (literaturtheoretisch ließe sich geradezu von einer Verschränkung von Systemtheorie und Dekonstruktion sprechen), ohne dass das eine das andere in seiner Daseinsberechtigung und seinem Gültigkeitswert in Frage stellen oder aufheben würde; im Gegenteil: für die Bereiche Naturwissenschaft und Literatur wird exemplarisch gezeigt, dass das eine ohne das andere schlechterdings nicht ,zu haben' ist.

192 Zur (freilich entideologisierten) Rezeption des Futurismus vgl. Gerhard Regn: Nach der Moderne, S. 331-337. 
Der Roman betreibt Wirklichkeitsanalyse, indem er nicht nur die Schichten realer Prozesse der Wahrnehmung, der Wirklichkeitsmodellierung, der Wissenserzeugung, der Sprache etc. thematisiert ${ }^{193}$ und damit die geschichtete Struktur von Realität überhaupt - das Geschichtet-Sein, das Ge-Schichte-Sein als ihr quasi-ontologischer Status - offen legt, sondern vorrangig die Wirklichkeit der naturwissenschaftlichen Arbeit (in ihrer Verwobenheit mit der Lebenswelt, insbesondere aber mit der Ästhetik) realistisch abbildet. Die horizontale Vernetzung dieser Tiefenschichten erzeugt den Effekt, dass die verschiedenen Wirklichkeitsebenen aufeinander verweisen und sich wechselseitig begründen, kommentieren, erklären und deuten. ${ }^{194}$ Dabei werden sowohl die vielschichtigen Bezüge zwischen den fiktionsimmanenten Realitäten als auch zwischen Fiktion und Wirklichkeit hergestellt. Durch die eklatante ,Theorielastigkeit' der fiktionsimmanenten Diskurse (und dies gilt für den Brahe- wie auch für den Epstein-Plot), aber auch durch das horizontale Geflecht von Korrespondenzen und Ähnlichkeiten werden Textschichten aufgehäuft und zugleich analytisch durchdrungen; ebenso wird dadurch die fiktionsimmanente Textwelt mit der ,externen“ wissenschaftlich-philosophischen wie literarischen Textwelt verschränkt, ja Wirklichkeit selbst als eine primär textuell verfasste, d.h. immer schon theoretisch-konzeptionell geprägte, gefilterte und vorinterpretierte ausgewiesen. Indem der Roman in allen seinen Schichten reale und fiktionale

193 Die Schichten des Sehens reichen vom sinnlich-dinghaften Sehen über das begrifflichtheoretische Sehen bis zu einem inhaltsleeren, absolut geistig-abstrakten Sehen, die Wirklichkeitsmodelle von der materiellen Welt der Phänomene über die virtuell erzeugten, zeichenhaft plastizierten Weltbilder von einer nicht mehr sichtbaren mikrophysikalischen, immateriellen, formlosen, wahrscheinlichen Welt bis hin zu einer nur noch geistigen Innen-Welt, die jedes geistunabhängige Außen dementiert und ihrerseits in einem ,Alles-ist-Licht` gipfelt; damit korrespondieren die Weisen der Wissenserzeugung, die von induktiv-experimentellen über imaginär-fiktionale bis hin zu deduktiv-rationalistischen Formen reichen, sowie die sprachlichen Konzepte, angefangen von Sprache als materiellem Sinn- und Sinnenträger (Begriffe, Formeln, Metaphern, Diskurse und Viskurse) und ineins damit Sprache als kommunikatives Medium bis hin zu ihrer Auflösung in eine immaterialisierte, rein ,energetische‘, wortlose Sprache, die zugleich eine der Nicht-Kommunikation ist.

194 Wie Epstein seine Ästhetik des neuen Sehens auf der Grundlage der naturwissenschaftlichen ,Immaterialien' errichtet, so stiften seine ästhetischen Ausführungen den Deutungsrahmen für die Vorgänge im CERN. Gerade die auf der horizontalen Ebene eingeflochtenen komplexen Beziehungen und Verweise verhindern dabei allerdings eindeutige kausale Zuweisungen, d.h. kein Diskurs kann für sich beanspruchen, den anderen in einem ganz bestimmten Aspekt zu begründen etc.; vielmehr funktionieren die genannten hermeneutischen und heuristischen Funktionen wiederum punktuell, so dass sich spätestens nach der Zweitlektüre des Romans nicht mehr sagen lässt, welcher Diskurs nun ursächlich und hauptsächlich einen Aspekt des anderen Diskurses beleuchtet. 
Textwelten nachahmt und diese auch schichtweise durchdringt, ist er nicht mehr imitatio rerum, sondern imitatio textorum. - Der Realismus des Romans besteht paradoxerweise gerade darin, dass er auf eine reale (Text)Welt Bezug nimmt, die die Realität - vor allem die Realität der Natur - problematisiert und damit sich selbst und ihren Seinsstatus als Realität in Frage stellt. ${ }^{195}$

Obgleich die für die horizontalen Ebenen charakteristische ,mycelische“ Struktur zu einer Einebnung der Unterschiede zwischen der literarischästhetischen und der naturwissenschaftlichen Welt tendiert, sind es vor allem die vertikal geordneten Tiefenschichten sowie die parallel komponierten Ereignis-, Wahrnehmungs- und Denksequenzen, die ein auf Differenzierung und Abgrenzung zielendes Gegengewicht schaffen. Wo diese Differenzierung durch das komplexe Mycel nicht nur gestört, sondern in der Lektüre (zumindest temporär) verhindert wird, werden die vertikal und parallel gesetzten Schnitte - in der Sprache der Kartographie: die aus der Textfläche herausragenden Reliefs selbst zu chiffrierten Signaturen der Differenz und ergehen als Aufforderung zur Dechiffrierung - gleichsam als Frage nach den von ihnen geleisteten Differenzierungsfunktionen - an den Leser. Durch das Verfahren der Vernetzung einerseits, der Abgrenzung andererseits wird ein gemeinsamer, Literatur und Naturwissenschaft gleichermaßen tangierender Problemzusammenhang hergestellt dieser betrifft im wesentlichen den Kontext Wahrnehmung - Darstellung Erkenntnis bzw. Wissen -, ohne beide Bereiche indifferent miteinander zu verschmelzen. Es entsteht gleichsam eine gegenläufige Dynamik: Durch die aufgezeigten Interferenzen werden die starren Grenzen zwischen beiden Bereichen destabilisiert, zugleich aber - und dies spiegelt sich in der ästhetischen Ord-

195 Der Roman tendiert in dieser Perspektive in zweifacher Weise zur „Antifiktion“: Als fiktionales Kunstwerk ist er zum einen jene „eminente Form der Fiktur, die die - moderne - Realität ist" (Odo Marquard: Kunst als Antifiktion - Versuch über den Weg der Wirklichkeit ins Fiktive, in: ders.: Aesthetica und Anaesthetica. Philosophische Überlegungen, Paderborn, München u.a. 1989, S. 82-99, hier S. 96), d.h. sein Antifiktionalität besteht in der fiktionalen Wiederholung einer zunehmend fiktionalen Welt; zum anderen ist er „Antifiktion“ (nun im eigentlichen Sinne Marquards), indem er „Zuflucht der Theoria“ ist, ,also dessen, was an der Theorie nicht bloße - ggf. fiktionsgeleitete - Sichtdisziplin ist, sondern wirkliche Erfahrung“ (ebd., S. 98), „Sehen des Übersehenen“ und „die Anerkennung: so ist es“ (ebd., S. 98 u. 99). Diesen Aspekt, der Antifiktion nun als eine Form des Widerstands gegen eine zunehmend ,durchfiktionalisierte“ (ebd., S. 82) Wirklichkeit meint, realisiert Del Giudice vor allem in der Gestalt anthropologischer und epistemologischer Entwürfe. - Zu einem ähnlichen Befund kommt Meindl: „Allgemein scheint für den postmodernen Roman zu gelten, daß er sich vor die heikle Aufgabe gestellt sieht, den fiktionalen Charakter von Wirklichkeit zu vermitteln, ohne sich so als Fiktion von der Realität abzusetzen“ (Dieter Meindl: Der amerikanische Roman zwischen Naturalismus und Postmoderne 1930-1960, München 1983, S. 226). 
nung des Romans - neu errichtet bzw. verschoben und solcherart die Diversität der Ordnungen des Wissens affirmiert.

Indem der Roman Einblick gewährt in die „epistemischen Maschinerien der Wissenserzeugung“ - in die komplexen Organisationsstrukturen und Verfahrensweisen des physikalischen Experiments, in die technologischen Voraussetzungen und ästhetischen Praxen naturwissenschaftlicher Bild- und Objektgenerierung, in die letztlich semiologisch und poietisch erfolgende Rekonfiguration natürlicher Ordnungen ${ }^{196}$ usw. -, konfrontiert er die Wissenschaft mit den Voraussetzungen und Methoden ihres Wissen-Schaffens. Die mannigfaltigen Strategien der Wissenserzeugung innerhalb ihres institutionellen Rahmens belichtend, kennzeichnet er die experimentelle Hochenergiephysik als ein selbstreferentielles, autopoietisches System. Damit dementiert er keineswegs die wissenschaftlich beanspruchte Gültigkeit theoretisch wie experimentell gewonnener Erkenntnis, weist dieser aber sehr wohl den Status eines liminalen Wissens zu. Die epistemologische Funktion des Romans ist vor allem darin zu sehen, dass er die in der wissenschaftlich betriebenen Epistemologie (immer noch) weitgehend verdrängte ${ }^{197}$,Sub-Textualität‘ wissenschaftlicher Wissenserzeugung im Medium des Narrativen an die textuelle Oberfläche hebt, das naturwissenschaftliche Wissen an die Grenzen des Nicht- oder Noch-nichtWissens zurückverfolgt und auf diese Weise das den hard und strong sciences incodierte „schwache Wissen“ bloßlegt. Epistemologie als Aufklärung meint im Zusammenhang des Romans auch Epistemologie als anamnesis, ${ }^{198}$ die hier un-

196 Vgl. Knorr-Cetina: Wissenskulturen, S. 61.

197 In der Regel gelten ,ästhetische Phänomene als kulturelle Peripherie einer im Kern autonomen Wissensproduktion“ (Peter Geimer: Einleitung, in: Ordnungen der Sichtbarkeit. Fotografie in Wissenschaft, Kunst und Technologie, hrsg. v. ders., Frankfurt/M. 2002, S. 7-25, hier S. 8; zit. n. Heßler: Einleitung, S. 25). Entsprechend würden Bilder gemeinhin als „,Supplemente“" fungieren, „die den eigentlichen wissenschaftlichen Diskurs, seine zentralen logischen und rationalen Argumente, nur begleiten“ (Dieter Mersch: Naturwissenschaftliches Wissen und bildliche Logik, S. 406).

198 Dieses anamnetische Verständnis von Epistemologie ließe sich stützen durch den im Roman ebenfalls angelegten Erinnerungsdiskurs. An dieser Stelle sei lediglich auf die Metaphern des Magazins, des Alphabets und des Atlas verwiesen: Das Magazin speichert die Instrumente des Sehens, die wiederum mit Ordnungen der Wahrnehmung korrelieren; das Alphabet steht im Dienste einer Enzyklopädisierung und Ordnung des Wissens, ebenso kann der Atlas als ein topographischer Wissensspeicher aufgefasst werden. Relevant ist in diesem $\mathrm{Zu}$ sammenhang, dass über diese Metaphern jeweils etwas sichtbar gemacht wird, was in der gängigen wissenschaftlichen Praxis verborgen bleibt (aus Effizienzgründen zum Teil auch verborgen bleiben muss). 
trennbar mit der epistemologischen Funktion der Bewusstseins- und Ideologiekritik (letztere im wörtlichen Sinn einer Bild- und Bildlogikkritik) einhergeht.

Epistemologie als jener wissenschaftliche Ort, an dem sich die Wissenschaften ein Wissen über sich selbst verschaffen, geschieht hier am nichtwissenschaftlichen Ort der Literatur. Dem Roman liegt vorrangig ein ,metaepistemisches' Interesse zugrunde: Erzählt wird die Geschichte von den Bedingungen der Generierung naturwissenschaftlichen Wissens. Zum akzentuierten Gegenstand der literarischen Erzählung werden dabei gerade diejenigen Aspekte epistemischer Verfahrensweisen, die in der konventionellen Forschung im Verborgenen bleiben und entsprechend auch nicht veröffentlicht werden, namentlich die technologischen, theoretischen und ästhetischen Dispositionen diskursiver bzw. viskursiver und hermeneutischer Praktiken und deren Relevanz für die Entfaltung und Vereinheitlichung von Wissensgebieten, für die Bildung von Theorien und die Gewinnung von Erkenntnissen, kurz: Thematisiert wird alles, was in den Tiefenschichten und Vorhöfen der wissenschaftlichen Wissensproduktion geschieht, wohingegen die definierten Sachgehalte und fertigen Resultate, kurz: das propositionale Wissen ausgeblendet bleiben. ${ }^{199}$ Die metapoetischen Metaphern von ,Hintergrund' und ,Vordergrund' bzw. ,Positiv' und ,Negativ‘, wie sie Epstein zur Beschreibung seiner frühen Ästhetik verwendet, erscheinen in der Poetik des Romans programmatisch umgesetzt und epistemologisch funktionalisiert, wobei sich das Verhältnis Hintergrund-Vordergrund, Positiv-Negativ gegenüber der realiter praktizierten Wissenschaft und Epistemologie umkehrt: Während der wissenschaftliche Diskurs das ,positive“ Resultatewissen in den Vordergrund rückt ${ }^{200}$ und die $\mathrm{zu}$ diesem Wissen führenden poie-

199 Die Realitätsnähe der romanhaft dargestellten Prozesse naturwissenschaftlicher Arbeit konnte im Rekurs auf wissenschaftstheoretische und -soziologische Studien bestätigt werden, wobei ausdrücklich darauf hinzuweisen ist, dass die im Roman gestellten Fragen etwa nach dem Zusammenhang von digitalisierten Bildern und wissenschaftlichen Erkenntnissen, nach der Bedeutung kommunikativer Prozesse bei der wissenschaftlichen Konsensbildung usw. erst seit der Jahrtausendwende expliziter Gegenstand epistemologischer Forschung sind.

200 Was Rheinberger für die experimentell verfahrenden Wissenschaften am Beispiel von Claude Bernard anschaulich ausführt, kann - wir haben es am Beispiel des historischen Gauß gesehen - für Wissenschaft schlechthin gelten: Die „nachträgliche Fixierung [...], die seit dem 19. Jahrhundert auch in der Standard-Anlage wissenschaftlicher Publikationen zum Ausdruck kommt“, mache den historischen Entdeckungsprozess unsichtbar: „Die Seitenwege, [...], die ,Nachtwissenschaft‘, [...] bleiben unterschlagen. Die Logik der Forschung fällt der Logik der Darstellung zum Opfer. Die Konsequenz ist die epistemologische Marginalisierung des Forschungsexperiments“ (Hans-Jörg Rheinberger: Experimentelle Virtuosität, in: „Interesse für bedingtes Wissen“. Wechselbeziehungen zwischen den Wissenskulturen, hrsg. v. Caroline Welsh u. Stefan Willer, München 2008, S. 331-342, hier S. 339). 
tisch-ästhetischen Faktoren und Prozesse weitgehend in den unsichtbaren, ,negativen' Hintergrund rückt, verschiebt und ,negativiert' der Roman die positive Erkenntnis in den Hintergrund und ,positiviert' das der episteme eingeschriebene negativ-liminale Wissen zum sichtbaren, reliefartig hervorgehobenen Vordergrund. Was der Blick in diese Tiefenschichten enthüllt, ist letztlich die Unhintergehbarkeit imaginativer, ästhetisch-literarischer und rhetorischtropischer Momente im wissenschaftlichen Erkenntnisprozess, mit anderen Worten: die der wissenschaftlichen Erkenntnis inhärente Fiktionalität (die Fiktionalität im wissenschaftlichen Erkenntnisprozess und nicht die Fiktionalität der wissenschaftlichen Erkenntnis!).

Die Frage nach dem Modus des Transfers von Wissenschaft in Literatur kann dahingehend beantwortet werden, dass in Atlante occidentale gerade nicht eine Fiktionalisierung propositionaler Erkenntnisse erfolgt, sondern eine Fiktionalisierung der diesen Erkenntnissen innewohnenden Fiktionalität. Das Fiktive als ein reales Moment naturwissenschaftlicher Arbeit ist hier das naturwissenschaftliche Faktum, das der Roman im Medium des Fiktiven wiederholt. Der dadurch erzielte Effekt ist nun alles andere als eine potenzierte Fiktionalität (etwa im Sinne einer ,reinen' Phantastik): In dem Augenblick, in dem der Roman dieses Faktum als ein im naturwissenschaftlichen Diskurs verborgenes sichtbar macht, es also nicht nur im Sinne der Fiktionalisierung ästhetisiert, sondern es im Sinne der sinnlichen Wahrnehmbarmachung aisthetisiert, wiederholt er das Faktum der Fiktionalität und beginnt es bereits zu überschreiten. Wenn Wahrheit das Offenlegen und Entbergen von Verborgenem und Vergessenem bezeichnet - es sei noch einmal an das griechische Wort für Wahrheit, aletheia, erinnert -, dann ist diese ästhetisch erfolgende Aisthetisierung ein literarischer Erkenntnisprozess, der die Wahrheit über ein wissenschaftliches, aber anästhetisiertes Faktum offen legt. ${ }^{201}$ Es geht hierbei also nicht um die Darstellung eines Undarstellbaren, sondern um die Darstellung eines durchaus Darstellbaren, das aus wissenschaftspragmatischen, aber auch wissenschaftsideologischen Gründen nicht dargestellt wird.

Die Darstellung der Fiktionalität als Faktum der Wissenschaft ist nun nicht als ein ,Kampf der Kulturen“ gestaltet, sondern - um ein Zentralmotiv des Romans aufzugreifen - als eine freundschaftliche Begegnung. Sie erfolgt nicht kritisch-problematisierend, sondern heiter-affirmativ. Während sich das Freundschaftliche in der Begegnung zwischen Brahe und Epstein vor allem in der aufgeschlossenen Teilhabe am Experiment des anderen und im Verzicht auf

201 Der implizite Autor appliziert gleichsam Epsteins frühe Ästhetik: Das dem ,Ding‘ Wissenschaft inhärente menschliche Handeln und Denken usw. wird literarisch vergegenständlicht. 
diskursive Macht zeigt, artikuliert es sich auf der diskursiven Ebene des Romans dahingehend, dass das Ästhetische - und mit ihm das Sinnliche, Narrative, Fiktive, Poetische, Imaginäre - und das Epistemische - und mit ihm Wahrheit, abstrakte Erkenntnis, positives Wissen - als ein anthropologisches Moment ausgewiesen werden, das für alle kulturellen Tätigkeiten konstitutiv ist. So wenig die Literatur die Gebietshoheit über das Ästhetische beanspruchen kann, so wenig kann die Naturwissenschaft die Gebietshoheit über das Epistemische beanspruchen. Die Kategorien des Ästhetischen und Epistemischen erscheinen damit aus den Bereichen Wissenschaft und Kunst ausgelagert - gleichsam entdiszipliniert - und als prinzipiell allen Menschen verfügbare Dispositive und jede kulturelle Handlung mitprägende Merkmale ausgewiesen. Entsprechend erweisen sie sich für eine distinkte Verhältnisbestimmung von Literatur und Wissenschaft als untauglich. ${ }^{202}$

Die Frage nach den Möglichkeiten einer Differenzierung von Wissenschaft und Kunst diskutiert der Roman nicht explizit; gleichwohl gibt er - und dies vor allem auf der Ebene des Diskurses - eine Antwort oder besser gesagt: der Diskurs vollzieht Antwort, ist antwortend. Inwiefern? Obgleich der Roman, wie wir gesehen haben, an den Ordnungen des Wissens festhält, geht es im Kern gar nicht um eine revolutionäre Verschiebung der disziplinären Grenzen; stattdessen vollzieht der Roman eine Aufklärungsbewegung, in die Kunst und Wissenschaft gleichermaßen hinein genommen sind. Er bescheidet sich damit, dass er, ausgehend von der aktuellen Verfasstheit von Wissenschaft und Literatur ihrem status quo zum Zeitpunkt der Entstehung des Romans - und unter Rekurs auf den zeitgenössischen philosophischen Diskurs, einen Weg aufzuzeigen versucht, wie Wissenschaft und Literatur unter eben diesen aktuellen Bedingungen in ein kommunikatives Verhältnis zueinander gesetzt werden können. Dabei werden nicht wissenschaftliche Intentionen, Methoden oder Zielsetzungen diskreditiert, sondern schlichtweg epistemologische Leerstellen literarisch ,entdeckt' und, wenn schon nicht gefüllt, so doch mit Sinnangeboten angereichert, die wegweisend für eine wissenschaftlich betriebene Epistemologie sein können.

In diesem Kontext ist auf die bereits angesprochene mäeutische Funktion der Romanpoetik zurückzukommen. Indem der Roman das der Naturwissenschaft immanente Ästhetische und Poietische narrativ extrapoliert und eine epistemologisch funktionalisierte Poetik etabliert, zeigt er nicht nur die unvermeidbare Kunstverwiesenheit und Kunstbedürftigkeit der Wissenschaft bei der

202 Vgl. dazu auch Paul de Man: The Epistemology of Metaphor, in: Critical Inquiry 5 (1978), S. $13-30$, bes. S. 30 . 
Erzeugung ihres Wissens auf, sondern hebt zugleich Poetologie und Ästhetik als unverzichtbare Wissenszweige einer wissenschaftlich verfahrenden Epistemologie hervor: Nur eine Poetologie und Ästhetik inkludierende Epistemologie vermag die Wissenschaft über ihr ästhetisch-fiktionales ,Anderes‘ aufzuklären. Eben darin liegt auch das Wegweisende der epistemologisierten Poetik des Romans: Ihre primäre Funktion ist nicht darin zu sehen, dass sie die Fiktionalität als ein (epistemisch verdecktes) Faktum der Wissenschaft ,entdeckt ${ }^{\star}$ und darstellt, sondern dass mit ihr Aspekte einer Methode vorgestellt sind, die für eine epistemisch verfahrende, d.h. für eine wissenschaftlich betriebene, auf Selbstaufklärung jener der Wissenschaft immanenten Ästhetizität und Poetizität gerichtete Epistemologie, produktiv gemacht werden kann. ${ }^{203}$

Aufgrund dieser Beobachtungen kann Atlante occidentale als eine im eigentlichen Wortsinn „epistemologische Metapher“ beschrieben werden. Während Umberto Eco mit diesem Terminus die für eine Epoche charakteristische künstlerische Form bezeichnet, die durch „Umwandlung des Begriffs in Gestalt“ die „Art, wie die Wissenschaft [...] die Realität [...] sieht, wiederspiegelt“, ${ }^{204}$ und ihr im wesentlichen die Funktion zuschreibt, „zwischen der abstrakten Kategorie der Wissenschaft und der lebendigen Materie unserer Sinnlichkeit“ zu vermitteln, ${ }^{205}$ ahmt Del Giudices Roman gerade das der Wissenschaft selbst immanente nicht-begriffliche Gestalthafte, Figurative und Metaphorische nach. Er erfüllt somit vorrangig auch nicht die Funktion, „die Errungenschaften der Wissenschaft [...] mit der allgemeinen Fühlweise zu verbinden und so bestimmte Situationen, die zur Zeit nur die Vernunft konfigurieren kann, bildlich, gestalthaft, zugänglich zu machen, so dass sie dann in gefühlsmäßiger Beteiligung erlebt werden können“, ${ }^{206}$ sondern deckt Ikonizität, Sinnlichkeit und Emotionalität als das den Vernunfthypothesen selbst inbegriffene ,Andere‘ auf, das seine unhintergehbare Evidenz besonders dort entfaltet, wo die Wissenschaft im subatomaren, anästhetischen Bereich operiert. Mit Blick auf den Ro-

203 Lassen sich, so muss man fragen, die der Wissenschaft inhärenten ästhetischen, fiktionalen und metaphorischen Tiefenstrukturen und die mit diesen jeweils verbundenen spezifischen Logiken, Regeln und Funktionen ohne eine Ästhetik und Poetologie der Wissenschaften überhaupt adäquat erfassen? Ist angesichts einer auch poietisch und ästhetisch praktizierten episteme eine Epistemologie ohne Poetologie (im Sinne einer Reflexion von ars und techne, im Sinne also einer auf die metaphorisch-bildhaften und narrativen Prozesse bezogenen Poetologie und einer auf die technische Produktion bezogene Poietologie) künftig überhaupt denkbar? 204 Umberto Eco: Das offene Kunstwerk, aus dem Italienischen v. Günter Memmert, Frankfurt/M. 1973, S. 46.

205 Ebd., S. 165.

206 Ebd., S. 414. 
man ist deshalb zwischen epistemischer und epistemologischer Metapher zu unterscheiden: Er ist epistemische Metapher, insofern er poetisch-narrativ das Metaphorische der episteme thematisiert; er ist epistemologische Metapher, insofern er poetologisch die der episteme selbst inhärente poetisch-ästhetische Logizität - ihre Poeto-Logik - aufdeckt und Poetologie als eine nicht länger zu exkludierende Theorie der Epistemologie einfordert. Der Roman - und hierin liegt ein durchaus utopisch-visionäres Moment - entwirft und appliziert im Medium des Literarischen eine epistemologische Poetik, die, indem sie das Ästhetische und Fiktionale als das nicht identifizierbare Identische von wissenschaftlichem und literarischem Diskurs ausweist, ${ }^{207}$ wegweisend für eine ,allgemeine Narratik“, wie sie Lyotard postuliert hatte, sein kann, eine „Narratik“, die - aus der Sicht des Romans - ihrerseits Bestandteil einer allgemeinen Anthropologie zu sein hätte; „ma questo è solo un punto di partenza“ (AO 85 [116]).

207 Der Aspekt des Ästhetischen und Fiktionalen, daran gilt es noch einmal zu erinnern, führt nicht zu einer Indifferenzierung des wissenschaftlichen und literarischen Diskurses, also nicht zu einer Diskursidentität im Allgemeinen; vielmehr ist er Implikat - Tiefenschicht - des wissenschaftlichen Diskurses, d.h. mit der Rede von der Diskursidentität ist lediglich jene gemeinsame, als solche eben nie genau zu umreißende und zu identifizierende Schnittmenge markiert, in der sich das ästhetisch-fiktionale Implikat der Wissenschaft mit der Fiktionalität der Literatur berührt. 